2016-06-01

\title{
Picture Books as Mentor Texts for 10th-Grade Struggling Writers
}

David Willett Premont

Brigham Young University

Follow this and additional works at: https://scholarsarchive.byu.edu/etd

Part of the Teacher Education and Professional Development Commons

\section{BYU ScholarsArchive Citation}

Premont, David Willett, "Picture Books as Mentor Texts for 10th-Grade Struggling Writers" (2016). All Theses and Dissertations. 6368. https://scholarsarchive.byu.edu/etd/6368

This Thesis is brought to you for free and open access by BYU ScholarsArchive. It has been accepted for inclusion in All Theses and Dissertations by an authorized administrator of BYU ScholarsArchive. For more information, please contact scholarsarchive@byu.edu, ellen_amatangelo@byu.edu. 
Picture Books as Mentor Texts for 10th-Grade Struggling Writers

David Willett Premont

A thesis submitted to the faculty of

Brigham Young University

in partial fulfillment of the requirements for the degree of

Master of Arts

Terrell A. Young, Chair

Bradley Ray Wilcox

Deborah Dean

Department of Teacher Education

Brigham Young University

June 2016

Copyright (C 2016 David Willett Premont

All Rights Reserved 


\author{
ABSTRACT \\ Picture Books as Mentor Texts for 10th-Grade Struggling Writers \\ David Willett Premont \\ Department of Teacher Education, BYU \\ Master of Arts
}

The purpose of this study was to fill gaps in the research to determine if picture books in the high school classroom can enhance student writing especially with word choice, sentence fluency, and conventions. Previous research has not fully considered employing picture books as mentor texts to examine writing traits in the high school Language Arts classroom. The population was 12 participants from two low track English 10 Reading classes. Six participants were identified from each class as low, medium, or high-performing students based on an informal narrative writing activity. This study employed an action research methodology (Sagor, 2000). Students were taught from an inquiry-based approach as the teacher read aloud each book, and asked students what they noticed. Students reviewed the picture books to guide them as they were challenged to improve their writing. Findings from the study illustrate that picture books as mentor texts can help secondary students of all ability levels improve their word choice, sentence fluency, and conventions in narrative writing as measured by a writing trait rubric created by Vicki Spandel and adapted by Jim Burke. Picture books were tools that helped students think and act like writers. Conclusions also highlighted the lack of word choice and sentence fluency instruction in the students' formative years. This study shed light on the abstract nature of sentence fluency, and an effective way to mitigate this problem. This study provided a new angle with which to teach the writing traits through narrative composition instruction, and teacher modeling. Further, this study adds to the literature of effective high school instruction as picture books as mentor texts are less common in the high school English Language Arts classroom.

Keywords: Picture books, word choice, sentence fluency, conventions, mentor texts, narrative writing 


\section{ACKNOWLEDGEMENTS}

I am indebted unto my parents and my God for their mentoring and support throughout my life. They are my champions. Thank you for removing the limits I place on myself.

The hard work and patience of my committee does not go unnoticed. I am lucky to have such talented people work so closely with me.

I would like to thank my committee chair, Terry Young, for his copious hours spent mentoring me, ensuring my success academically and personally. I would not be where I am today without his influence.

I am grateful to Brad Wilcox, who carefully considered the nuances of my writing and provided invaluable feedback. He continually impressed me with his love and availability to work with me outside of the normal work hours.

For Deborah Dean, who allowed me to reimagine picture books as a student in her undergraduate class that ultimately afforded me a rich opportunity to pursue this wonderment in a formal research thesis. Her guidance and feedback as a committee member made me a better writer and researcher.

Thank you to my cohort and professors who spent countless hours with me. Your feedback and infectious personalities allowed me to grow and enjoy this experience more than I thought was possible. I am a better person for having experienced this journey with you.

Finally, I want to thank Johnny Allred and Amber Hanson. To Johnny, for asking me what my plans were for graduate school, reinvigorating my search to pursue higher education. And for Amber, who introduced me to this program at Brigham Young University. 


\section{TABLE OF CONTENTS}

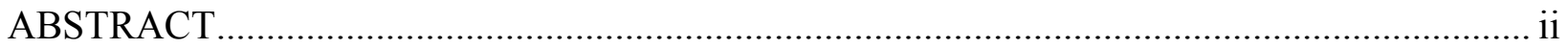

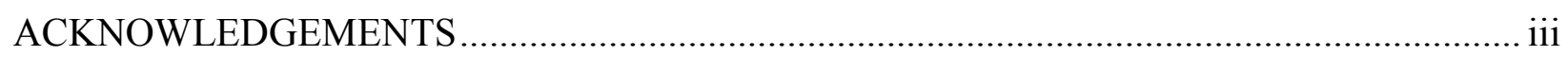

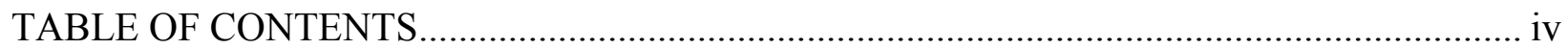

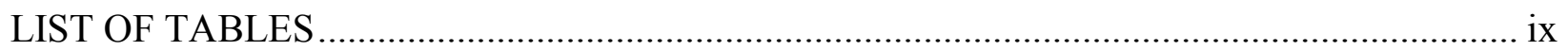

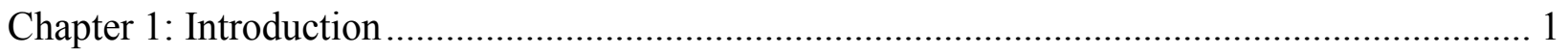

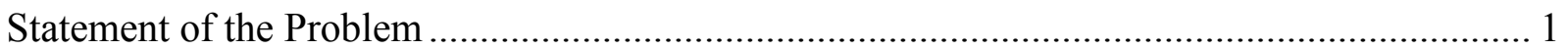

Statement of the Purpose ............................................................................................. 3

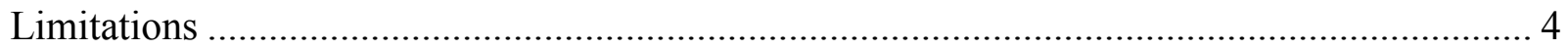

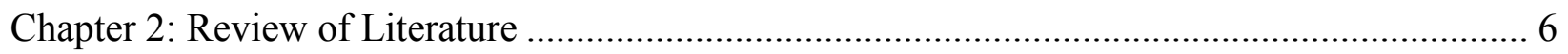

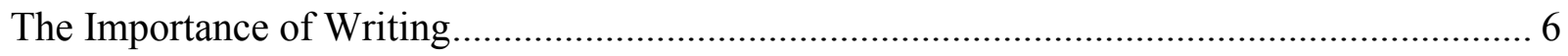

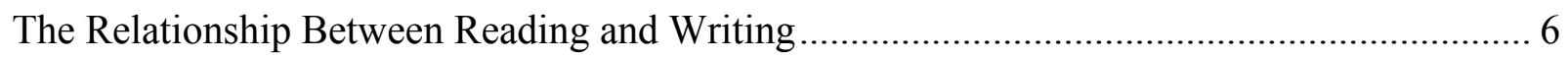

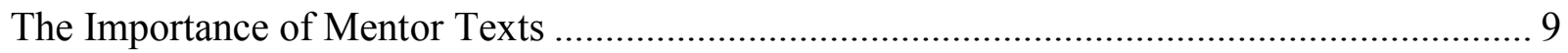

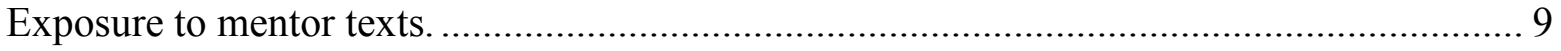

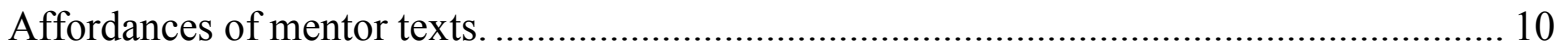

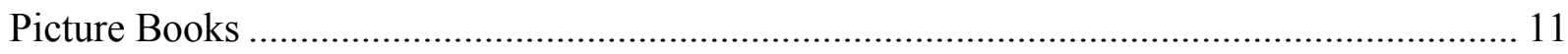

Picture books as mentor texts. ................................................................................ 11

Picture books for older pupils........................................................................... 13

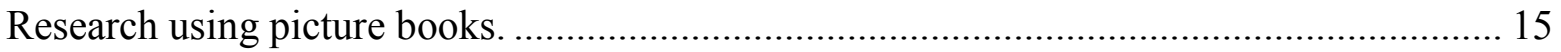

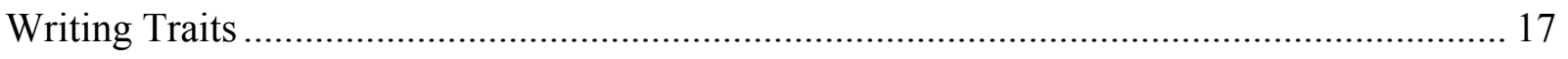

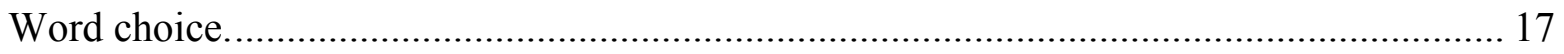




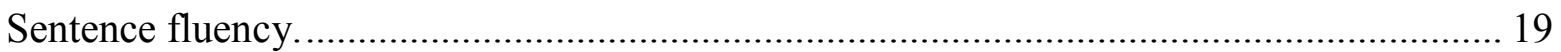

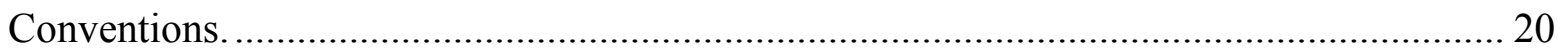

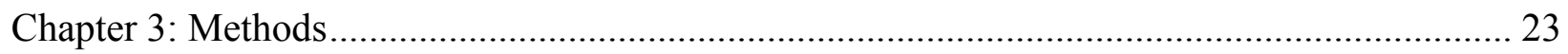

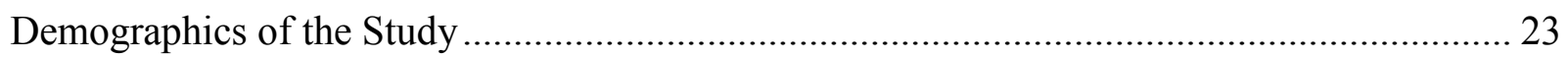

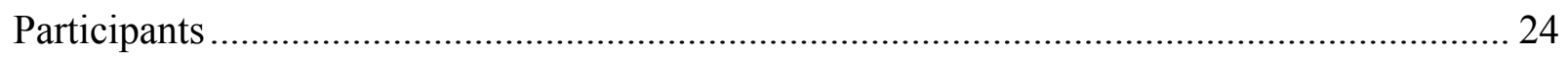

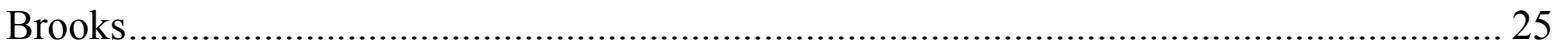

$\operatorname{Jim}$

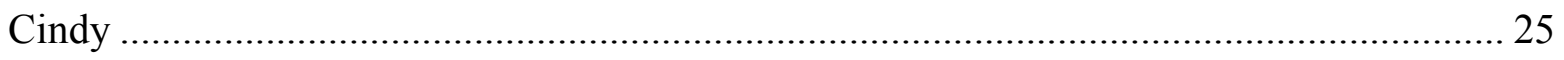

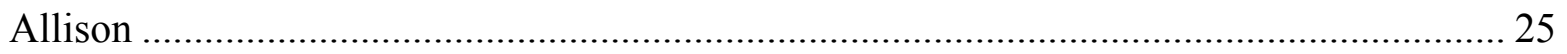

$\mathrm{Cal}$

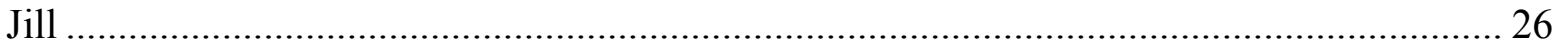

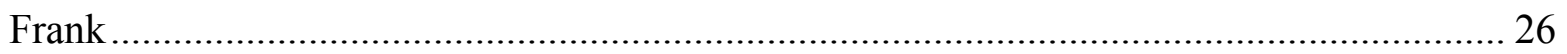

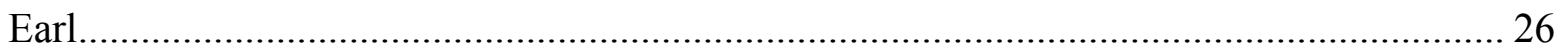

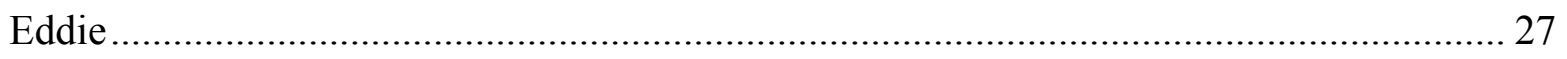

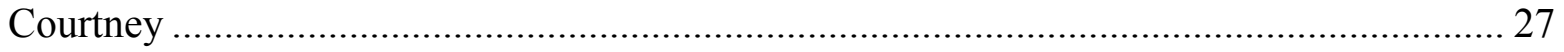

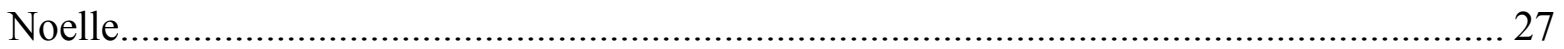

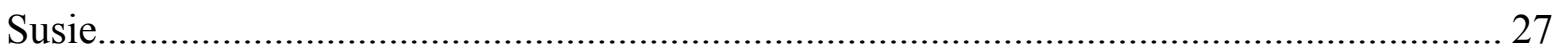

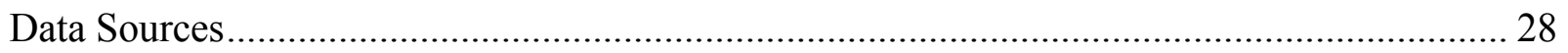

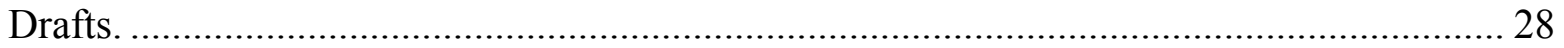

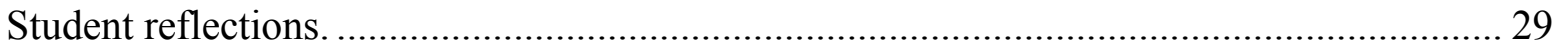




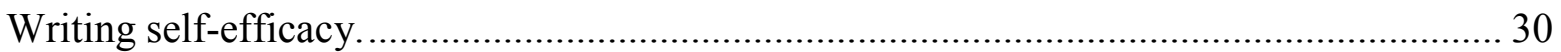

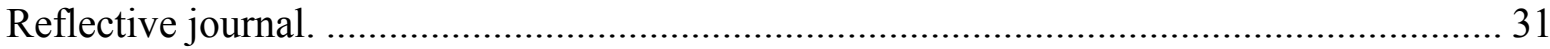

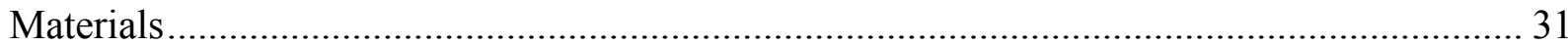

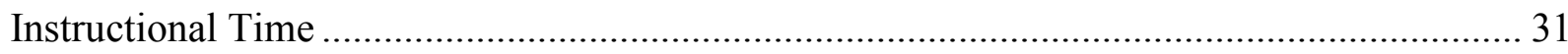

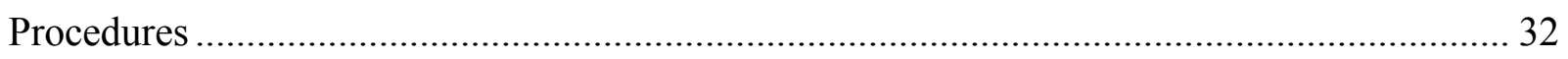

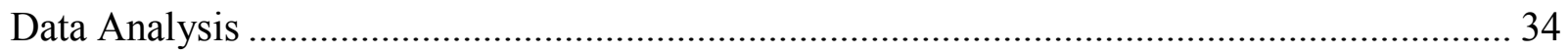

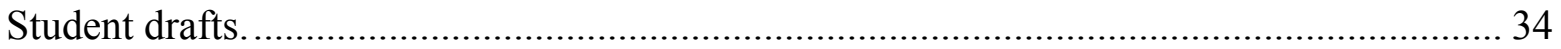

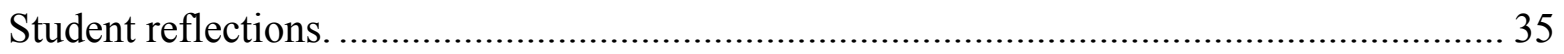

Self-efficacy scale

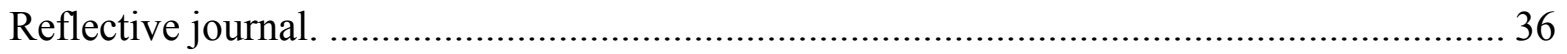

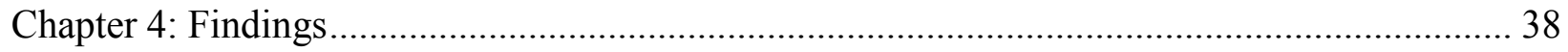

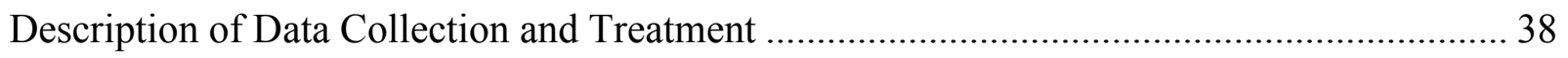

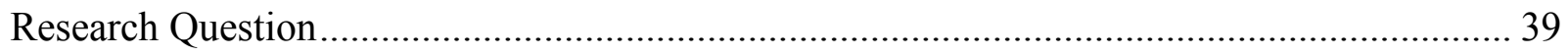

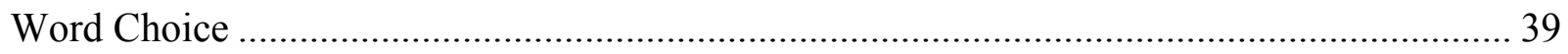

Susie

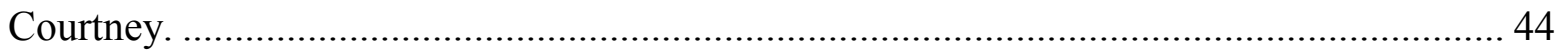

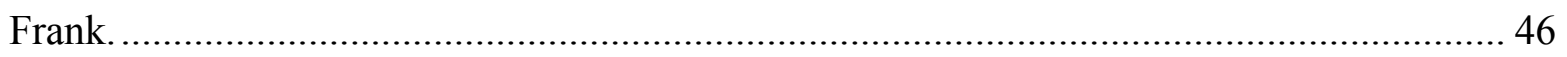

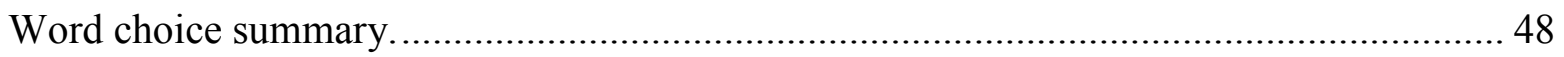

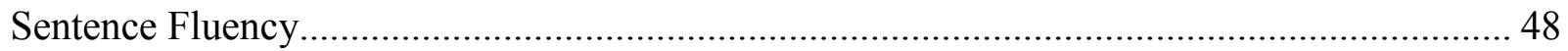

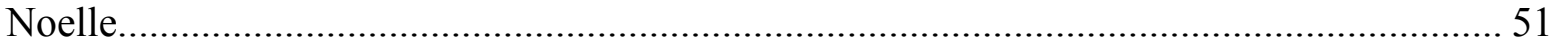




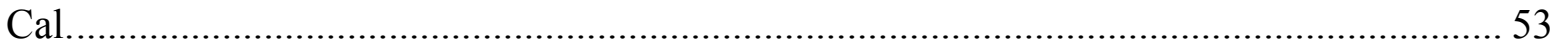

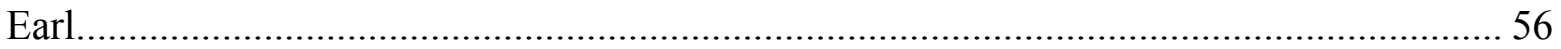

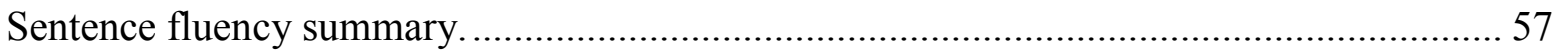

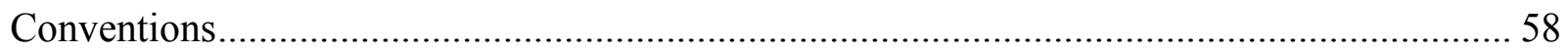

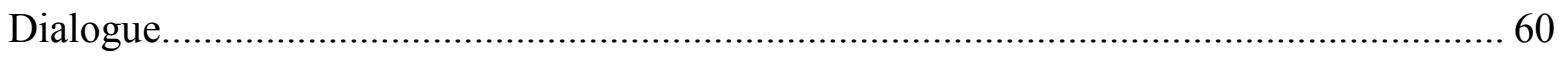

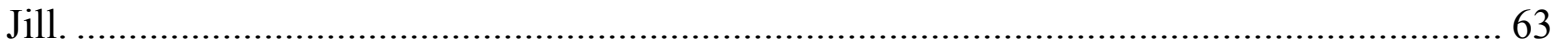

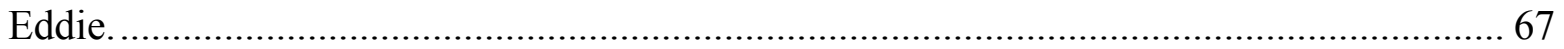

$\operatorname{Jim}$

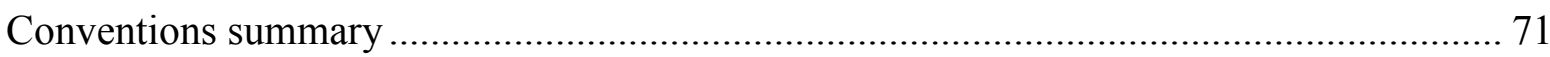

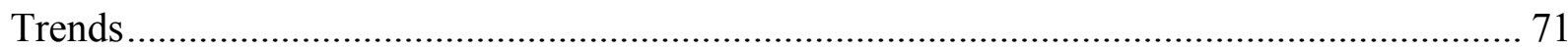

Picture books as mentor texts and coaches....................................................................... 71

Recognizing mentor texts as coaches in student reflections............................................ 72

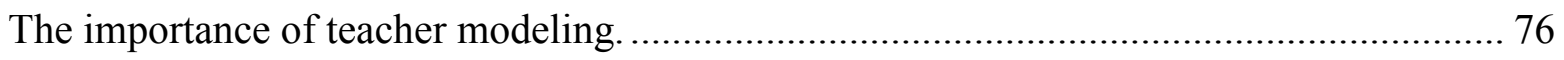

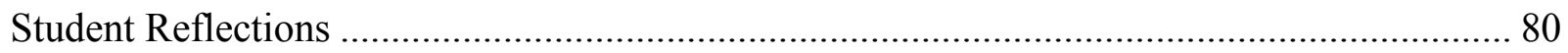

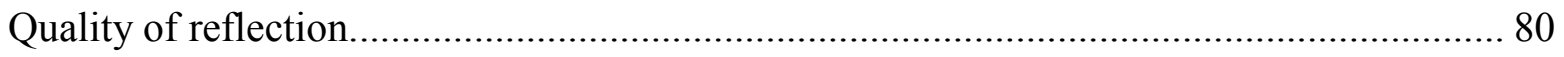

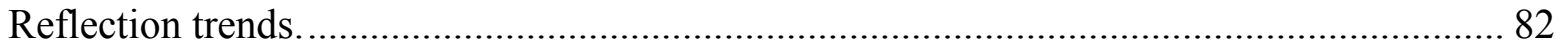

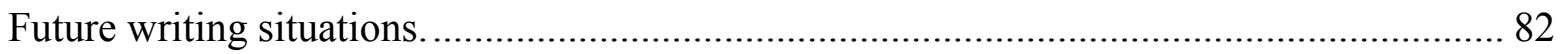

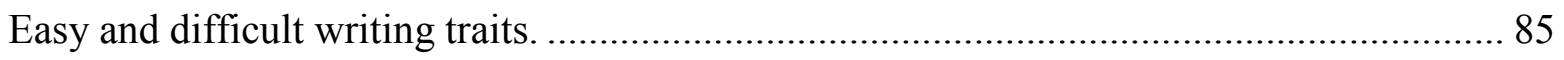

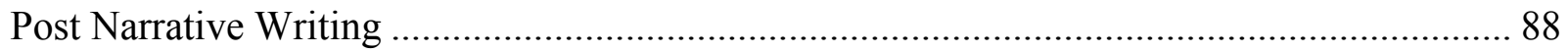

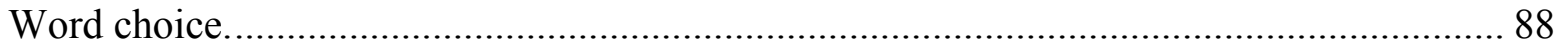




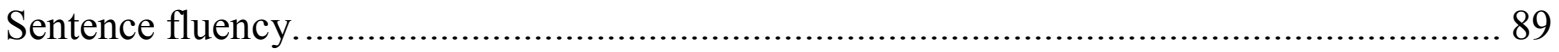

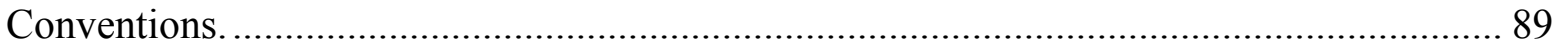

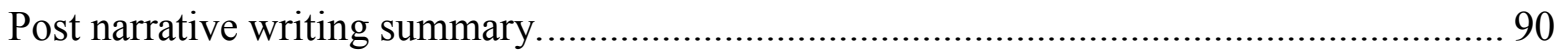

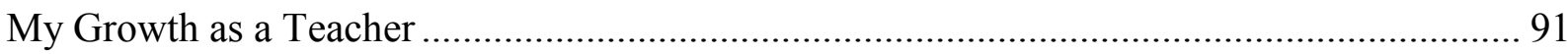

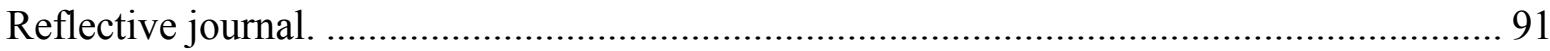

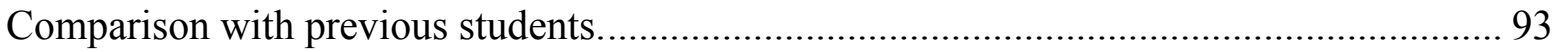

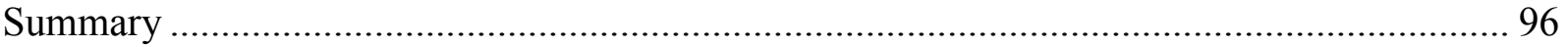

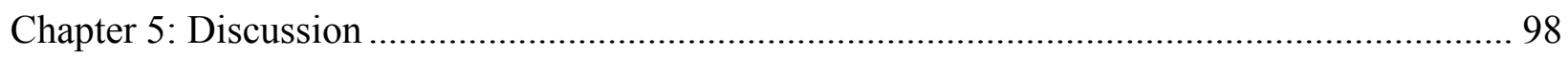

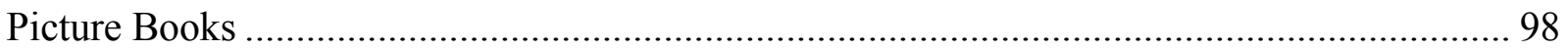

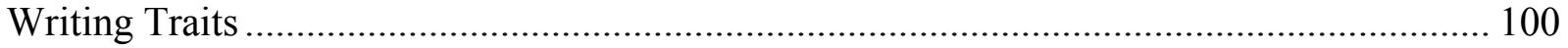

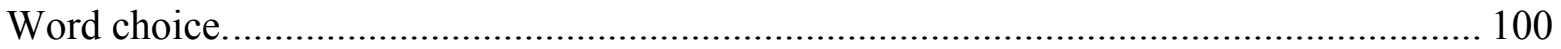

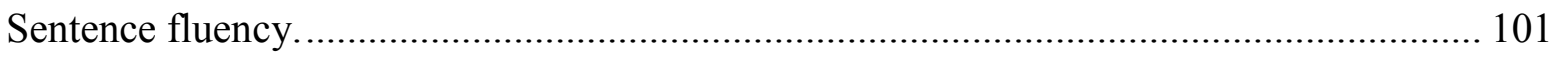

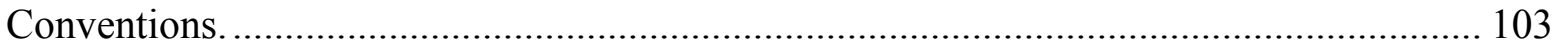

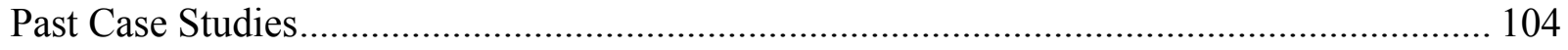

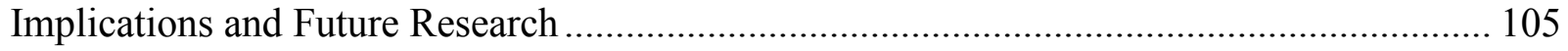

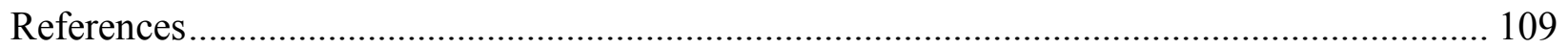

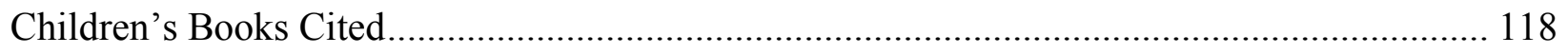

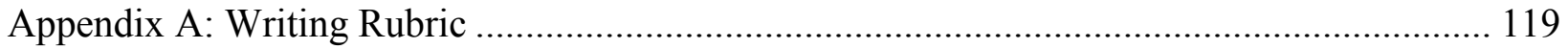

Appendix B: Picture Books Employed .................................................................... 121

Appendix C: Perceived Writing Self-Efficacy Beliefs Rate Scale ..................................... 122

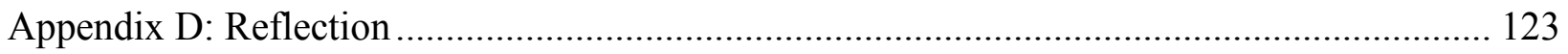




\section{LIST OF TABLES}

Table 1: Word Choice Scores Across All Students on 5-Point Scale ............................................ 41

Table 2: Sentence Fluency Scores Across All Students on 5-Point Scale .................................. 50

Table 3: Sample of Cal's Growth in Sentence Fluency Over Time ........................................... 54

Table 4: Convention Scores Across All Students on 5-Point Scale .......................................... 59

Table 5: Sample of Jill's Growth in Conventions Over Time ................................................... 65

Table 6: Students' Selection of Traits Expected to be Beneficial for Future Writing.................. 82

Table 7: Students' Selection of Most Natural Writing Trait ................................................... 86

Table 8: Students' Selection of Most Difficult Writing Trait ................................................... 86

Table 9: Final Writing Trait Scores for Previou Students, 2013-2014 School Year .................. 94 


\section{Chapter 1}

\section{Introduction}

Since the inception of the Common Core State Standards (CCSS) in 2010, English Language Arts students have been challenged to increase their writing abilities (National Governors Association Center for Best Practices \& Council of Chief State School Officers, 2010). The CCSS attempts to minimize the gap between secondary schools and colleges and universities (Dean, 2010) by requiring a more rigorous curriculum in conjunction with a larger volume of writing. As secondary students graduate, they are expected to have attained a higher writing ability than previous state standards envisioned to better prepare them for the future. Because of the CCSS and the increased expectations, students need strategic ways to enhance their writing ability and to have a clear idea of what is expected. An additional advantage is learning how professional writers perform (Gallagher, 2011). The ability to use mentor texts may be one way to help students improve their writing. A mentor text is an exemplary piece of writing, which is used to expose the writer to potential writing possibilities. Some refer to mentor texts as any text that can teach a student about strategies employed by writers (Anderson, 2005).

Before clarifying the purpose of this study, I will examine the problems. Following the purpose I will address the limitations.

\section{Statement of the Problem}

Many secondary English Language Arts students lack the necessary foundational skills to become effective writers. In Kelly Gallagher's most recent book, In the Best Interest of Students (2015), the author suggests "we [teachers] raised a generation of memorizers who have trouble thinking deeply and who can't read and write well” (p. 8). For this reason, exemplars in writing can provide a necessary model and may act as a guide for writers. Mentor texts provide students 
with clear and effective examples of prose that can become the center of writing instruction (Graham \& Perrin, 2007a), ultimately enhancing the writing (Fletcher, 2011). Strategic writing is a natural outgrowth as students become privy to the decisions writers make (Pytash \& Morgan, 2014). Although considerable research has been devoted to mentor texts in secondary schools, much less has been devoted to examining picture books as mentor texts on the sentence level in high schools. There are also no identifiable research studies examining the effectiveness of teaching writing traits with picture books at the high school level even though others have used picture books in their curriculum. For example, Dean (2010) employed picture books in secondary classrooms to share historical concepts as a means of frontloading a unit, and Springer (2013) used picture books to teach stylistic elements like tone and mood.

Using picture books as mentor texts may allow students to explore a non-threatening text in a strategic way that allows them to enhance their writing. The crux of creating good writing for many secondary students is strongly influenced by the example of others (Gallagher, 2011). To see how good writing is shaped and structured allows students to attain a level of writing excellence that may otherwise have been beyond their grasps.

One study examining picture books and target skills, such as organization and conventions, was conducted in elementary classrooms. The study was conducted with the oldest students in the fourth grade (Anderson-McElveen \& Dierking, 2000). However, it is unclear if similar results appear at the secondary level. The purpose of this study is to explore if picture books in the high school classroom can enhance students' word choice, sentence fluency, and conventions in narrative writing. The practice of using picture books has rarely been examined in this light, and it is possible that new perspectives and angles on using picture books as mentor texts can contribute to the field of study. Secondary teachers feel the need to improve all aspects 
of student writing, but the need to improve word choice, sentence fluency, and conventions is especially important. Culham (2014) suggested that these traits can be improved through the use of mentor texts, but the absence of studies conducted at the high school level, in addition to the lack of references in the literature, suggest that the writing traits found in picture books are not often used as models in the high school classroom.

The CCSS require that students use strategic words, phrases, and clauses all while varying the writing structure in order to create cohesion (National Governors Association Center for Best Practices \& Council of Chief State School Officers, 2010). Having the capacity to weave a variety of writing techniques seamlessly is a skill that can be used in academics, transactional, and functional writing. Beyond this, wrestling with the decisions that writers make, allows students to think, act, compose, and reflect throughout their lives (Langer, 2011). As the demands for state writing standards increase, the need for quality exemplars necessitates itself even more now than previously. Writing instruction that employs effective mentor texts can improve a writing curriculum. Additionally, it can teach students to wrestle with concepts and make the decisions that writers make. Langer (2011) advocated that "students need opportunities to experience disciplinary inquiry first-hand" (p.156). By using picture books as mentor texts to guide them, students may take one more step to becoming proficient writers, and may have the opportunity to discover and explore how writers make their decisions.

\section{Statement of the Purpose}

The purpose of this study is to explore the use of picture books as mentor texts for struggling readers and writers in a secondary high school setting. The research question is as follows: how do picture books as mentor texts influence academically struggling 10th-grade students' word choice, sentence fluency, and conventions in their narrative writing? 


\section{Limitations}

This study contained certain limitations. First and foremost my position was reflected in the work I chose to examine. I had been introduced to picture books as a tool to provide background information during my undergraduate years and found that intriguing. I also was exposed to picture books as a way to refine analytical skills for students a few years later. Because of my exposure to picture books and my affinity for writing, I reflected on how I could use picture books to enhance student writing on the sentence level. This general interest shaped the course of study for my students and predetermined what they would study in-depth for part of the school year.

A second limitation is the individual value placed on education and writing for the participants. Prior to this school year, all of the participants in this class were identified as struggling in some capacity. Yet, I perceived some participants value education much more than other participants, and that was reflected in the writing they constructed. This was also evident in their attitudes that I perceived. Those participants who came to class with what I perceived to be a positive attitude had much more success than those who I perceived had a poor attitude regardless of being identified as a low-performer or high-performer. The same intervention was in place for all participants, but the very nature of each student influenced potential.

Third, writing development requires time. Students need time to allow their writing to mature, wrestling with it daily throughout their educative experience. Students in this study worked on their narratives on a bi-daily basis according to the $\mathrm{A} / \mathrm{B}$ schedule. Because most students in this class rarely showed the willingness to complete work outside of class, I did not require students to work on their narratives at home. This limited students to revise only two to 
three times per week, and occasionally even fewer times where students were absent or school was closed. 


\section{Chapter 2}

\section{Review of Literature}

The review of literature will address the importance of writing, and the foundational relationship between reading and writing in becoming a developed writer. I will also address how mentor texts can be integral in developing student writing. Researchers have studied the benefits of exposure to mentor texts, outlining what mentor texts offer, and the relationship between reading and writing. This review will then address what is known about how picture books can act as mentor texts, especially with older students. It will also cover the research completed using picture books. Lastly, it will examine a portion of what is known about writing traits, specifically word choice, sentence fluency, and conventions.

\section{The Importance of Writing}

Writing is vital in education and civic life: it is ubiquitous in the academic world and plays an integral role in employment and promotion as well as interaction in everyday venues such as e-mail (Graham \& Perin, 2007b). Unfortunately, adolescents who do not learn the skills of writing are disadvantaged because colleges increasingly use writing as a way to measure academic competence, and many employers even replace verbal communication with writing. Currently, adolescent writing ability is insufficient for school and the work force (Graham \& Perin, 2007b). As teachers pursue methods that stretch their students to write more professionally, they take the necessary risks to push their boundaries: a sign of the expert teacher (Bullough \& Baughman, 1997).

\section{The Relationship Between Reading and Writing}

Writers such as Culham (2014), Gallagher (2015a), and Rupley, Logan, and Nichols (1999) have identified reading and writing as being reciprocal. In order to truly become a writer, 
one must be a reader (Ray, 2006). Some argue that only the act of reading (as opposed to explicit instruction) can possibly teach writers all of the intricacies of composition (Smith, 1988). The connections fused by reading and writing start as early as prekindergarten and extend past high school; yet, some believe that the connection has its flaws (Brenner et al., n.d.). Others note that "when we write, we read; when we read, we compose meaning" (Anderson \& Briggs, 2011, p. 546). Similarly, Tierney and Pearson (1983) believe that reading and writing engender the same kind of process in making meaning, and that readers compose meaning just as writers do: in planning, in drafting, even in revision.

Ray (1999) indicated that there are five elements of reading like a writer: readers notice the texts, they discuss why the writer employed the text, they provide a name for the text, they think of other writings with similar text, and they have the vision to see how the craft can be incorporated in personal writing. As students read like writers, then, any piece of writing can become a mentor text (Friese, 2010) when they can notice these elements. Pam Allyn indicated that reading and writing is similar to breathing in and breathing out, or that they are inherently connected (as cited in Culham, 2014).

This strong relationship between reading and writing brings a heightened cognizance in the statement from Anderson and Briggs (2011) explaining that when students see the reciprocity between reading and writing it expedites the learning. It is believed that proper writing instruction leads to a stronger reading ability (Graham \& Hebert, 2011). After all, writers "must read like a writer in order to learn how to write like a writer" (Smith, 1988, p. 23). It is no surprise then that students who struggle to read also struggle to write (Ray, 2006).

El-Hindi (1997) conducted a study that suggested that reading and writing are connected by learners who are meta-cognitively aware to create meaning through text. In like manner, 
Smith (1988) argued that the best way to learn to write a certain genre is to read that genre. Clearly, the best way to learn to write in a new genre is not through a textbook, but, in fact, through reading prose in that genre. Consequently, to truly participate in the act of writing, pupils need to have authentic moments employing acts of reading (Harste \& Short, 1988).

Graham and Hebert (2011) constructed a meta-analysis about the relationship between reading and writing. For students between the grades of 2 and12, they found that writing about material that was previously read increased reading comprehension. A resounding $94 \%$ of the studies produced a positive effect size. The study was statistically significant and all of the variance was accounted for through the use of sampling error. The study showed data that indicated a positive impact on struggling readers and writers. The analysis also showed that writing instruction improved reading comprehension for students in grades 4 through 12 . Lastly, increasing student writing enhanced reading comprehension in grades 1 through 6 in language arts classes.

In a study examining the relationship between reading and writing, El-Hindi (1997) used volunteers from a 6-week academic program in 1993 for incoming students for a major university in the northern United States who were identified as "at risk." Questionnaires were given to assess metacognitive activity for each student in both reading and writing. Reading log entries were also required. The analysis from the questionnaires showed a strong increase in metacognitive awareness of reading. The reading log demonstrated the metacognitive strategy employed.

El-Hindi's study showed that the relationship between reading and writing was enhanced through the use writing in the reading logs. The students also demonstrated the ability to 
coherently discuss the metacognitive process during their reading. One student in this study even emphasized the relationship between reading and writing in a reflective analysis.

\section{The Importance of Mentor Texts}

The use of mentor texts is intentionally using the rich relationship between reading and writing to improve writing. A mentor text can be defined as "any text, print or digital, that you can read with a writer's eye" (Culham, 2014, p. 31), and a book that provides bounteous opportunities for students and teachers to learn to think and act like writers (Dorfman \& Capelli, 2007). Suggestions have been made that every student can benefit from using mentor texts; thus, there is a need for mentor texts. Among the many benefits of mentor texts, they allow students to strengthen reading and writing skills (Culham, 2014), and students gain a strong understanding of how texts are well crafted (Pytash \& Morgan, 2014).

The following section will address further the benefits of exposure to mentor texts and what they offer young writers. It will also discuss a portion of what known about the relationship between reading and writing.

Exposure to mentor texts. Exposure to mentor texts allows students to see what good writing looks like, and provide a clear structure to replicate (Dorfman \& Capelli, 2009), almost as if the published author were in the room as a coach (Culham, 2014). This can be a powerful model because mentor texts become co-teachers in the classroom to demonstrate the finest of writing (Culham, 2014; Pytash \& Morgan, 2014). This allows students to return to the text as often as necessary to examine the nuances of writing (Dorfman \& Capelli, 2007). Because what we see ultimately ends up in our writing (Anderson, 2005; Dorfman \& Capelli, 2007), students become aware of the decisions writers make that they, too, can make (Pytash \& Morgan, 2014). 
This helps them identify elements within good pieces of writing that become a framework for the prose that they can create (Ray, 2006). This facilitates independence.

One of the key goals for most writing instructors is to develop strategies for students so that they can learn to become writers and not merely produce writing (Dean, 2010). By being exposed to mentor texts frequently, students can apply their observations and experiences to their independent writing and share their knowledge of strategic prose with their writing community (Anderson, 2005; Dorfman \& Capelli, 2009). This can be especially helpful when students are faced with a composition task outside of school. They need to know how to write without a prescribed method beyond what is found in graphic organizers and formulas (Ray, 2006). This can encourage students to analyze a mentor text to employ similar components, elements, and patterns in their own writing (Anderson, 2005; Graham \& Perrin, 2007a; Pytash \& Morgan, 2014; Ray, 1999).

Affordances of mentor texts. Mentor texts offer many opportunities for students to enhance their prose. For example, students can improve their writing as mentor texts offer examples of various text structures and examples of word possibilities (Ray, 1999). Multiple mentor texts offer an even larger influence on the writer for an added measure of support (Dorfman \& Capellli, 2009). When students read they can take a "snapshot" of the moment and then examine the strategies, skills, and structure for personal use for optimal writing. This evokes the idea that the reader's schema is important for organizing and arranging previously identified and also newly acquired material (Day, 1996).

In addition to what has been stated, mentor texts (a) offer students to reflect on strategies of effective writers, and learn to understand how the text works to create options as they discover that there is not one correct way to write (Culham, 2014); and (b) allow for conversations with 
students about specific possibilities for students to experiment with in their own prose (Pytash \& Morgan, 2014).

In today's era of education, teachers can find mentor texts even without a classroom library. School and public libraries, newspapers, magazines, advertisements, brochures, and the Internet provide adequate models of mentor texts (Culham, 2014). "In the natural course of our reading lives, we find mentor texts all around us, even when we're not searching for them" (Marchetti \& O’Dell, 2015, p. 14).

\section{Picture Books}

Although not everyone agrees on the definition of a picture book, traditionally it has components of pictures and words working interdependently to share a story. Some characterize picture books as short pieces of writing (Ray, 1999; Reif, 1992; Saunders, 1999). Bishop and Hickman (1992) argued that the pictures supplement the understanding of the story. They explained that picture books have defining characteristics: pictures appear on each page, the writing is precise, and both the picture and the prose make the greater whole. Goldstone (2001) asserted that picture books are defined by their format of pictures and text while O'Sullivan (1987) argued that picture books include simple plots, quick reading, and minimal characters. However they are defined, picture books have the capacity to "teach critical thinking skills, visual literacy skills, and interpretive strategies" (Pantaleo, 2008, p. 67).

I now examine picture books as mentor texts, and what is known about their usage with secondary students. Research using picture books will also be examined.

Picture books as mentor texts. Danielson (1992) argued that a picture book in the possession of the right teacher can be a learning tool for any student. This is in part because picture books make for great mentor texts (Elleman, 1996; Newkirk, 1992; O’Sullivan, 1987), 
and they have the capacity to strengthen writing skills in developing writers (Saunders, 1999). This may be in part because they (a) allow the writer an easier avenue to view the structure of the writing (Ray, 1999), and (b) because the language is often poetic, saturated with metaphors and simple writing (Reif, 1992). Further, picture books present an appealing platform to teach good strategies of writing in an "interesting format" (Dorfman \& Capelli, 2009, p.4), and the need to find innovative and strategic pedagogical tools appeal to a diverse student body (Uccelli, Dobbs, $\&$ Scott, 2013). Much of the appeal is due to people of all ages having the capacity to enjoy quality picture books (Bishop \& Hickman, 1992; Carlisle, 1992b; Jenks, 1992; Ranck-Buhr, 2013; Reif, 1992). Also, they are always appropriate for school settings, allowing for a wider range of instruction (Ray, 1999).

O’Sullivan (1987) argued that picture books act as august examples of mentor texts because the text is "manageable" for writers who lack confidence. For example, they (a) provide efficient examples of applied text structures (Ludlam, 1992), (b) have an understandable organization and flow of ideas (Bishop \& Hickman, 1992), (c) can engender creative sets of formats and topics that spark learning when students claim they have exhausted their ideas (Mitchell \& Pullum, 1998), and (d) contain a variety of sentence types with reoccurring structure that allows students to follow the structure found within the book (O'Sullivan, 1987). These intricacies can be a boon to inexperienced writers (Ray, 1999; Rief, 1992) and "actively invite the reader to coauthor the text" (Goldstone, 2001, p. 363). Plenty of picture books as mentor texts like this exist (Friese, 2010).

Picture books display variation of form, permitting traditional or unique arrangements of the writing to impact the structure or organization. Some allow for creative elements while others 
use more conventional patterns (Bishop \& Hickman, 1992). This allows for more choices in a particular genre because they will understand it better (Mitchell \& Pullum, 1998).

Picture books facilitate the reading and writing instruction for students (Bishop \& Hickman, 1992) as they can engender critical thought, additional inquiry, and discussion (O’Sullivan, 1987). Teachers who consistently discuss strong writing techniques from children's literature provide moments for their students to think and act like writers (Anderson-McElveen \& Dierking, 2000). For instance, various techniques of writing can be found in picture books as well such as effective repetition (Bishop \& Hickman, 1992), and the strategic use of one isolated word (Heard, 1992). These easily identifiable patterns are helpful because the writing within picture books can be a guide for students to create their own writing (Ludlam, 1992).

Picture books for older pupils. The practices for effective use of picture books are expanding (Goldstone, 2001). Some may question using picture books for secondary readers and writers; however, picture books can be an effective resource for older students (Carlisle, 1992a; Heard, 1992; Kiefer, 1995; Ludlam, 1992) because the content of the books are complementary to various courses, or provide topics of interest. Even picture books meant for younger audiences can be looked at through a more mature lens with an older audience (O'Sullivan, 1987). This adds depth for the reader because such books may contain information not disseminated in textbooks (Bishop \& Hickman, 1992).

If people look to the picture book as a unique medium of both literature and art, then all pupils can learn from them as they have been shown to evoke mature ponderings and questions in older audiences (Carlisle, 1992b; O’Sullivan, 1987). For example, Elleman (1996) suggested that picture books are great sources for engendering a dialogical classroom. 
Picture books can also aid students in their literacy development, and even offer challenges for skilled readers (O'Sullivan, 1987). One example of literacy development is generating a stronger awareness to language (Bishop \& Hickman, 1992), and to promote academic literacy (Ranck-Buhr, 2013). "Picture books help the reader build greater awareness of language and offer opportunities to explore and learn the conventions" (Graham, 2000, p. 5). This may be in part because picture books have their own unique "canvas" to evoke the same feelings and emotions that traditional prose creates (Carlisle, 1992b), and some picture books are sophisticated enough that the irony or parallel stories provide a deeper level of understanding than either the words or pictures can provide alone (Day, 1996).

Goldstone (2001) suggested that picture books also allow students to participate in acts of literacy. An act of literacy can be defined as any text that allows the opportunity to search, analyze, compare, discuss, react, or add additional points (Langer, 2011). There are many reasons why picture books may be considered an act of literacy. Picture books eliminate barriers that make learning so exclusive because they are accessible to the vast majority (Ludlam, 1992). This includes easier text to understand for English language learners (Jenks, 1992; O'Sullivan, 1987), allowing them greater access and understanding through the short length, use of images, and fewer words (Hadaway \& Mundy, 1999). Students can do this by fusing lived experiences with information in the text. The reader's knowledge helps to co-build the text as they support, supplement, and compose meaning as they pull together the missing components of the text to create meaning (Goldstone, 2001). Because picture books have the capacity to be the center of acts of literacy within a classroom, then employing picture books in a high school curriculum is a legitimate learning tool. With all of the new intricacies to picture books, they are becoming common in some secondary classrooms now (Costello \& Kolodziej, 2006). 
Research using picture books. Few research studies of picture books as mentor texts have been conducted at the high school level, heightening the importance of my study. In this section I illustrate two studies in which elementary students worked with picture books to improve their writing.

Anderson-McElveen and Dierking (2000) conducted a study using picture books with 50 students either in kindergarten or the $4^{\text {th }}$ grade. Children were shown examples of powerful words and phrases found in picture books. Results showed that the youngest writers paid special attention to small bursts of words, while more experienced writers were able to see the power of a simile. Later, the students crafted their own prose, implementing those elements in their own writing. Researchers reported that reading a text was not enough for their students; students needed the teacher to model the procedure for their students. This study demonstrated that it is also critical that the instructors craft their own texts in front of the students so they see the struggle and thought involved by the teacher-the most advanced writer in the classroom (Dorfman \& Capelli, 2009; Gallagher, 2011). My study builds on using the six-trait usage of vocabulary as is emphasized in the Anderson-McElveen and Dierking study, but with an older age group. My study will add to the existing literature on how word choice is acquired and implemented using picture books.

Similarly to Anderson-McElveen and Dierking's study, the U.S. Department of Education conducted a study with $5^{\text {th }}$ grade students. Researchers used picture books as part of a greater whole to demonstrate proper writing characteristics found in the $6+1$ writing traits (Coe, Hanita, Nishioka, \& Smiley, 2011). A portion of the study emphasized writing conventions throughout the year because they felt that writing conventions were appropriately needed at all times. Teachers were then provided with hundreds of picture books to review at 
their discretion. They were also exposed to different techniques for implementing the picture books to model the writing traits. In a similar fashion, writing trainers provided picture books for teachers to review and delineated how the picture books could be utilized to show examples of specified writing characteristics. The writing trainers specifically modeled how teachers could use the picture books to introduce and demonstrate different writing traits to their students (Coe et al., 2011).

The trained group received instruction from the use of picture books as mentor texts for seven traits including word choice, sentence fluency, and conventions. The results indicated a statistically significant difference in the writing scores of students with an effect size of 0.109 $(p=.023)$. Ultimately, this means that the treatment group was .11 standard deviations greater than the anticipated average score of the control group. Another way to look at this is through the use of percentile scoring. An effect size of this nature would increase the achievement level from the $50^{\text {th }}$ percentile to the $54^{\text {th }}$ percentile (Coe et al., 2011).

The study examined the impact of the $6+1$ writing traits on student success in certain writing characteristics (organization, word choice, and voice). The implementation of the $6+1$ writing traits had a statistically significant effect with effect sizes from 0.117 to 0.144 ( $p=.031$ to .018). Although the mean score of the students in the treatment group was higher than the students in the control group for remaining traits (ideas, sentence fluency, and conventions), the differences were not statistically significant (Coe et al., 2011).

My study again builds on the existing literature of using picture books as mentor texts, but with a more mature age group. Similarly, I examine conventions as the Coe et al. study did, but my research expands on their study as I explore word choice and sentence fluency with picture books in addition to conventions. 


\section{Writing Traits}

In this section I review some of the literature of the three writing traits I explore in my study. First, I highlight word choice; second, I illustrate sentence fluency; and lastly, I detail conventions.

Word choice. Word choice can be defined as "the vocabulary the writer uses to convey meaning and enlighten the reader" (Culham, 2014, p. 24), "the use of rich, colorful, precise language that moves and enlightens the reader" (Smith, 2003, p. 3), and "a knack for selecting the just right word or phrase that makes everything come clear for the reader"' (Spandel, 2009, p. 3). Word choice "addresses the variety, precision, and evocativeness of the language" (Coe et al., 2011, p. ix), and is included in the $6+1$ writing model (Spandel, 2009) that displays effective strategies of writing. Finally, by building a rich vocabulary with an arsenal of words, students can construct meanings (Hennings, 2000), and elicit responses in their readers (Sloan, 1996).

There are a few reasons why word choice may be especially critical to study. The first is because schools in general have failed to strategically implement vocabulary acquisition (Hiebert \& Cervetti, 2012). The second is because not many teachers focus on enhancing vocabulary (Beck, McKeown, \& Kucan, 2002). Yet, teaching vocabulary has the ability to improve comprehension when scaffolding is used properly and the activities are designed to encourage active processing (Ibrahim \& Yaworski, 2001). The study of words can also be beneficial because good word choice grabs the attention of the reader, and beginning writers usually enjoy “fun," new words (Spandel, 2009).

Students' abilities to recognize words and grow their vocabularies are necessary components of a comprehensive literacy program. Not only is word choice an aid in style of the writer, but having a robust vocabulary has been linked to one's general intelligence level 
(Anderson \& Freebody, 1979). Similarly, some argue that a robust vocabulary is the benchmark of an educated person (Beck et al., 2002). Findings from other studies suggest indirect experiences such as independent reading, and listening to adults read aloud can also expand a student's word repertoire because of the repeated exposure of words in meaningful contexts (Penno, Wilkenson, \& Moore, 2002).

When students write, they get to choose their own words, instead of the teacher and author choosing the words for them (Elbow, 2004), and that requires a robust vocabulary. Finding the precise word is more than finding a word that will work: it is finding the just right word (Culham, Blasingame, \& Coutu, 2010; Dean, 2010; Spandel, 2009). Writers build and convey meanings with their word selection. If the most appropriate word is employed, then imagery, imaginations, and connections can be conveyed: it is how writers can make the mundane become the astounding, and a source of inspiration (Culham et al., 2010). Finding powerful and precise words allow the writer to convey moods, images, and expressions (Smith, 2003). Each word communicates meaning to the reader, and the ability to employ strong word choice brings a strong meaning to the reader (Murray, 1995).

Educators cannot assume that students naturally have the necessary understanding that produces rich content learning, or the ability to derive meaning from words in literature (Hennings, 2000). One way to combat this problem rests on the shoulders of the teacher. Young students can learn new words by exposure and through teacher identification and elaboration (Elley, 1989). My study addresses this need by identifying new words found in picture books, and affording students a chance to employ them correctly in a narrative.

Rupley, Logan, and Nichols (1999) advocated the learning of new words through instruction. Part of this role can be filled through the use of examining words through picture 
books. Saunders (1999) argued that picture books offer great examples of word choice. Further, word choice viewed through the lens of picture books provides an invitation for integration of language study with other texts (Carnicelli, 2001). Students are also better able to cultivate their understandings of words from meaningful contexts (Carnicelli, 2001). This can be aided by picture books. It is also perceived that words are learned in context (Beck, et al., 2002). This is one reason why picture books can be powerful. Through them, students are exposed to a robust variety of language, growing their semantic schema (McKeown, Beck, \& Sandora, 2012).

Sentence fluency. Sentence fluency can be defined as "the way words and phrases flow through the piece" (Culham, 2014, p. 24), and the "rhythm and flow, the music and poetry of language - how it all plays to the ear" (Spandel, 2009, p. 3). Sentence fluency is also referenced as syntactic fluency, and there is a strong connection between sentence combining and improving syntactic fluency (Rose, 1983). This is similar to Culham's (2014) suggestion that varying sentence types improves sentence fluency. John Mellon's study in 1969 was the first recorded to use sentence-combining skills rather than just learning grammar (As cited in Brooks, 2000).

Sentence fluency puts the emphasis on the flow and tempo of the language (Paquette, 2007), and an excellence in understanding often exhibits a nice "flow" and "rhythm" with a varied structure indicating a strong command (Crawford, Helwig, \& Tindal, 2004). Spandel (2009) shared three of her discoveries about sentence fluency: (a) sentence variety is the essence of sentence fluency (see also Culham, 2014), especially length, beginnings, structure and even repetition; (b) particular groups of wording imitate sentence patterns that strengthen meaning, and an ability to attempt new forms to vary the structure; (c) different genres require different sentence structure. However, it may be helpful to providing students with picture books as 
mentors that match their target genres. Friese (2010) identified this strategy to be especially helpful when writing other genres.

Culham (2014) suggested that mentor texts emphasizing sentence fluency can be found in a plethora of places, and that sentence fluency can be improved through the use of mentor texts by looking at the varied sentence structure in professionally crafted prose. She also explained that writers can break the conventional rules of writing to place emphasis on a particular syllable or to sound more authentic. The goal is to have the writing be smooth enough that the thoughts in the writing flow freely without interruption. One way to accomplish this is to read the writing aloud (Culham, 2014; Spandel, 2009). Some also advocate for writers to look for the "technique, ways of execution, phrasing, rhythm, tonality, pace" (Hugo, 1979, p. xi) used by published writers. The craft of teaching and understanding sentence fluency is conducive for picture books because of the oral component, ease of repetition, and length, making them effective for teaching this trait.

Further, Culham (2014) argued that strong sentence fluency can be a result of good revision as unnecessary words and phrases are omitted, and sentence structures are varied. She reasoned that strong sentence fluency can also provide the prose with strongly-crafted sentences, and refined and effortless flow. This is needed for strong academic writing, often polished in sentence combining (Myers, 2003).

Conventions. Conventions have been defined as "the mechanical correctness of the piece" (Culham, 2014, p. 24), and the "skill in using an editor's tools (punctuation, spelling, grammar, capitalization, and layout) to enhance readability and meaning" (Spandel, 2009, p. 3). It is how authors make writing easy on the eyes for readers (Culham, 2014). Some have also defined conventions as qualities of effective writing or target skill (Anderson-McElveen \& 
Dierking, 2000, p. 362). Conventions can be nebulous as scholars disagree on what is correct conventionally, limiting writers as they define conventions in terms of "correctness" (Spandel, 2009). For example, some clarified that writing conventions include the ability to incorporate generally agreed-upon spellings, punctuations, capitalization, and sentence fluency (Bruning, Dempsey, Kauffman, McKim, \& Zumbrunn, 2013). Culham (2014) also argued that the conventions remain constant enough across genres of writing. Even so, she suggested that one must remember to have appropriate grade level expectations and reinforce them perpetually. However, in some instances it is appropriate and effective to make non-traditional choices, and some mentor texts demonstrate that it is appropriate to "break the rules" for emphasis, voice, and for the overall reading pleasure once the students know the rules and know how to properly break them (Culham, 2014; Spandel, 2009).

Students write for various reasons, but without the proper mechanics the message in the writing will not be delivered correctly (Bruning et al., 2013; Mullis \& Mellon, 1980). Controlling the foundation of mechanics to command the writing is essential (Bruning et al., 2013). The writer's message will be delivered accurately if the proper conventions are employed. (Anderson-McElveen \& Dierking, 2000). Using accepted conventions become critical for students because they "mostly" cannot draw upon contextual support to convey meaning, but rather must use the parameters designated by proper conventions to construct meaning, and can, presumably, form a sense of their writing potential (Bruning et al., 2013). There are many ways that conventions can be discovered and explored correctly in writing (Clark, 2013). Mentor texts, published with proper conventions, can increase the variety of the conventions in the student's own writing (Culham, 2014). 
The present study will examine only three writing traits previously defined, even though there are others. These writing traits present only a portion of the potential areas of writing to examine using picture books as mentor texts. 


\section{Chapter 3}

\section{Methods}

This action research involved 12 students from two English 10 Reading classes at Sherwood High School (pseudonym). Each student in both classes received the same education and instruction with picture books; however, I only collected data for 12 strategically identified students. Traditionally, students have been selected for the reading class by end-of-year testing that the state requires; however, this year students were identified for the class by their most recent English/Language Arts teacher from their respective junior high schools. First I explain the demographics. Second I describe the participants. Third, I discuss the data sources. Next, I focus on material, time, and procedures. Finally, I highlight how each of the data sources was analyzed, a reference to the materials, and my use of instructional time.

\section{Demographics of the Study}

This study took place in what is considered a suburban high school, but many students come from a rural community where farming is common. It is located close to a small university that many students attend after graduation, and where they can earn credit as part of concurrent enrollment classes Sherwood High School offers. As of February 8, 2016, there were 1,938 total students that matriculated in Sherwood High School at the commencement of the 2015-2016 school year. Of these students, 965 were female and 973 were male. The majority of the student population was Caucasian students with a total number of 1,733 making up $88.4 \%$ of the student population. The remaining $11.6 \%$ of students are categorized into five ethnicities: Hispanic (142 students), Asian (22 students), American Indian (14 students), Pacific Islander (14 students), and Black (13 students). 


\section{Participants}

I chose 12 total participants from two English 10 Reading classes that I taught, six participants from second period, and six participants from sixth period. The final student count for both classes was as follows: there were 26 total students (12 female; 14 male) in my second period class from which I chose to select six participants. Of the 26 total students, nine were Hispanic (six male; three female), and the remainder were Caucasian. My second period class consisted of 32 total students (14 females; 18 males) in which five students were Hispanic (three male; two female), and the remainder was Caucasian. These two classes fell on alternative days and were 96 minutes long. On Tuesdays the time in class changed (to accommodate weekly professional development meetings), and were only 83 minutes. We had school announcements during this time that varied in length, but usually did not exceed 10 minutes.

Without considering previous writing, activity, or scores, I chose the highest, lowest, and average performing male and female students after students examined a mentor text titled This is 45 (Mendell, 2014), and crafted their own writing about what it means to be 15 -year-olds. The students only wrote one draft, and I scored the writing holistically out of 15 points, examining the command of language and overall coherency of the writing. I then selected the two highest scores, the two lowest scores, and two average scores for this writing activity from each class to select the 12 participants. A few students did not submit this assignment and were thus not eligible to be considered as a participant.

I developed a relationship with all of these students throughout the course of the 20152016 school year as their teacher. I have an opinion of these students based on the work they have done in class, the attitude they have portrayed, and their willingness to work. All of the 
names of the participants are pseudonyms. I will introduce and briefly describe Brooks, Jim, Cindy, Allison, Cal, Jill, Frank, Earl, Eddie, Courtney, Noelle, and Susie.

Brooks. A Caucasian male, Brooks is one of the low scorers in second period. He lacks focus, attention, and desire during class sometimes, often choosing to talk to his peers. He seldom disrupts class, but he is capable of better focus and better work, and occasionally submits his work late. While he is respectful of me as a teacher, I still need to monitor his behavior in class to make sure he is on task at times.

Jim. Jim, also a Caucasian male, is the other low-scoring participant from second period. He has an excellent attitude and is always willing to participate in class activities and work independently. Jim is a quiet student who often stays to himself, but he maintains a strong focus in class and always gives his undivided attention to the day's lesson. He shows an impressive desire to learn and improve, and does his best to incorporate the day's lesson into his writing. Rarely does he choose not to complete and submit an assignment on time.

Cindy. Cindy is an average-performing, Hispanic female student in second period. Her first language is English, but she chooses to be quiet during class. Cindy is unsure of herself as a writer, often needing someone of greater knowledge to assist her as she incorporates new strategies in her writing. It is important to note that Cindy will take risks as a writer, but typically only when I am available to guide her. Cindy submits most of her work on time, but occasionally does not submit assignments or submits late assignments.

Allison. Allison is an average-performing Caucasian female in second period. When seated away from certain peers, Allison is an excellent student. When she sits near her friends, though, she often lacks the focus needed to succeed in class. Allison is willing to participate and 
share her responses when called upon, and typically works efficiently in class. Allison usually submits all of her assignments on time.

Cal. Cal, a high-performing Caucasian male student in second period, works hard in class, but is susceptible to losing focus and talking with his peers. Cal is an extrovert who constructively voices his opinion to questions I pose on many occasions. He also enjoys sharing his work with others and reviewing others' work. While his voluntary participation is a good trait, he occasionally succumbs to participating unconstructively with his peers in class, but quickly returns to work once I ask him. Cal submits most of his assignments on time, but occasionally does not submit assignments, or submits them late.

Jill. Jill, a Caucasian female, is the other high-performing student in second period. An introvert who does not willingly talk with her peers, Jill is a hard worker, provides her undivided attention in class, and efficiently works on her assignments when given time. She has a great attitude about class and occasionally volunteers her thoughts on writing during class discussion. Jill typically submits all of her assignments on time.

Frank. Frank, a Hispanic male whose first language is English, is a low-performing student in sixth period. He is an introvert who is reluctant to share his ideas with others, and typically does not ask for help. He has a good attitude and does what he is asked to do. Frank pays attention in class and does his best to incorporate the day's activities into his writing. When given one-on-one attention Frank is capable of excellent writing. Frank occasionally chooses not to submit assignments.

Earl. A Caucasian male, Earl is a low performing student in sixth period. He is not shy about voicing his displeasure with school and writing, but I believe he does that, at least 
partially, to appeal to his peers. Earl occasionally chooses not to submit assignments, but is ultimately motivated by a passing grade. Because of that, he submits many late assignments.

Eddie. Eddie, a Caucasian male, is an average performing student in sixth period. He typically stays to himself, but is not afraid to unconstructively talk to the person next to him. He pays attention in class on most days, and he works hard on his writing when he is focused. Eddie submits most of his work on time, but occasionally submits late assignments.

Courtney. An average-performing student in sixth period, Courtney is a Caucasian female. She is a quiet student who works efficiently, only occasionally distracted by peers for a few moments. Courtney has a great attitude in class and is willing to work hard. Courtney submits most of her work on time, but occasionally chooses to submit late assignments, or not turn them in at all.

Noelle. Noelle, a Caucasian female, is a high-performing student in sixth period. She has a bright countenance and is efficient in class. She prefers to remain quiet, but is not afraid to share her ideas when called upon. Noelle works hard, has a good attitude, and is not afraid to put her pencil to the paper and write. Noelle typically submits all of her work on time and works efficiently.

Susie. A Caucasian female, Susie is a high-performing student in sixth period. She works hard in class and incorporates the day's lesson into her writing. She has an excellent attitude in class, and uses her time efficiently and wisely. She is not afraid to volunteer to share her ideas about writing with the class or share her work with me. Often when I give her ideas about improving her writing she does her best to incorporate those ideas. Susie typically submits all of her work on time, but there are rare occasions when she submits assignments late. 
I talked with each student individually, away from the rest of the class, to ask permission to use his or her work in my study. This explicit consent was required by the International Review Board at Brigham Young University. I explained that all would receive the same education whether or not they agreed to be participants in the study, that there would be no compensation for agreeing to be a participant, and that they would receive a pseudonym to protect identity. Because they are minors, I indicated that I would call a parent or guardian to ask for final permission. All parents and students agreed without hesitation.

\section{Data Sources}

There were four main data sources for my research question: "How do picture books as mentor texts influence academically struggling $10^{\text {th }}$-grade students' word choice, sentence fluency, and conventions in their narrative writing?" Every student in both of my classes, even those not acting as participants, completed all three of the data sources in conjunction with the same curriculum to ensure that every one received the same education. The data sources were drafts, student reflections, the writing self-efficacy scale, and my own reflective journal.

Drafts. The first data source was a comparison of the first, second, and final drafts that students composed after spending 11 weeks examining word choice, sentence fluency, and conventions found within picture books. In all three drafts of writing, I used Jim Burke's 5-point scale (n.d.) to rate students' word choice, sentence fluency, and conventions (see Appendix A). The writing scale that I used to score the informal writing was the same scale that I used to score each draft of the participants' narratives.

These drafts were good indications of the growth students experienced throughout the study as most of the participants' word choice, sentence fluency, and conventions improved. I read the 12 student participants' drafts after they were submitted and provided a score for each of 
the three writing traits. For my second period class, the first draft was scored on November 17, 2015; the second draft was scored on December 14, 2015; and the final draft was submitted on January 25, 2016. For my sixth period class the first draft was scored on November 16, 2015; the second draft was scored on December 15, 2015; and the final draft was submitted on January $22,2016$.

I scored each of the participants' drafts based on the same rubric for the three writing traits. It is important to note that I did not provide any of the participants with more feedback or direction in their writing than others. I only wrote a few notes to myself to justify scores so that I could ensure that each student received the same education regardless of whether he or she was a participant. I examined each participants' narrative drafts, examining precisely at how the word choice, sentence fluency, and conventions changed throughout the course of the study, and from each draft.

I also I compared the participants' final narrative draft to an informal piece of writing they composed on February 8 (second period) and February 9 (sixth period). The informal writing was submitted to determine if the students could transfer their writing skills beyond the formal submission of their narrative draft. It was also intended to make a more accurate assessment of the results because writers make different decisions knowing that a piece of writing is formal and polished as opposed to informal. This happened approximately two weeks after the study was completed. Having a chance to look at the free write after the instruction from the unit gave me a more comprehensive understanding of the students' ability to incorporate writing strategies in multiple situations.

Student reflections. A second data point I analyzed was a reflection from each of the 12 participants in the study (each student completed a reflection, but I only collected data on 12). I 
asked students to reflect on which aspects of learning with mentor texts were most conducive to their educational experience and writing development: (a) Explain how using picture books helped improve your word choice; (b) Explain how using picture books helped improve your sentence fluency (e.g., repetitious phrases and short, consecutive sentences); (c) Explain how using picture books helped improve your conventions (e.g., colons, semicolons, and commas); (d) Explain what writing trait explored through picture books was most helpful to your writing development; and (e) What additional activities with picture books do you think may have helped improve your writing?

In addition to these questions, I asked students to reflect on two of the following four questions: (a) Which of the following practices that you used might be of use to you in future reading and writing situations? (b) How will these writing characteristics help you be a better writer in the future, whether in other classes or in your own personal writing? (c) What practices of reading and writing did you do with this assignment that helped you in completing this assignment with more success? (Dean \& Grierson, 2005). And (d) Which writing characteristic (word choice, sentence fluency, and conventions) came the most naturally to you? Why? Which one was the most difficult? Why? While I reviewed all of the writing of my students, I paid special attention to the reflections of the 12 participants, scouring their reflections for themes and additional information.

Writing self-efficacy. A third data source was the Perceived Writing Self-Efficacy Beliefs Rate Scale (Honeck, 2013). All students completed the same writers' self-efficacy scale once before the study began, and once after the study concluded. This is a critical data point because it measured student beliefs of his or her writing level before the study began, and afforded an opportunity to measure his or her beliefs when the study ended. This is an important 
distinction because it reflects each student's beliefs and not my beliefs as his or her teacher. One of the more critical aspects of this data point is that it cannot be dismissed or undervalued as subjective due to the teacher: it allowed each student to indicate if he or she believed his or her writing improved during the course of the study.

Reflective journal. Each day with few exceptions I reflected in writing on the day's class. I documented what picture book we read, the writing trait emphasized, and any pertinent student observations shared with the class. I also documented student triumphs and student struggles concerning their writing as they tried to incorporate what was found in the picture books.

\section{Materials}

I read 12 picture books to my classes to demonstrate strong word choice, sentence fluency, and conventions. A complete listing of the picture books, authors, writing traits, emphasis, and dates taught can be found in Appendix B.

\section{Instructional Time}

Much of the class time consisted of whole class inquiry-based instruction. I define inquiry-based as "an educational approach that supports critical thinking, skill building, and problem solving, in addition to content learning" (as cited in Zeek, 2011, p. 76). There were also a few occasions where I arranged different stations for students to work in groups as they explored and reviewed separate writing traits found in the picture books we had previously discussed as a class. By doing this, I hoped that the chance to review the books independently allowed students to internalize the writing techniques found in the picture books. Ultimately, this was an invitation for them to read like writers (Smith, 1988). 
I revisited some picture books with my classes on days that we did not have sufficient time to write after inquiry-based instruction, or on days when I felt we needed to review a specific writing trait. I hoped to create a classroom dialogue to help students wrestle with the same decisions the published authors made in creating strong word choice, sentence fluency, or conventions. After the classroom dialogue concluded each day, I invited my students to revise their current draft to reflect the writing trait found in the picture book we had just examined. I also allowed my students a chance of exploratory instruction in groups or independently, as they reviewed picture books at their own pace.

I hoped to conference individually with all of my students, not only the participants, about their writing during this study. I felt this could have guided many of the writers to improvements not only in the three writing traits we studied, but also as a holistic enhancement of their narrative. However, I discovered early that my students were not mature enough to work independently without my presence, so, unfortunately, this learning opportunity was not realized.

\section{Procedures}

In this section I explain the specific procedures that I employed while using picture books to teach word choice, sentence fluency, and conventions. A complete list of picture books in Appendix B describes pertinent information about each book.

The first step for using picture books as mentor texts was to identify which traits to examine. I chose word choice, sentence fluency, and conventions because they are personal interests, and because I saw the need for this instruction reflected in student writing. The second step was to identify picture books that exemplified these writing traits. I hoped the books would extend student thinking, allowing them to think like writers. I needed help identifying most picture books because I do not have an extensive background in such literature. Members of my 
committee were integral in helping me decide which picture books and supplementary material. I also reached out via e-mail and Twitter to writing scholars, Ruth Culham and Carol Jago, who provided suggestions for picture books I could use in my study. I strategically selected the same specific picture books for each class, focusing on what I felt the students needed to improve their writing as a whole.

Next, I read each picture book aloud to my students and followed an inquiry-based style of learning. After reading the book aloud, I asked students to share what they observed about the book. Most days I read only one picture book aloud; however, there were a few days when I read two. With some pictures books, I positioned the class to focus on specific writing traits before I read it aloud. For example one day I invited the class to focus on engaging words, or to focus on the way the sentences interacted with each other. I allowed volunteers to comment about the book, and I occasionally added commentary on his or her idea. Sometimes few students chose to respond at the completion of the book, so I commented about what I felt was worth discussion.

After I read each picture book and we discussed the emphasized writing trait as a class, I invited my students to revise their narratives and apply the writing trait. During this time I afforded my students an opportunity to examine the picture book we recently finished either in small groups or alone if they desired. On a few occasions I modeled examples of my own writing in front of the class to demonstrate how I applied the writing trait. As students revised their writing, I walked around the classroom and helped those who required additional assistance. I also invited students to share with me what they revised. I rarely answered student questions during this time. Instead, I placed a picture book on the student's desk and asked how the picture book responds to each question. 
Students were required to submit three narrative drafts. Each time we read a picture book and I invited students to revise, they wrote directly on their most recent draft. We went to the writing lab four times so students could print clean copies of their writing with their revisions, although students only turned in three drafts.

\section{Data Analysis}

The data analysis was conducted in ways to ensure the findings of the study were trustworthy and appropriate. The data for the research question were collected over an 11-week period from November 3, 2015 to January 25, 2016. First, I describe the process of my reflective journal. Second, I highlight the participant drafts. Third, I illustrate the student reflection, the self-efficacy scale, and my reflective journal.

Student drafts. I analyzed the participants' drafts, paying particular attention to their word choice, sentence fluency, and conventions. I then scored the drafts according to the writing scale discussed previously. I paid close attention to these writing traits to determine what happened to students' use of them as they were exposed to picture books exemplifying the same traits. In addition to positive examples, I constantly looked for evidence to disprove my study. I will now consider first, second, and third drafts.

First draft. Writing is never finished in the purest sense of the word, so I had my students write three drafts to provide the highest chance of becoming authentic writers - to wrestle with the decisions that a writer makes and to go through the entire writing process. In the first draft I helped students develop a base of their writing, asking them to write a 300-word narrative. Using that initial narrative as a base, we focused on colons, while also briefly exploring sentence fluency and commas. I read closely through the first draft of the 12 participants and coded the 
data, indicating where strong word choice, sentence fluency, and conventions were used according to the writing scale.

Second draft. The requirements of a second draft are often new to my students as most are used to only a rough draft and a final draft. The second draft was submitted, and I closely read the 12 participants' writing, looking for more precision in word choice, sentence fluency, and conventions. The same coding used in the first draft was employed.

During this phase we focused on the conventions found within dialogue, strong sentence fluency, and conventions. Students had more than adequate time of class instruction with picture books to make changes to their original drafts during this phase. Revisions took place primarily in class after we discussed a writing trait that was demonstrated by a picture book. Students wrote and revised in class daily with few exceptions, and few students wrote at home.

Third draft. The starting date for the third draft was December 14/15, 2015 for my second and sixth-period classes, respectively. We focused on word choice and revisited sentence fluency primarily while also learning about semicolons. During this time we had a review day during which students could choose a station to attend to review a writing trait that they felt they needed extra practice. Before students submitted the third draft, they participated in a peer review. I also afforded my class a chance to go to the computer lab to draft a clean copy before we made the final changes. Typically I prefer to have two peer reviews before a third draft is submitted, but I doubted the value of the feedback since many needed to be reminded to stay on task.

Student reflections. At the conclusion of the study, I invited my students to complete a reflection on their journey of using picture books as mentor texts. This reflection was strategically designed to have each participant reflect on all three writing traits that we examined 
during this study. I required all of my students to reflect on the first five questions. Students could choose to respond to two of the four remaining questions. See Appendix D for the complete reflection.

I read each participant's reflection multiple times, and I coded each non-linearly. I discovered trends in their reflection, such as which of the optional questions were most frequently answered. I also noted pertinent information that I could share in various sections of this research thesis.

Self-efficacy scale. The Perceived Writing Self-Efficacy Beliefs Rate Scale (Honeck, 2013) was distributed prior to the study and students self-assessed their writing ability. The same self-efficacy scale was distributed to all students at the completion of this study when students, again, self-assessed their writing ability. I examined four questions closely that I felt most reflected the writing traits emphasized in this study: (a) I can write a fluent paragraph; (b) I can write a fluent essay; (c) I can correctly punctuate an essay; and (d) I can use a wide range of vocabulary in essays. I examined the initial scores of each participant before the study began, and I examined the final scores from each participant when the study concluded. A full version of the self-efficacy scale can be found in Appendix C.

Reflective journal. I recorded 29 entries in my reflective journal and coded them in a non-linear fashion, identifying the trends I observed as I read these notes. These trends are discussed in the fourth chapter of this thesis. I discovered multiple trends including students' recognition of picture books as mentor texts; the importance of teacher modeling; the organic observation and application of conventions and word choice; the challenging nature of sentence fluency; and an emerging trend of increased participation. These trends were coded by analyzing the field notes and they were supported through examples from student drafts. 


\section{Chapter 4}

\section{Findings}

The purpose of this study, conducted from November 3, 2015 to January 25, 2016, was to examine the use of picture books as mentor texts for struggling 10th-grade writers. Each day, with few exceptions, I focused on their use of word choice, sentence fluency, and conventions in three separate drafts of narrative writing for each of the 12 participants. I then scored the writing traits using a scale created by Vicki Spandel and adapted by Jim Burke (see Appendix A). This chapter will share the results of the 12 participants and their journey through narrative writing with picture books as mentor texts. First, I remind the reader of the data collection and treatment as well as the research question. Then I explain and highlight the findings for each of the writing traits analyzed in this study: word choice, sentence fluency, and conventions. Next I illustrate the trends. Afterwards I discuss the student reflection and post narrative writing. Following this, I review my growth as a teacher during this study. Finally, I present a summary of the findings.

\section{Description of Data Collection and Treatment}

I structured this unit to be inquiry-based. During the instructional time, I read a picture book to the class and asked students what they noticed about the book, allowing volunteers to comment. I hoped students would notice the salient writing trait or traits of a particular picture book, but allowed them to comment on anything they felt was important. At times when I perceived that students did not understand the trait being emphasized, I explained what I thought was represented well in the writing. On some occasions I hinted as to what students should look for before we read. For instance, some days I told the class to pay special attention to the word choice, or to pay special attention to the way the words interacted with each other or the way the words and phrases repeated within the books. 
I believe that writing is best taught in context (Weaver, 1996), so each time I taught with a picture book and we discussed it as a class, I invited my students to integrate the same writing trait or traits that we observed in their personal writing. I perceived that sometimes the students responded with enthusiasm, and at other times I perceived them to view this as "just another class assignment." However, one aspect of the unit is clear: the students' growth was evident as we progressed throughout the study because their writing constantly improved as they made revisions each day while adding, removing, or altering their prose. This suggested that the picture books influenced their writing positively.

One of the unforeseen challenges I encountered was the physical positioning of the students as I read each book, especially on days focusing on conventions as they needed to examine the text closely. I tried methods of repositioning the class, walking up and down each aisle, and even using the document camera, but a problem of access to the text arose in every situation. I ultimately decided to leave the students in their seats and walk through the aisles.

\section{Research Question}

The research question was as follows: How do picture books as mentor texts influence academically struggling $10^{\text {th }}$-grade students' word choice, sentence fluency, and conventions in their narrative writing? I will respond to my research question in this chapter.

The beginning of each trait examined in the study (word choice, sentence fluency, and conventions) will begin with a vignette. These vignettes represent, in general, the struggles or triumphs of each writing trait and how students responded to them throughout the study.

\section{Word Choice}

"Mr. Premont, you look gnarled today! I bet you were hobnobbing with Zombies last night," Stephen enthusiastically shouted. His words came out crisp, with an 
enthusiasm unlike any other I have observed when I explored word choice with my students. My students vigorously raised their hands to share the new words they learned as I read The Shoetree of Chagrin (Lewis, 2001) and even used these words orally. I was pleasantly surprised that this book resonated with my students so well. Never in my career had students been so apt to apply the words they recently encountered. The energy in the room was palpable, and the students stopped laboring and began working. This was the word choice instruction, and energy, that I sought while in my previous years. I constantly looked for ways to improve my instruction of word choice. I knew its potential, power, and place in the writing world, but I was not satisfied with the previous methods I employed to teach. $(12 / 16 / 15)$.

This vignette shows some of the enthusiasm exhibited on the first day I introduced a book with strong word choice in class. It also reflects my satisfaction with a new material to teach word instruction. Below, this point is further explicated through the use of writing scale data in Table 1 , and through the examples of the participants' writing.

Table 1 shows the participants' growth in word choice throughout the study. According to the 5-point writing scale adapted by Jim Burke (Spandel, 2001), less than $20 \%$ of the participants employed words that were "interesting, powerful, engaging" in their first drafts. This low percentage is not alarming because many of the participants lacked a strong foundation of effective words. As can be seen, when the study was completed $50 \%$ of the participants employed "interesting, powerful, engaging words" (Spandel, 2001) in their final drafts. It is worthwhile to note that the powerful words students employed by the final draft were a combination of specific words observed from picture books, the use of the thesaurus, or common 
words used in uncommon contexts. Words that are generally believed to be common added energy to the participants' writing when used in an uncommon context. Students added an extra flavor to the writing that had been absent prior to their effective use of the thesaurus. It is valuable to know that not every participant who incorporated strong words in his or her writing applied them correctly. Some participants used words out of context that distracted from the intended message. This problem was likely a cause of lack of focus and attention to detail from the participants, and a general misunderstanding of new words.

Table 1

Word Choice Scores Across All Students on 5-Point Scale

\begin{tabular}{lllll}
\hline \multicolumn{1}{c}{ Student } & Draft 1 & Draft 2 & Draft 3 & Percent Increase \\
& & & & \\
\hline Noelle & 3.0 & 2.0 & 3.0 & - \\
Courtney & 3.0 & 3.5 & 4.0 & $33 \%$ \\
Jill & 4.0 & 5.0 & 4.5 & $11 \%$ \\
Frank & 2.0 & 2.0 & 3.5 & $43 \%$ \\
Brooks & 3.0 & 3.5 & 4.0 & $33 \%$ \\
Jim & 2.0 & 3.0 & 4.0 & $66 \%$ \\
Cindy & 2.0 & 2.5 & 3.5 & $43 \%$ \\
Allison & 2.0 & 3.0 & 3.0 & $33 \%$ \\
Cal & 4.0 & 4.5 & 4.5 & $11 \%$ \\
Earl & 2.0 & N/A & 2.0 & - \\
Eddie & 1.0 & 2.0 & 2.0 & $50 \%$ \\
Susie & 3.0 & 3.0 & 4.0 & $33 \%$ \\
\hline
\end{tabular}

Of the three writing traits I examined, word choice generated the most enthusiasm. I observed the class holistically to gauge the interest of the students as a collective whole. Many students became enamored with the word selections that we examined in our picture books (Reflective Journal, 12/16/2015). My students replicated the excellent word choice found in picture books in both their verbal language and their prose during the day's class. For example, my second period class had limited time the first day we examined The Shoetree of Chagrin 
(Lewis, 2001), but when we revisited this picture book the following class, the same enthusiasm was present. Students showed interest in reviewing the book, they used a dictionary to define the words, and they asked good questions (Reflective Journal, 12/18/2015). Reading these books and discussing new, engaging words was helpful as most students did not include any interesting word selections in their first or second drafts. The first two drafts were completed before I explored a picture book illustrating strong vocabulary with the class. The final drafts exemplified a much stronger word choice than their previous drafts. Students included new and exciting language in their writing after we had reviewed picture books that included a plethora of appealing words, suggesting the power and influence of word choice found in picture books.

The following sections will highlight some of the writing of the participants as we progressed throughout this study. I also couple their prose with the remaining two data points: the Perceived Writing Self-Efficacy Beliefs Rate Scale in Appendix C (Honeck, 2013) and their reflections in Appendix D. First I present Susie's work; next I highlight Courtney's work; and lastly I explain Frank's work. I will then present a summary of the word choice findings.

Susie. Susie was selected as high-performing writer in this study. She integrated specific words we learned from the picture books while also employing a thesaurus, a strategy we learned while reading The Right Word: Roget and His Thesaurus (Bryant \& Sweet, 2014). One sentence that Susie wrote was, "To the chagrin of my mom, I had gotten a broken arm" (Final Draft, Susie, 1/22/16). While her second clause is problematic, the strength of her sentence is the use of the word chagrin. Susie's successful incorporation of this word came from reading The Shoetree of Chagrin (Lewis, 2001), and after I modeled the word chagrin I noticed many students struggled using it properly (Reflective Journal, 12/17/2015). Susie's correct application of the word chagrin enabled her to grow as a writer and fight "word poverty" (Gallagher, 2015). 
Another sentence Susie wrote that demonstrated her growth as a writer and exemplified her application of using picture books as mentor texts occurred when she used the thesaurus to incorporate the word agony. Susie replaced her original, insipid word pain in her first two drafts to a word that resonated deeper with her. She wrote: "When I did the front flip tears came out of my eyes from just remembering the difficulties and agony [emphasis added] of my broken arm" (Final Draft, Susie, 1/22/16). This was the first time I noticed her using a thesaurus this school year; in fact, most of the students in the class used a thesaurus that day (Reflective Journal, 1/14/2016). Her third draft demonstrated a stronger focus on her words, adding energy to her writing found in the thesaurus that she learned from the picture book The Right Word: Roget and His Thesaurus (Bryant, 2014). Susie even utilized words that we did not observe in a picture book, but rather words that she explored independently, or words that we discussed as a class with the help of a thesaurus such as gigantic, sobbing, and throb. Like Susie, multiple students employed this language tool to enhance their writing, suggesting that The Right Word: Roget and His Thesaurus had additional power beyond the specific words the author used.

Susie reflected on her use of word choice at the conclusion of the study: "Using picture books helped me improve my word choice by realizing that there's more than just simple words . . ." (Reflection, Susie, 1/26/16). Susie's reflection demonstrates the growth she experienced during this unit, and brought new vision to her writing. Like her reflection suggests, her first two drafts employed rather simple words. It was only after we examined picture books with powerful words that her word selection became stronger. Susie also indicated on a separate question during her reflection that word choice will be a focus in her future writing: "I think word choice and sentence fluency will help me in the future. Word choice is very important because I never knew that certain words could be switched to make my words and sentence 
fluency sound so smooth" (Reflection, Susie, 1/26/16). While Susie included sentence fluency in her statement, she also suggested the importance of employing strong word choice in her future writing, suggesting that the picture books will have a lasting effect.

This paradigm shift is also reflected in her Perceived Writing Self-Efficacy Beliefs Rate Scale (Honeck, 2013), the third data point. Before the unit began, Susie rated herself a 6 on the 10-point scale in her vocabulary usage. By the time the unit concluded, her assessment was 8 . This is reflective of the growth she achieved while writing; yet, she still left room for improvement, as her reflection suggests that word choice will be a powerful writing trait in future writing situations.

Courtney. Courtney, a participant selected as an average-performing writer, was another student who benefitted from exposure and focus on word choice. She wrote, “... the nurse was hobnobbing with me when she told me" (Final Draft, Courtney, 1/22/16). Courtney's use of the word hobnobbing adds a jovial, informal tone to the story. Whether or not the nurse in Courtney's story was meant to be portrayed in that light is inconclusive, but her use of a new and interesting word is clear.

A second sentence validated Courtney's understanding of engaging words: she wrote, "to my chagrin, I was dirty with mud, dirt and crap" (Final Draft, Courtney, 1/22/16). Courtney, like many in sixth period, incorporated the word chagrin in her writing as we discussed that word in class the day we read The Shoetree of Chagrin (Lewis, 2001). While most students did not include new and engaging words in their first or second drafts, Courtney's second draft did include the latter two sentences. The day we went to the writing lab to draft our second copy, Courtney was absent. Upon her return we examined a picture book with new and exciting words, which Courtney incorporated when she submitted her second draft. Like Susie, Courtney 
demonstrated an ability to incorporate words from the picture books we read as a class. These are specific words found in The Shoetree of Chagrin that I observed Courtney to employ in her personal writing. Thus, because of the exposure to Lewis' (2001) word selection, Courtney enhanced her word choice in her writing.

Courtney also incorporated strong words as a result of using the thesaurus. For example, she wrote, "That night my body was aching, throbbing, I was in a lot of pain, I was in agony" (Final Draft, Courtney, 1/22/16). There are a few grammatical errors in this sentence, but her word choice is deliberate and intentional, appearing in her final draft only. Similarly, Courtney employed the same technique in a different sentence, "Nothing worked, but I wasn't in a fret yet" (Final Draft, Courtney, 1/22/16). The importance of reading Bryant's The Right Word: Roget and His Thesaurus (2014) is twofold: it taught students new words and it taught them the value of synonyms found in the thesaurus. We see this exemplified in both Susie and Courtney's work. Courtney's use of the words fret, aching, throbbing, and agony do not appear in any of her previous drafts. Although these specific words do not appear in The Right Word: Roget and His Thesaurus we discovered new words from the thesaurus after discussing Bryant's picture book. Courtney, like Susie, successfully incorporated engaging words from the use of picture books and the thesaurus after our class discussion. As is suggested in her progression from each draft and her enhanced word choice, the book, The Right Word: Roget and His Thesaurus, afforded Courtney an opportunity to select the just right word (Spandel, 2009).

Courtney's reflection helped me understand her growth in word choice throughout this unit. She wrote, "They [picture books] had good sentences and some had big words in them and they were able to help me understand how to use them. They also taught me how to add detail with words" (Reflection, Courtney, 1/26/2016). Courtney's reflection demonstrated the value of 
picture books as mentor texts for improving word choice. Not only was she introduced to new words, but she also successfully incorporated them into her writing.

Finally, Courtney's self-assessment of her vocabulary usage also increased during this time. Before my study began, Courtney rated herself a 5 on the 10-point scale for the statement, "I can use a wide range of vocabulary in my essay." At the completion of the study, Courtney rated herself a 7 on the same scale. This self-assessment correlates to work she submitted as her word choice increased dramatically from her second draft to her third draft — the period of time when we emphasized the trait.

All three data points suggest that Courtney's usage of new and engaging words in her writing is improved. Her ability to construct sentences with exceptional words was influenced by the study of picture books as suggested in her reflection and her self-efficacy ratings. What's more, the application of those words is evident in her final draft, suggesting that she did in fact internalize the concept of using powerful words. These three data points when considered together suggest that The Shoetree of Chagrin (Lewis, 2001) and The Right Word: Roget and His Thesaurus (Bryant, 2014) influenced her word selection dramatically.

Frank. Frank struggled with his word selection; however, he still incorporated engaging words in his final draft that were not present in his first or second drafts. He made considerable progress from his first draft, despite being selected as a low-performing writer. I hoped Frank would have employed a much more appealing word selection than his final draft demonstrated because he specifically sought a picture book that emphasized strong words earlier in the unit (Reflective Journal, 1/8/2016). I was underwhelmed with his word selection in his final draft after a first reading of it, perhaps because of my expectations. Yet, a second analysis of his final draft allowed me to see some progress. "I [sic] rather be on the cold hard ground during the 
winter and the warm sometimes cracked [emphasis added] sidewalks in the summer" (Final Draft, Frank, 1/25/16). There are multiple words in this sentence that provide a strong image for the reader. His ability to capture these words suggests an influence from The Promise (Davies, 2014). Frank's first and second drafts did not employ these strong word selections.

A second sentence exemplifying Frank's focus on words demonstrated his ability to use the thesaurus. He wrote, “... you get older and you think, why was I horrified of the dark ..." (Final Draft, Frank, 1/25/16). In that same section of his second draft, Frank wrote, “. . you get older and you think why was I afraid of the dark ...” (Second Draft, Frank, 12/14/15). His ability to use stronger words (e.g., afraid became horrified) added to the quality of his writing. The Right Word: Roget and His Thesaurus (Bryant, 2014) seems to have enhanced his word selection just as it did with Susie and Courtney.

Frank's reflection provided a slight glimpse on how picture books influenced his word choice. He wrote, "It [word choice] helped by seeing what I could improve on what words to change" (Reflection, Frank, 1/25/16). His reflection suggests that word choice is recursive in nature and the ability to revise words enhances the writing. Frank also reflected on which writing trait he may use in the future: "Word choice because I kinda now [sic] how to choose my words rightly" (Reflection, Frank, 1/25/16). This speaks to Frank's disposition on the importance of word choice, and how it can enhance his writing.

Frank's word choice improved from his first draft to his final draft, and his selfassessment suggests an increase in his perceived writing ability in word choice. Frank's selfassessment before the study began was a 6/10. When the study concluded, Frank assessed himself as a 7/10. This suggests that Frank is a bit more confident in his ability to choose powerful words in his writing. These three data points when considered together suggest that 
The Promise (Davies, 2014) and The Right Word: Roget and His Thesaurus (Bryant, 2014) enhanced the word choice of these disadvantaged writers.

Word choice summary. A few observations and trends from the use of examining word choice arose organically. I never saw my students more excited about a specific writing trait, and ultimately, those who worked hard to improve their word choice found appropriate places to incorporate strong words in their own writing. The application and use of these words were much more concrete for the students than other writing traits examined in this study. Words have power, and the construction of the just right word (Spandel, 2009) provided energy and excitement that students had previously not experienced. Further, students' understanding of writing improved through their diction, and that was a chance to celebrate as was demonstrated by their excitement from their word choice. Overall, the use of picture books in class led to an improved word selection from students, suggesting that the picture books played an integral role in helping students become work to grow a robust vocabulary to enhance their writing.

\section{Sentence Fluency}

Silence. The absence of participation and student involvement created the deafening silence in the room. I felt the struggle with my students as I tried to elicit some response - any response - from them about the way the sentences moved and interacted with each other in the picture book. Instead I got more silence. This was not the first time I experienced the tension between sentence fluency and my students. But what could be done? Sentence fluency is such an abstract concept that I needed a novel way to approach it with my picture books. (Reflective Journal, 11/10/2015). 
This vignette highlights the struggle that students experienced when being exposed to I Wish You More (Rosenthal, 2015). Although this book presented unforeseen challenges, it showed a recognizable pattern of strong sentences that did not resonate with students. This topic is further explored using the data from the participant writing as displayed in Table 2 and through the participants' writing.

Table 2 provides writing scores for students across drafts for the participants' sentence fluency. As reported in this table, many of the participants' final drafts exhibit stronger sentence fluency than their initial drafts. However, these scores also seem to reflect the students' lack of understanding of strong sentence fluency from earlier instruction. Table 2 also has the lowest average score for the first draft of any of the writing traits examined. Clearly there was a need to teach sentence fluency with more urgency in young, developing writers. It is also important to note that students struggled mightily with simply recognizing strong sentence fluency in the early stages of instruction. Internalization of sentence fluency was more difficult than the other two writing traits. The abstract and difficult nature of sentence fluency necessitated more exposure to picture books emphasizing this trait. Thus, half of the picture books employed in this study had, at the least, a partial emphasis on strong sentence fluency.

Students were challenged by sentence fluency much more than they were with a similar approach to word choice and conventions. Initially, some students made nice revisions in their writing, but the majority of the student revisions attempting to demonstrate strong sentence fluency was underwhelming (Reflective Journal, 11/24/2015). This was a consistent pattern for most students during the first few picture books examined for sentence fluency. Yet much stronger sentence fluency emerged as we continued to examine it throughout the unit. 
Table 2

Sentence Fluency Scores Across All Students on 5-Point Scale

\begin{tabular}{lcccc}
\hline \multicolumn{1}{c}{ Student } & Draft 1 & Draft 2 & Draft 3 & Percent Increase \\
\hline Noelle & 2.0 & 3.0 & 5.0 & $60 \%$ \\
Courtney & 2.0 & 3.5 & 4.5 & $55 \%$ \\
Jill & 3.0 & 3.5 & 5.0 & $40 \%$ \\
Frank & 2.0 & 2.0 & 3.5 & $43 \%$ \\
Brooks & 3.0 & 3.5 & 3.5 & $14 \%$ \\
Jim & 2.0 & 4.0 & 4.5 & $55 \%$ \\
Cindy & 1.5 & 2.5 & 4.0 & $62 \%$ \\
Allison & 3.0 & 3.0 & 4.5 & $33 \%$ \\
Cal & 4.0 & 3.5 & 5.0 & $20 \%$ \\
Earl & 1.0 & N/A & 2.0 & $50 \%$ \\
Eddie & 2.0 & 2.5 & 2.5 & $20 \%$ \\
Susie & 3.0 & 3.5 & 4.5 & $33 \%$ \\
\hline
\end{tabular}

After the first picture book with strong sentence fluency, I knew I needed to combat the difficult nature of composing sentences with strong fluency strategically. Therefore, I provided students with a handout of all of the text found in Scarecrow (Rylant, 2001). Affording all the students access to the writing found in the picture book as I read to the class was helpful. Allison noticed that some words are repeated. A non-participant noticed the repetition in the sentences such as "His hat is borrowed, his suit is borrowed, his hands are borrowed, even his head is borrowed" (Rylant, 2001). Allowing students to have access to the text during and after the class reading of Rylant's (2001) picture book was more beneficial than our traditional class reading and subsequent conversation. In light of this discovery, I perceived that students were working and thinking more critically (Reflective Journal, 12/21/2015).

Allowing students to have access to the text was a turning point in understanding the abstract nature of strong sentence fluency. Some recognized the repetition of words and phrases, and in subsequent books they were able to recognize the same. Even though I still had to 
emphasize strong sentence fluency for the entirety of the study, the foundation was set by reading Scarecrow (Rylant, 2001).

Many students revised their work to show their understanding of sentence fluency, even though some student examples were stronger than others. Those who made an honest effort were rewarded for their hard work with their prose. The following paragraphs illustrate some examples of sentence fluency from Noelle, a high-performing writer; Cal, another highperforming writer; and Earl, a low-performing writer. This section will conclude with a summary of the findings from sentence fluency.

Noelle. Although Noelle's first draft did not contain examples of strong fluency, her second draft did exhibit slightly better fluency — but nothing eye-opening. Both drafts were coherent; there was simply nothing noteworthy about her sentence fluency. Real growth occurred in her third draft where she constructed more effective sentences. Noelle wrote: "Her funeral was a few days after in Brigham. The funeral was so beautiful. She was wearing her favorite dress and looked so peaceful" (Final Draft, Noelle, 1/22/16). This was an interesting sentence to examine because it contained an emphasis in sentence fluency from two separate picture books that we examined. Her repetition of the word funeral in two simple sentences is a strategy seen in Scarecrow (Rylant, 2001). Interestingly enough, Noelle also incorporated a skill seen in The Most Magnificent Thing (Spires, 2014) as she weaved another simple sentence into this portion of her writing. In The Most Magnificent Thing, we examined short sentences in succession, without repeating words, to establish a strong sentence fluency. Noelle's sentence demonstrates that aspects from both of these picture books seem to have influenced her sentence fluency positively. 
An item worthy of note is that the lesson on sentence fluency using The Most Magnificent Thing was delivered on November 24, 2015, with plenty of time remaining before the second draft was due. Why Noelle did not include a similar sentence with strong fluency replicating Spires' (2014) work in her second draft is unknown. It is likely, however, that she had not internalized the concepts of constructing strong sentence fluency at this point in the study, a pattern consistent with other participants at that moment. Nevertheless, Noelle synthesized the fluency of both Rylant (2001) and Spires' (2014) work in the construction of sentences in her final draft, suggesting that she internalized the information with time and exposure, and she was finally able to apply it into her own writing.

Noelle crafted a similar sentence as the one discussed previously when she wrote, "He doesn't care if you have been abrupt to someone, he doesn't care if you have done bad things in your life, and he will love you unconditionally even if you don't deserve it" (Final Draft, Noelle, 1/22/16). Noelle employed a similar pattern in this sentence, repeating the phrase "he doesn't care if you have" in the first two clauses, followed by a third, similarly constructed clause without the repetition. A variation of this sentence did not appear in either her first or second draft, and it is apparent that Allyssa's understanding of sentence fluency emerged in the stages after her second draft. Perhaps this suggests that students need additional time and exposure to mentor texts with strong fluency before they feel comfortable applying it in their own writing. Ultimately it appears that Scarecrow (Rylant, 2001) and The Most Magnificent Thing influenced Noelle's sentence fluency positively in her final draft.

Although each of Noelle's drafts suggests improvement, her reflection also discussed part of her experience with crafting strong sentence fluency. She wrote: "It [sentence fluency] helped because it showed me that you dont [sic] need to have long phrases or sentences" 
(Reflection, Noelle, 1/26/16). Noelle's prose demonstrated this ability. She also wrote: "I think the sentence fluency was the hardest for me. Trying to make a sentence sound right was very difficult. These books helped a lot" (Reflection, Noelle, 1/26/16). This statement suggests that Noelle wrestled with her decisions when constructing her sentences. It is clear from the absence of strong fluency in her first two drafts that growth occurred in her third and final draft. These two data sources suggest that Noelle experienced growth through the use of picture books as mentor texts. They also suggested the picture books helped reify an otherwise abstract concept.

Noelle's third data point, the self-efficacy scale does not, however, suggest a perceived improvement in her sentence fluency. Before the study commenced, Noelle rated herself 7/10 for the statement "I can write a fluent essay." The final assessment concluded with the exact same rating. Similarly, Noelle initially rated herself an 8 on the question: "I can write a fluent paragraph." Her final rating for that same question was a 7 . Both of these scores are surprising given the growth I observed in her writing.

Cal. Cal exemplified the strongest examples of sentence fluency of all of the participants. Selected as a high-performing writer, Cal worked hard during his time in class and composed a strong narrative. He built numerous effective sentences, allowing the words to interact with each other in various ways. The sentence he constructed with what I perceived to have the strongest fluency is one that appeared in his first draft, and was refined in each subsequent draft. He turned an average sentence into a beautiful sentence. The strength of Cal's sentence was his ability to use single word repetition effectively, a skill we learned after a class reading and discussion of the picture book, The Promise (Davies, 2014). Cal wrote, "I leaned over my bed to look underneath: desperately, nothing ... nothing ... nothing" (Final Draft, Cal, 1/25/16). This deliberate repetition added value and style to enhance his writing. Additionally, 
he employed ellipses as a tool to add intrigue and suspense, a writing tool that we did not discuss in class - a writing tool that enhanced the repetition and the value of the word nothing. Cal's successful incorporation of effective repetition and use of ellipses suggests that The Promise had a profound influence on his writing, and that he understood the concept of sentence fluency well enough to take risks in his writing.

Cal's second draft contained a similar sentence, but the repetition of the word nothing is absent. He wrote, "I leaned over my bed to look underneath: desperately, nothing" (Second Draft, Cal, 12/14/15). Certainly the grammar is correct in this sentence, but the flow of the writing is not present the same way it is in his final draft. His first draft contains a similar idea, although less developed than both the second and third draft. In his first draft Cal wrote, "I began to lean over to look under thinking it was one of my family members, I looked and nothing, nothing was there" (First Draft, Cal, 11/17/15). In this sentence Cal used the repetition of the word nothing, albeit much less effectively. He also had a comma splice in his writing as he separated two independent clauses with a comma.

Cal's final draft exemplified the highest standard of sentence fluency when compared to the other participants. His strategic repetition of the word nothing with the ellipses suggests that he understands how to manipulate his prose to add meaning in his writing "beyond correctness" (Gallagher, 2015, p. 33). Table 3 shows the growth in sentence fluency for Cal across drafts. Table 3

Samples of Cal's Growth in Sentence Fluency Over Time

First Draft $\quad$ Second Draft $\quad$ Third Draft

\begin{tabular}{lll}
\hline "I began to lean over to look under & "I leaned over my bed to & "I leaned over my bed to look \\
thinking it was one of my family & look underneath: & underneath: desperately, \\
members, I looked and nothing, & desperately, nothing." & $\begin{array}{l}\text { nothing ... nothing ... } \\
\text { nothing." }\end{array}$ \\
\hline
\end{tabular}


Another exemplary sentence that Cal constructed was, “All of a sudden I violently awoke Mind [sic] awake, eyes closed falling deeper so disoriented the clock on the wall seemed scrawled, or blurry" (Final Draft, Cal, 1/25/16). This sentence is problematic for a few reasons; however, because he used a capital $M$ when writing the word Mind, it made me wonder if he meant to put a period after the independent clause preceding that word. If that is the case then his sentence would read, "Mind awake, eyes closed falling deeper so disoriented the clock on the wall seemed scrawled or blurred." He would only need to place a comma in a few places to make the sentence grammatically correct, and a sentence demonstrating excellent fluency. This sentence followed a similar pattern of construction as the previous example. In his previous draft, Cal wrote, "All of a sudden I violently awoke so disoriented the clock on the wall seemed scrawled, or blurry" (Second Draft, Cal, 12/14/15). In this example Cal omitted a few nominal phrases that he ultimately included in his final draft.

Interestingly enough, in his first draft, Cal opened his narrative with "Mind awake, eyes closed falling Deeper and Deeper [sic] into slumber" (First Draft, Cal, 11/17/15). This sentence could be altered slightly to enhance it, but the foundation of this sentence is strong. Again, Cal used nominal phrases in his first draft. His ability to revise his writing suggests that he believed writing to be recursive in nature, a paradigm that will always benefit him. This particular sentence did not follow a distinct pattern from any of the picture books we read, but his growth is evident nonetheless. Although Cal's sentence fluency is stronger than the other participants, even in his first draft, I am still impressed with his growth throughout the study.

Cal seems to have noticed his own progress. Prior to this study, Cal rated himself a 2/10 on the statement, "I can write a fluent essay." His final assessment for that question was a 7.5. Similarly, he initially rated himself a 5 on the question, "I can write a fluent paragraph." His 
final assessment was 8. Clearly his confidence increased during this unit: it is evident from draft to draft and it is grounded in his beliefs.

Cal's reflection is another piece that adds clarity to his growth. He wrote: "It [sentence fluency] showed me many different situations on how to use them correctly. Like I use [sic] to just place them wherever, but now I now [sic] how to use them" (Reflection, Cal, 2/1/16). Cal's reflection, his three drafts, and his writing self-efficacy scale when considered together suggest that picture books as mentor texts afforded him opportunities to improve this writing trait.

Earl. There were few aspects of the final draft that Earl did correctly. Selected as a lowperforming writer, he struggled throughout this unit with focus and motivation. In fact, Earl did not submit a second draft because of his inability to use class time effectively. His final draft did not portray strong sentence fluency, but he did at least make an attempt. In one instance, Earl wrote, “... 'will that turn into a small space and will I get one of those moments that I hate so so so much"' (Final Draft, Earl, 1/22/16). This followed a similar pattern of repetition found in The Promise (Davies, 2014) as Davies repeated the word planted in her picture book to emphasize the amount of time spent planting seeds. Even though Earl's choice of sentence fluency was weak, I understood what he tried to accomplish with the repetition of the word so, a similar pattern that Cal used effectively by emphasizing the word nothing. At the very least, this sentence demonstrated an awareness of the need for strong fluency that was absent in his first draft. Earl's effort at this was less effective, but did suggest that The Promise influenced the sentence fluency of even a low level writer who exhibited a lack of self-discipline.

In a similar example, Earl replicated this same pattern when he wrote, "I really hate, hate, and hate this fear" (Final Draft, Earl, 1/22/16). This sentence is almost identical in structure to the previous one. His repetition of this style of sentence is a bit contrived, yet, also intriguing. 
The fact that he used this pattern twice suggests that he did not merely "jump through a hoop" for a better grade, but that perhaps he valued this pattern and believed that it improved the quality of the writing. This understanding suggests the influence of picture books on his writing, and the power of The Promise (Davies, 2014) on even the most novice writers.

Earl's reflection and self-assessment are not consistent with the drafts he submitted. In his reflection, Earl wrote: "They [sentence fluency] showed me different ways to write storysbetter" [sic] (Reflection, Earl, 1/26/16). Even though the sentence fluency in Earl' drafts is not strong, it did improve from his first draft, suggesting some validity to his statement. He also wrote: "Sentence fluency came more naturally because, I understood it better and It [sic] was easier to use and do" (Reflection, Earl, 1/26/16). These two data sources, his narrative and reflection, when considered together suggest that growth did occur in Earl's sentence fluency from each draft, however minute it may be.

Earl thought highly of his ability to craft strong sentences on his self-efficacy scale. He gave himself an 8/10 on the statement, "I can write a fluent paragraph." He also rated himself an 8 on the statement, "I can write a fluent essay." However, the quality of Earl's work did not merit such a high rating on this scale, suggesting he misunderstood the statement or purposefully inflated his scores. Earl missed the week of school when I administered the same scale before the study began, so he did not assess himself prior to the study.

Sentence fluency summary. As a whole, many students struggled with crafting effective sentences in their writing initially. However, I was impressed with the final drafts and the examples of strong sentence fluency. It appears time and exposure were important for many students. Sentence fluency was the only writing trait that I presented at least one new picture book while constructing all three drafts. What I learned is that sentence fluency is more abstract 
in nature and requires more critical thought. Thus, I believe that it should be introduced early and taught often with numerous examples and opportunities for practice. As a result, the students' understanding and ability to incorporate strong sentence fluency improved slowly, but it was valuable.

\section{Conventions}

I tried not to cringe as the student closest to the whiteboard struggled to correctly represent the colon. He initially used the symbol for a semicolon, and then after being quickly reprimanded by the class for his inaccuracy, he erroneously used ellipses. Not wanting to embarrass him, I quietly walked to the whiteboard and taught the class that the colon is symbolized by two vertical dots, modeling it correctly. This was eye-opening for me as a writing instructor to realize how unaware some high schoolers are of the language that surrounds them every day. It was also a good indication of how much help some of my students needed to become effective writers. Even though this student struggled mightily, I did not feel overwhelmed. I trusted the process of using picture books as mentor texts and believed its ability to help my students become writers. After all, these struggling students are the very ones I prepared to help. (Reflective Journal, 11/11/15).

This vignette explores the struggle that one student experienced when initially discussing conventions. While his experience is not entirely representative of the class, other students struggled with conventions in different ways. There were many students who understood and applied effective examples of semicolons and colons in their writing after examining the picture books. This concept is explicated below in Table 4 and through the writing of the participants. 
Table 4 shows the participants growth in conventions throughout the study. As a whole, conventions were the most tangible writing trait for my students to grasp. Few students included strong forms of conventions (e.g., semicolon and colon) in their first draft, but as they were exposed to picture books with strong conventions more students applied them accurately and effectively in their subsequent drafts. As can be seen, every student increased his or her effectiveness in conventions from the first draft to the final draft. This high percentage seems to reflect the hard work of the participants. It is worthwhile to note that as the study progressed students required less direct instruction from me to accurately and effectively include strong forms of conventions in their writing. This included students who neglected to employ strong forms of conventions until just two weeks before final drafts were due. (Reflective Journal, 1/8/16). Students ranked as high-performing, average-performing, and low-performing all demonstrated their growth with conventions.

Table 4

Convention Scores Across All Students on 5-Point Scale

\begin{tabular}{lcccc}
\hline \multicolumn{1}{c}{ Student } & Draft 1 & Draft 2 & Draft 3 & Percent Increase \\
& & & & \\
\hline Noelle & 3.0 & 4.0 & 4.5 & $33 \%$ \\
Courtney & 2.0 & 4.0 & 4.0 & $50 \%$ \\
Jill & 4.0 & 4.5 & 4.5 & $11 \%$ \\
Frank & 1.0 & 2.0 & 2.5 & $60 \%$ \\
Brooks & 2.0 & 3.5 & 3.5 & $43 \%$ \\
Jim & 2.0 & 4.0 & 4.5 & $55 \%$ \\
Cindy & 2.5 & 2.0 & 3.0 & $17 \%$ \\
Allison & 3.0 & 2.5 & 3.5 & $14 \%$ \\
Cal & 3.0 & 3.5 & 4.5 & $33 \%$ \\
Earl & 1.0 & $\mathrm{~N} / \mathrm{A}$ & 2.0 & $50 \%$ \\
Eddie & 2.0 & 3.5 & 3.0 & $33 \%$ \\
Susie & 3.0 & 4.0 & 4.5 & $33 \%$ \\
\hline
\end{tabular}


Incorporating the conventions throughout the unit had two phases: (a) the isolated understanding of each concept, and (b) the application and transfer from what was observed in the picture books into the student writing. To my surprise, students struggled much more than I expected with the proper punctuation of dialogue. Even after we examined picture books as a class and discussed it, many students did not punctuate dialogue properly in their personal writing. Some students even did not incorporate the proper use of punctuation within dialogue in their final drafts. The following paragraphs will discuss dialogue, which include the work of multiple students. Then, I will focus on the conventions of Jill, Eddie, and Jim. I will conclude with a summary of the findings of the conventions.

Dialogue. Many students could not determine the rules of punctuation simply by observation on the day I introduced dialogue. When no one could verbalize the rule, I split them into groups with picture books containing dialogue for closer examination (Reflective Journal, 12/2/2015). There was much more participation on the second day we discussed dialogue, and we established a number of rules: (a) quotes are used only to show speaking; (b) some [quotes] end in commas within dialogue; (c) periods end sentence in and out of dialogue; (d) capitals to start every sentence; (e) we can add "she said" to complete a sentence; (f) When dialogue ends an independent clause we use a period; and (g) all grammar goes before punctuation (Reflective Journal, 12/4/2015). Even after establishing these rules, many students struggled to apply those same concepts in their own writing. However, some of the participants improved their work when they received additional, individual instruction from me, or consulted a picture book.

Courtney's second draft best exemplified the class' struggle as a whole. For example, one sentence in her writing reads thus: “. . . he said 'sure I'll be there in about 20 minutes' my uncle Clay, said to him 'okay call us when you get here'” (Second Draft, Courtney, 12/15/15). 
She omitted a comma before the dialogue began, and she did not begin a new paragraph with the introduction of a new speaker. Courtney's struggle with dialogue is reminiscent of the majority of the class (Reflective Journal, 12/11/15). These two errors were pervasive with many students and I discussed this concern with some individually, and with the aid of a picture book.

Courtney was not in class the day we went to the computer lab to finish draft two. This was a day I spent a considerable amount of time helping students clean up their dialogue by making the punctuation correct - an opportunity that Courtney missed. A similar sentence with the same errors appeared in Courtney's final draft (1/22/16).

Courtney made similar mistakes at a later portion in her second draft. She wrote, "My other uncle, Justin called he said 'I'm here come meet me by the old tractor. The one that is by the green gate in the front.' Clay repled [sic] saying 'okay we will be there"' (Second Draft, Courtney, 12/15/15). Again, Courtney omitted a comma prior to the dialogue, and she did not start a new paragraph when a new speaker emerged. This same sentence appeared in Courtney's final draft without any revisions.

Cindy struggled similarly with dialogue, and I helped her considerably in the computer lab the day students typed their second drafts. She struggled with the proper punctuation and paragraphing. The difference with Cindy's experience with dialogue is that she received help from me and examined the dialogue found within picture books to construct a more accurate understanding. After reviewing the punctuation found in the picture book Slightly Invisible (Child, 2011), and discussing it with me, Cindy corrected her own errors (Reflective Journal, 12/10/2015). Her second draft read as follows: The lady told me, "get on it's your turn." / "Ok," I said. (Second Draft, Cindy, 12/14/15). With the exception of excluding a capital letter at the 
onset of her dialogue, Cindy correctly punctuated it. This showed considerable progress from when she started that day.

Cindy's third draft built on her understanding of proper conventions within dialogue. In her second draft, Cindy continued the previous dialogue by adding one more line to the employee. Cindy wrote: "The lady says 'have fun and enjoy the ride" (Final Draft, Cindy, 1/25/16). Cindy was successful at starting a new paragraph when the speaker changed, but she committed errors that were common for my students. She omitted a comma to start the dialogue and committed a less-common mistake by not finishing her sentence with a period.

Further, Cindy added one more instance of dialogue with similar success and errors. She wrote: "My cousin told me 'how was it? " [sic] / I said 'It was pretty fun actually." (Final Draft, Cindy, 1/25/16). Cindy was successful at starting a new paragraph when the speakers changed, and this time she included the proper punctuation at the end of both lines of dialogue. However, she still omitted the comma prior to the speaker beginning the dialogue. It is important to consider that I did not specifically help Cindy with her dialogue after our miniconference on December 10, 2015. Cindy, identified as an average-performing writer, either recalled her understanding of dialogue for her final draft, or was able to reference the picture books to construct her understanding of dialogue.

There were multiple times when I sat down with students individually to discuss the proper conventions of dialogue with the help of a picture book after it had been taught (Reflective Journal, 12/7/2015; 12/10/2015; 1/8/2016). Every student I helped under those circumstances left the instruction having improved the conventions associated with dialogue, much as Cindy did. 
Using forms of advanced conventions (e.g., colons and semicolons) was not as challenging for most students. Although few students, if any, used an advanced form of punctuation in the first draft, most students grasped the concepts and applied them to their own writing in subsequent drafts. As we examined the picture books, most students followed a similar pattern: recognizing the salient characteristics of colons and semicolons, asking pertinent questions, and carrying that understanding into their writing. Students felt comfortable asking questions about the proper use of conventions, and most of the time these questions demonstrated their understanding of the concept. For example, on a day when we discussed semicolons while reading When I Heard the Learn'd Astronomer (Whitman \& Long, 2004), a non-participant asked if it were acceptable to move the semicolon in one clause (Reflective Journal, 12/14/2015) and another student, a non-participant, asked on a separate day how a writer knows when to use a colon (Reflective Journal, 11/18/2015) as we read The Dinosaurs of Waterhouse Hawkins (Kerley, 2001). These questions suggest that students were engaged in the concept being taught, and understood it enough to ask pertinent and valuable questions so that they could wrestle with the same decisions that writers do. As I observed student work, I saw the proper application of the conventions in their writing (Reflective Journal, 12/14/2015; $12 / 15 / 2015 ; 1 / 8 / 2015)$.

The following paragraphs illustrate the work of a few participants after they were instructed on conventions with picture books. First I present Jill's work, a high-performing writer; second, I describe Eddie's work, an average-performing writer; and finally, I highlight Jim's work, a low-performing writer.

Jill. Jill's final narrative draft demonstrated many of the conventions we had been working on in class, including her use of advanced conventions. She demonstrated an 
understanding of colons that introduce when she wrote, "We all separate into three groups: younger kids, teenagers, and parents" (Final Draft, Jill, 1/25/16). In this sentence she correctly applies a colon after an independent clause, introducing the three groups. Her correct use of this convention suggests that examining the conventions found in picture books influenced her writing positively.

Similarly, she demonstrated her understanding of colons when she wrote, “. . I was trapped, being forced to go on the ride I had feared as long as I could remember: the White Rollercoaster" (Final Draft, Jill, 1/25/16). This sentence is of particular interest because Jill employed the colon as a means to emphasize the ride she most feared while simultaneously introducing it. Her correct understanding and application of this convention a second time suggests that she was deliberate and intentional when making her decisions. This is an indication of her learning and application of what she observed from the picture books we examined.

A similar sentence appeared in Jill's second draft, with only slight modifications to the flow, ". . . I was being forced to go on the ride I had feared all my life: the White Rollercoaster" (Second Draft, Jill, 12/14/15). Although there is only a slight change in her sentence, there is considerable growth from where this same sentence began in her first draft.

In her first draft Jill did not use a colon at all. Instead, she wrote, "I was forced to ride the White Rollercoaster, the ride I had feared all of my life, along with most of the other rides at Lagoon" (First Draft, Jill, 11/17/15). Jill's use of an appositive phrase is grammatically correct, but the effect the colon has in her final draft adds suspense and a brief pause before naming her most feared ride. As the progression of this sentence suggests, her conventions were edited "... to bring about additional meaning to the piece ... for reasons beyond correctness" (Gallagher, 2015 , p. 33). This is an indication that she wrestled with the same decisions as the writers of the 
picture books we examined in class. Not only did Jill recognize the power that conventions have generally in writing, but she also demonstrated a sound understanding of the proper use and effect of colons specifically. Table 5 shows Jill's growth in conventions throughout the study.

Jill's reflection, the second data point, shed light on her growth using conventions with picture books as her guide. Jill responded to the question about which writing trait examined came most naturally to her: "Conventions came most naturally because I already knew how to use them, but now I know even better" (Reflection, Jill, 1/27/16). It is clear from the three drafts of her sentence that growth occurred. Yet, her reflection suggests that she already had a great deal of confidence as a writer prior to this study. These two data sources when considered together suggest that using picture books as mentor texts allowed her to strengthen an already strong area in her writing.

Table 5

Sample of Jill's Growth in Conventions Over Time

\begin{tabular}{ccc}
\hline First Draft & Second Draft & Third Draft \\
\hline $\begin{array}{c}\text { "I was forced to ride the White } \\
\text { Rollercoaster, the ride I had }\end{array}$ & $\begin{array}{c}\text { go o I was being forced to } \\
\text { all my life: the White } \\
\text { feared all of my life, along with } \\
\text { most of the other rides at } \\
\text { Lagoon." }\end{array}$ & $\begin{array}{c}\text { Rollercoaster." } \\
\text { to go on the ride I had feared as } \\
\text { long as could remember: the } \\
\text { White Rollercoaster." }\end{array}$ \\
\hline
\end{tabular}

Jill's perceived writing self-efficacy confirmed her perceived ability before the unit began. She rated herself $9 / 10$ in her ability to punctuate. After we completed the unit, she again rated herself a 9/10. Although this number remained the same before and after the unit, it is clear she improved her use of conventions per other data.

Along with a clear understanding of colons, Jill also exemplified an excellent understanding of semicolons, varying her sentence structure throughout. One example showed 
her understanding of semicolons linking two independent clauses of similar ideas: "I've never liked the feeling I get when the rollercoaster goes up, down or if it flings me left and right; I've never felt safe when I get in a rollercoaster" (Final Draft, Jill, 1/25/16). Jill's final draft showed excellence in all areas of the study, and her use of a semicolon linking two independent clauses is demonstrated here, suggesting influence from the picture books we observed in class.

One aspect of teaching that I find challenging is affording all students an opportunity for growth in a unit. Jill's reflection suggests that even students who consider themselves advanced writers can benefit from the use of picture books as mentor texts in their writing. I believe it was evident that most of the low-performing writers experienced growth during this unit. Even so, using picture books allowed Jill, a high-performing writer, to grow in her writing development as suggested in her reflection. Thus, this methodology of using picture books as mentor texts in the high school classroom suggests a way to afford all students an opportunity for writing growth, a benefit that even the most talented writing instructors seek.

A final, more interesting example of Jill's understanding of advanced conventions is shown through her use of two semicolons in the same sentence.

As the ride came to a slow, shrieking stop, I was desperate to get out; I didn't enjoy the ride like everyone else and it gave me a pounding headache, but as I walked away from the White Rollercoaster and started to cool down in the light breeze; I realized with shocking amazement that I wasn’t afraid anymore. (Final Draft, Jill, 1/25/16) Jill's correct application of this complex sentence is only opposed by the subordinate word as in the fourth clause. If she eliminated that word, then this would be a grammatically correct sentence, more than halfway to a labyrinthine sentence. Jill's attempt to use two semicolons in the same sentence shows her critical thought during the day we discussed the 
picture book, When I Heard the Learn'd Astronomer (Whitman \& Long, 2004). Whitman and Long's book is written entirely in one sentence, employing many semicolons throughout. Therefore, I taught that a sentence can have multiple semicolons (Reflective Journal, 12/14/2016). This concept resonated enough with Jill for her to experiment in her writing, suggesting that When I Heard the Learn'd Astronomer incited enough curiosity for her to experiment in her personal writing.

Jill's understanding of semicolons is still developing, but is advanced from the average struggling writer. This is evident, again, of her reflection when she indicated an already strong ability to use conventions properly and that growth occurred (Reflection, Jill, 1/27/16).

Eddie. Eddie was an average performing student who is capable of better work than what his final submission suggests. I feel this way because I perceived that if he would have exhibited more effort his writing would be stronger. However, he still showed an understanding of a colon and semicolon in his writing. Eddie used four colons in his writing: three are properly placed, and one is incorrect. In the first sentence Eddie used a colon is to introduce dialogue. He wrote, "I start watching scary movies when I was about 10 to 12 years old: 'we mostly watched ..."' (Final Draft, Eddie, 1/25/16). In this case the colon is used correctly to introduce dialogue in his writing. I find this interesting because most of the picture books that we used that incorporated dialogue did not use a colon to introduce a quote. Instead, on the day we discussed colons I taught that part of the function of the colon is to introduce (Reflective Journal, 11/12/2015). It is unclear if Eddie found a section of a picture book that introduced dialogue with a colon, or if he applied his knowledge of colons to introduce the dialogue in his writing. Regardless of where and how Eddie learned to use the colon to introduce dialogue, it is done accurately. This same sentence appeared in his second draft, but not his first draft, 
suggesting his progression came from the use of picture books in class with an understanding of dialogue.

Although Eddie correctly incorporated a colon in the above example, and two additional places in his writing, he did use a colon incorrectly: "When I watch scary movies: It takes me . . ." (Final Draft, Eddie, 1/25/16). As I evaluated this sentence, I think that Eddie is unfamiliar that the subordinate conjunction when demands that a comma be inserted instead of colon. If we remove the word when from his sentence, then his colon would be grammatically correct. One can argue whether or not a colon is the most appropriate form of punctuation in that instance, but it would not be wrong. Interestingly enough, this sentence has one colon and one semicolon, similar to a sentence that Jill used in her writing, employing multiple advanced forms of punctuation. Eddie's complete sentence reads thus: "When I watch scary movies: it takes me about 30 to $40 \mathrm{~min}$. to finally fall asleep when I'm set to bed; To [sic] me it's worth it to be scared after I watch a scary movie" (Final Draft, Eddie, 1/25/16). This sentence needs to be revised, but in spite of these issues I see that Eddie is, like Jill, taking risks in his writing.

In his second draft, that same section said, "When I watch scary movies: It takes me about 30 to $40 \mathrm{~min}$. to finally fall asleep when I'm set to bed; To [sic] me it's worth it to be scared after I watch a scary movie" (Second Draft, Eddie, 12/15/15). This draft was printed close to the day I taught When I Heard The Learn'd Astronomer (Whitman \& Long, 2004), suggesting that Eddie noticed multiple forms of advanced punctuation in the same sentence, and incorporated that concept in his own writing. In both instances the writing was grammatically incorrect. With the proper help and minor adjustments, these sentences could be revised to add meaning and clarity. In light of these unexpected findings from both Eddie and Jill, experiences 
with When I Heard the Learn'd Astronomer as a mentor text may have afforded these students increased confidence and space to take risks in the writing.

Eddie's reflection is not at the level of detail I hoped, but it did provide a little help. He reflected on how picture books influenced his use of conventions: "It make [sic] it easer [sic] for me to now [sic] when I need to use conventions" (Reflection, Eddie, 1/26/16). Although this does not clarify which picture books he found especially useful, it does help me understand that he perceived the picture books to be helpful in his development of conventions.

Even though Eddie's conventions dropped one-half point from his second draft to his third draft, his final draft still shows progress from his first draft. This is reflected in his perceived self-efficacy as he initially self-assessed himself to be a 4/10. When the study concluded, Eddie assessed himself to be a 6 on that same scale. This growth is reflected in his writing from his first draft to his last draft as well. A close examination of When I Heard the Learn'd Astronomer (Whitman \& Long, 2004) and other picture books as mentor texts improved Eddie's conventions during this study.

Jim. Although Jim was selected as a low-performing participant, his hard work and exceptional attitude allowed him develop into a stronger writer. I was impressed with his work as he wasted no time applying his newfound knowledge of conventions, crafting multiple sentences with colons that added emphasis. One of Jim's nine sentences using a colon reads thus: "I close my eyes and by the time I open them the ride is stopped: it's over" (Final Draft, Jim, 1/25/16). The emphasis on the clause it's over added an extra "punch" to the sentence. This suggests that Jim's experience with the picture books influenced him to become a more strategic writer. Additionally, Jim wrote, "I had watched movies and TV shows were [sic] roller coaster [sic] had fallen or they stop and the people riding are stuck: I do not want that to happen 
to me" (Final Draft, Jim, 1/25/16). This example suggests that he understood the application of using the colon to introduce an idea. I was impressed with his writing for many reasons, but considering that he was selected as low-performing writer suggests the power that picture books as mentor texts can have for those who work hard.

Jim employed nine colons in his second draft and 10 colons in his final draft. He carried every sentence with a colon from his second draft into his final draft, some with minor revisions, and added an additional sentence with a colon for his final draft. His new sentence with a colon in his final draft does not appear in his previous drafts. He wrote; "The flashing lights and buzzing sound form the games: the cling sound the old metal milk bottles made as rings hit the sides" (Final Draft, Jim, 1/25/16). This new sentence not only contained excellent sentence fluency and imagery, but he also incorporated a colon correctly. Jim's new sentence in his final draft suggests that he is beginning to perceive conventions in writing as a recursive process. Nine of the 10 sentences Jim used with a colon are grammatically correct, suggesting that his experience with picture books as mentor texts was a boon to his writing as he successfully incorporated numerous colons with different purposes.

Jim reflected on his journey: "The [picture] books showed me how to use semicolons and also just normal colons. I learned what they mean and also how to use them in my writing" (Reflection, Jim, 1/25/16). Jim certainly demonstrated his new found prowess with using colons. In fact, his quantity of colons in his writing surpassed all other students' in both of my classes. It is not so much the quantity that was impressive, but the quality that demonstrated a solidified understanding. These two data points when considered together suggest that picture books as mentor texts enacted growth in Jim's writing. 
Jim's perceived self-efficacy suggests that he already had confidence in his ability to use conventions. He self-assessed himself an 8 on the 10-point scale before the study began; yet, when it ended, his self-assessment remained the same. This rating spurred my curiosity because it is clear that growth occurred from draft to draft.

Conventions summary. Although most students did understand the concepts of colons and semicolons, some students in my sixth period class lacked the drive to understand (Reflective Journal, 11/12/2015). However, we did establish that colons introduce and generally separate two independent clauses. I believe that most students grasped the concepts of conventions because there are rules that must be followed initially. However, with more practice and more understanding, I believe that many students could do as Jill did and add additional meaning to her writing beyond correctness (Gallagher, 2015) with strategic use of conventions. Students wrote fine narratives that employed the strategies present in the picture books.

\section{Trends}

Multiple trends emerged during the data analysis process. The first trend I discuss is the students' recognition of picture books as mentor texts. Second, I describe students' recognition of picture books as coaches in the classroom. Third, I highlight the importance of teacher modeling.

Picture books as mentor texts and coaches. There are multiple examples of students recognizing the power of picture books as coaches in the classroom (Culham, 2014). In many instances, students willingly asked to look through picture books to improve their writing, or were able to improve their writing when I placed a picture book on their desk. Initially, most of the students' recognition of picture books as coaches occurred when I noticed that they struggled with a particular writing trait. This pattern resulted in me providing a picture 
book that emphasized the very trait that they struggled with. However, as the study progressed, more students asked to see picture books as I continually emphasized that students could look through the books as they wrote.

Recognizing mentor texts as coaches in student reflections. Cindy struggled with dialogue as she incorporated very little of it on her own. I showed her the picture book Slightly Invisible (Child, 2011) to indicate that dialogue is characterized by multiple people speaking. I let her work, but she only added one additional speaker, included on the same line as the previous speaker. Additionally, the punctuation was incorrect. After guidance from me and examples from the picture book, she discovered that a new paragraph emerged when the speakers change. My next step with Cindy was to properly punctuate the dialogue by following a similar pattern of affording her an opportunity to look at the picture book, looking specifically for punctuation within dialogue. After looking through the picture book, she was able to punctuate the dialogue correctly. To cement her new discoveries, I asked her to write one more line of dialogue. This sentence was constructed correctly with just one minor error (Reflective Journal, 12/10/2015).

When the study was completed, Cindy reflected on the most challenging aspect: "The one I think that was more difficult was dialoge [sic] but then I look for examples in books and got it right away" (Reflection, Cindy, 1/27/16). Cindy's reflection suggests that she regarded picture books as coaches in the classroom, and a valuable learning tool.

Courtney had a similar experience. She wrote: "I like how we were able to refere [sic] back to the books" (Reflection, Courtney, 1/26/16). Courtney's reflection suggests that her exposure to picture books was aided by the opportunity to refer back to them whenever she 
needed. This finding suggests the power of picture books, and their ability to act as coaches in the classroom.

Cal's reflection was similar. He wrote: "by Doing [sic] this I can help put things that I see in books and implenent [sic] them into my writing" (Reflection, Cal, 2/1/16). Like the previous two participants, Cal's reflection suggests that he considered picture books to be powerful coaches in the classroom.

On a day when Frank tried to incorporate strong words in his writing, he willingly raised his hand and asked me for a picture book that exemplified strong word choice (Reflective Journal, 1/8/2016). This was Frank's first experience volunteering for anything this entire school year. The fact that Frank asked for a picture book modeling strong words indicated his changing disposition. He made excellent strides in his word choice throughout this study.

A similar exercise in word choice occurred after we read The Right Word: Roget and His Thesaurus (Bryant, 2014) as a class. This picture book focused on using the just right word for the precise situation. This challenged students to find the perfect words for their situations. For example, I noticed that Susie replaced the word hurt with ache as she revised her second draft (Reflective Journal, 1/14/16). As the class continued, we examined insipid words in our writing and looked for ways to use powerful words in their place. While this picture book did not necessarily produce specific words that we incorporated, it afforded students a chance to think critically.

On one of the final days of the study we read the picture book The Promise (Davis, 2014) with eyes toward examining word choice. There were two passages in this picture book that used the same word three times for emphasis. For example, one portion of Davis' work read, "I pushed aside the mean and hard and ugly, and I planted, planted, planted" (2014). With 
this sentence as a coach, Cal revised one of his sentences to write, "I leaned over my bed to look underneath: desperately, nothing . . nothing . . nothing” (Reflective Journal, 1/21/2016) as mentioned earlier in this chapter. I find this interesting because Cal added to the structure of the sentence found in the picture book, by using ellipses. I suggested ellipses for his sentence when he showed me, but only after his last word. He came up with the ellipses in between the words nothing. As is suggested by his repetition of the word nothing, Cal recognized The Promise (Davies, 2014) as a coach in the classroom.

There is another passage in The Promise that the word blessed is used in an unconventional manner: "Its streets were as dry as dust, cracked by heat and cold, and never blessed with rain" (Davis, 2014). This led to a class conversation about how a word becomes more engaging when it is used in an unconventional manner. A non-participant used Davis' (2014) picture book to craft a unique sentence. She wrote, "I just stopped, paused and took a deep breath [sic] the biggest one I took for a while [I never felt so blessed with the light I saw]" (Reflective Journal, 1/21/2016, brackets in original). This was a unique sentence, and one that was clearly influenced by the reading of The Promise. The art of using the word blessed in an unconventional manner suggested that this student saw picture books as coaches in the classroom.

Many students struggled with the use of dialogue. For example, Earl struggled with dialogue, constructing very little of his own halfway through the study. I provided him with a picture book to peruse in hopes that he would incorporate dialogue. With the picture book as his guide, he began writing similarly (Reflective Journal, 12/9/2015). Earl improved his dialogue within his writing, but he did not begin a new paragraph when a new speaker emerged. I returned the picture book to him and this time asked him to examine the structure of the writing 
found in the picture book. He needed guidance from me, but he was ultimately able to discover that a new paragraph begins with the onset of a new speaker (Reflective Journal, 12/9/2015).

On one of the days I allowed time for students to work in class, I continued my pattern of observing students' work and discussing their writing with them as I walked around the room. I approached Frank and he showed me the dialogue in his narrative. When we discussed some of his incorrect punctuation, I provided him with a picture book to look through. He immediately fixed his error. A similar experience with consulting a picture book to correct an error occurred that same day with a non-participant (Reflective Journal, 12/7/2015). Susie also needed help with punctuating her dialogue; however, her writing was further along and, because of her tendency to focus and work hard, she needed only minor revisions. I gave her a picture book that exemplified correct punctuation and I began helping other students. When I returned, Susie made the necessary revisions in her writing and indicated she did so because of what she observed in the picture book (Reflective Journal, 1/8/2016). Both of these examples with Frank and Susie demonstrate the power that picture books have as coaches in the classroom. Both participants examined the picture books I strategically gave them, and they were able to selfcorrect and enhance their writing.

Another example of recognizing picture books as coaches for conventions occurred when we read When I Heard the Learn'd Astronomer (Whitman \& Long, 2004). This picture book is written in one sentence, separating the independent clauses with multiple semicolons. As part of the class discussion, the question we tried to answer was whether or not we can end a sentence with a semicolon. I suggested that we consult the picture book to see how it is done. After noticing numerous semicolons, we reached the last page of the book. I asked the class what piece of punctuation it ended with, and the students noticed the period. This led me to explain 
that a sentence cannot end with a semicolon (Reflective Journal, 12/14/15). As indicated earlier, this picture book had an impact on two participants' writing in particular.

The importance of teacher modeling. As the unit progressed, I noticed that modeling a writing trait was valuable to student growth. Reflecting on its importance, I realize now that I should have done more modeling with my students to help them grasp the writing traits more effectively. The first moment I recognized its importance occurred on a day when we discussed sentence fluency. Noting the abstract nature and challenge that sentence fluency posed for the students, I wrote in my reflective journal that "I may have to model my own sentences in front of them" (Reflective Journal, 11/24/2015). While this thought occurred when we discussed sentence fluency, the practice of teacher modeling was beneficial in all aspects of this study because "students also benefit greatly from studying models produced from the best writer in the classroom — the teacher" (Gallagher, 2015, p. 132).

The first time I documented in detail myself modeling a sentence occurred when I demonstrated how to properly use the word chagrin within a sentence. I noticed that most students struggled with using this word correctly. This was a word that students in both second and sixth period struggled with. For example, one student, a non-participant, wrote something to the effect of "I was feeling chagrin." I modeled multiple sentences with the word chagrin for sixth period. For example, I wrote, "To my chagrin, I had homework last night" in order to provide context of the word. Afterwards, most students understood how to use the word properly (Reflective Journal, 12/17/15).

The following day in my second period class, I wrote the sentence, "To my chagrin, I left my cell phone at my house" to demonstrate the word's proper use and context. I modeled the start of another sentence with this word by writing, "Much to the chagrin of adults" and then 
asked a non-participant to finish the sentence. She completed the sentence correctly for the full version to read, "Much to the chagrin of adults, some kids don't obey" (Reflective Journal, $12 / 18 / 15)$

On that same day, Cindy still had trouble properly using the word chagrin in her writing. Even after I modeled the few sentences, her writing began with "I was chagrin ..." (Reflective Journal, 12/18/15). I explained to her that this word could not be used in that context, but that we could revise it so that it would work. I suggested she start her sentence with the phrase, "To my chagrin ..." and asked how she could finish. Cindy struggled finishing the sentence until I referred her to the sentence that I modeled for the class, reading it aloud to her. Upon hearing it again, she immediately understood how to fix her sentence and wrote, "To my chagrin I was scared about not have [sic] ridden the roller coaster yet" (Reflective Journal, 12/18/2015). This sentence still needs revision, but her introductory clause with the word chagrin is correct. By modeling various sentences in front of the class, students were given yet another example to learn from, this time seeing the way I constructed correct sentences. Modeling my writing in front of the students influenced their writing positively. From this experience, I learned that when students can see examples from a book and from a teacher they can have additional writing success.

The last day of the study I reviewed a few passages from The Composition (Skarmeta, 2003) with the class to emphasize exceptional word choice and strong sentence fluency. I examined the sentences, "Pedro felt as though he were in a stadium with murmuring leaves," and, "His father looked at Pedro's mother as though the answer to the question might be written in her eyes" (Skarmeta, 2003). I came up with a few examples as I created my own sentences modeled after the ones found in The Composition: "I felt as though the aisles were urging me 
not to steal," and, "The cashier looked at me as if the answer to the question was scribbled across my face" (Reflective Journal, 1/25/2016). I then allowed time for students to write.

Cindy wrote, "The second time I went. It was like the rollercoaster was urging me to go.” Jim wrote, "The sound [smell] of cotton candy calling me over." A non-participant wrote, "The first time I attempted to jump off the slide because it felt like the slide was calling to me." Another non-participant wrote, "Every time I ask myself why I went door-bell ditching and think about it people can notice that [I'm regretting it] as if it's scribbled across my face" (Reflective Journal, 1/25/2016). As is suggested by the student examples, teacher modeling in conjunction with the prose found in The Composition (Skarmeta, 2003) were powerful tools to enhance student writing.

The first time I modeled as a strategic approach to enhance student writing happened on a day when we discussed the use of colons while reading The Dinosaurs of Waterhouse Hawkins (Kerley, 2001). We established that colons introduce, and that they generally separate two independent clauses. I noted that this lesson needed more scaffolding than I anticipated, so instead of having students add colons in their writing, I modeled sentences with their help (Reflective Journal, 11/12/2015). I did not include in my journal whether or not students found this helpful, but future modeling practices in this study suggested its importance and value.

Toward the end of the unit I had students work on various aspects of narrative writing, including the conventions we discussed much earlier in the study. I projected a picture from the movie High School Musical (High School Musical, 2006) and modeled a sentence using a semicolon. I wrote something similar to, "High School Musical used to be popular; we all had bad taste 7 years ago." I asked Earl if he would write his sentence using a semicolon on the board for the class to see. Before he agreed, he asked if he could revise his sentence, presumably 
after seeing the example I provided. He wrote his sentence on the whiteboard in front of the class: "They're jumping in the air; they're saying we don't care." The structure and pattern he used in his sentence reflected the structure and pattern of the sentence I modeled, suggesting his understanding occurred after he saw me provide an example (Reflective Journal, 1/12/2016). The evidence from these data suggest that teachers play a pivotal role along with picture books in guiding students in their writing.

One of the emerging trends in this study was the increased participation by my students. I use the term "emerging" because there is not enough data to make a conclusive statement. There were, however, moments during this study when students participated much more willingly than they had in the lessons given prior to the commencement of this study. In fact, before this study I perceived my students to be academically sluggish and lethargic for the first few months of school. However, when we started the unit I saw characteristics of this study bring out the best in them. Others benefited from the increased participation, too. Noelle wrote: "It help [sic] when we talked as a class. As other people talked it gave me there [sic] perspective" (Reflection, Noelle, 1/26/16).

Although every day was not filled with willing student participation, I generally saw much more energy from my students and a readiness to share their thoughts during the unit. I initially noticed this during the first picture book we explored as a class (Reflective Journal, 11/4/15). This moment occurred in my sixth period class, and was impressive because these students did not show enthusiasm for writing previously. Observing them make comments willingly was inspiring.

I noticed a similar experience as we discussed the use of colons found in The Dinosaurs of Waterhouse Hawkins (Kerley, 2001). As we read this picture book, Cal voluntarily shared his 
thoughts with the class on potential locations to insert a colon. A few moments later, a nonparticipant indicated that the colon added importance to the word (Reflective Journal, 11/11/15). This is not to say that a unit with picture books invited every student to participate. When we read I Wish You More (Rosenthall, 2015), students were lethargic as we discussed the writing traits found therein (Reflective Journal, 11/10/15). Interestingly enough, that same day as I read The Most Magnificent Thing with my students, their participation was much better than just moments before (Reflective Journal, 11/24/15). The data suggest that this unit, structured as an inquiry-based unit with materials uncommonly used in the high school classroom, was conducive to increased participation (Reflective Journal, 11/4/15; 12/14/15;12/16/15; 12/18/15).

\section{Student Reflections}

After the study was completed I invited my students to reflect on the unit and respond to a total of seven questions pertaining to their experience with the study. I assigned everyone to respond to the first five questions, and students had a choice of responding to two of remaining four questions (see Appendix D). Seven participants chose to respond to question six; five participants chose to respond to question seven; one participant chose to respond to question eight; and 11 participants chose to respond to question nine.

In this section, I will first highlight the quality of student reflections. This will include the stronger and weaker reflections from my students, and what I gleaned. Next, I will illustrate the trends I saw in the participants' responses. Following, I address the students' future writing as were composed in their reflections. Finally, I describe what traits were easiest and most difficult for the participants.

Quality of reflection. As a whole, participants provided surface level reflections in response to most of the questions. However, I noticed the participants who were identified as 
high-performing writers when the unit began provided much more detailed responses, the type of reflection I hoped for. For example, Susie, a high-performing writer, wrote, "Using picture books to improve my sentence fluency based on how often you use alliterations and using repetition is key to successful writing. And how smooth my writing became" (Reflection, Susie, 1/27/16). Susie's response afforded me an opportunity to make a judgment on what she valued in regards to sentence fluency. Susie emphasized the importance of alliteration and repetition in her writing, and used both alliteration and repetition in her final draft. For example, she wrote, "When I had my cast it was an experience, excellent, and exhausting" (Final Draft, Susie, 1/22/16). Additionally, her omission of short, consecutive sentences also gives me an understanding that she did not value that aspect of sentence fluency that we learned while learning with picture books.

Susie's example was detailed and thoughtful, but the same cannot be said for other participants in the study. For example, when Allison responded to the statement, "Explain how using picture books as mentor texts improved your use of conventions" she wrote, "it made alot [sic] more sense after reading over them" (Reflection, Allison, 1/25/16). There is not much information can be gleaned from that statement. Additionally, when reflecting on the question, "How will these writing characteristics help you be a better writer in the future, whether in other classes or in your own personal writing?" Allison responded with, "My writing will be more entertaining with the stuff ive [sic] learned with the picture books" (Reflection, Allison, 1/25/16). I understand that she perceived the unit to be helpful, but I do not understand how her writing will be more entertaining in the future. Unfortunately, both of the previous responses were submitted after I asked Allison to provide more information in her reflection. There were other 
aspects of her reflection that allowed me to understand that she enjoyed the unit and felt she grew as a writer, but the requisite detail needed to understand why was not present.

There are multiple trends that I noticed after analyzing student reflections. First, I describe the general trends. Next, I illuminate student responses for future writing situations. Finally, I highlight the writing traits that came most naturally and the most difficult for the participants.

Reflection trends. I gleaned pertinent information reading through the reflections, and I noticed trends between the participants' responses. Because not every student reflected well on each question, many students viewed question six and seven interchangeably. That is, six of the 12 participants ultimately explained what writing trait they felt they could use in future writing situations (although Eddie did reflect on this question, his response was invalid). Table 6 shows what students believed would be most beneficial to them in future writing situations. It is worthwhile to note that only Susie believed sentence fluency would be beneficial in the future. This may be because I pushed her to improve her fluency more than other participants. Table 6

Students' Selection of Traits Expected to be Beneficial for Future Writing

\begin{tabular}{lcc}
\hline Word Choice & Sentence Fluency & Conventions \\
\hline Jill & Susie & Jill \\
Jim & & Jim \\
Noelle & \\
Earl & \\
Susie & \\
Frank & \\
\hline
\end{tabular}

Note. Jill $=$ high-performing write; Jim $=$ low-performing writer; Noelle $=$ high-performing writer; Earl = lowperforming writer; Susie $=$ high-performing writer; Frank = low-performing writer.

Future writing situations. Noelle's response was unique because she did not necessarily comment on word choice in the sense that new words enhance the writing, but rather 
words used in uncommon contexts make the writing interesting, such as those found in The Promise (Davies, 2014) and The Composition (Skarmeta, 2003). Noelle wrote, "These characteristics will better my writing in the future. I will know that you can use different words for something that means nothing like the word (Never blessed with rain)" (Reflection, Noelle, 1/26/16). Davies (2014) and Skarmeta's (2003) work resonated with Noelle because of the abundance of common words used in uncommon contexts. Although the concept of transferring word choice was common among the participants who reflected on this question, Noelle's unique approach to word choice is separate from the rest. This approach is evident in her final draft, too. For example, Noelle wrote, "After that the room cracked by smiles and tears" (Final Draft, Noelle, 1/22/16). Noelle used the word cracked in an uncommon context, closely modeling the text found in the picture books we studied, and suggesting Noelle's correct application of picture books observed. As explained in Noelle's reflection and grounded in her final draft, the word choice found in picture books influenced her decisions as a writer.

Like Noelle, Jim's reflection documented the importance of word choice in future writing situations. He wrote, "I think it's fun to use different words and I liked it" (Reflection, Jim, $1 / 25 / 16)$. Jim's reflection is grounded in the writing he developed throughout this unit. For instance, Jim employed words that were present in the picture books, and words that he most likely drew from a thesaurus to enhance for his final draft. He wrote, "We see the gnarled wood" (Final Draft, Jim, 1/25/16). His use of the word gnarled was influenced by The Shoetree of Chagrin (Lewis, 2001). Jim also employed other words in his final draft that we saw in the same book including hobnobbing, chagrin, and ramble. Jim's reflection on the potential of word choice in future writing situations is also emphasized in his final draft as he scored a 4 on the 5point scale. 
In a similar pattern, Susie and Jill, highlighted the importance of word choice in future writing. Both scored 4 on the 5-point scale on word choice in their final drafts. Even Frank, a low-performing writer demonstrated a similar disposition to choose words carefully in the future. He scored a 3.5 on the 5-point scale in his final draft, making wonderful strides from his first draft. All of these students emphasized word choice in their reflections and their final drafts. Their reflections suggest that they will continue learning and incorporating new and exciting words in future writing situations.

I found Earl' reflection surprising because his final draft illustrated few exceptional words, even though he indicated that he will use this trait in future writing situations. One of Earl' two exceptional words was chagrin, influenced by The Shoetree of Chagrin (Lewis, 2001). He also attempted to use the word murmur, but he misspelled it writing mummer. It was also used in the wrong tense (Final Draft, Earl, 1/22/2016). The majority of his narrative was riddled with insipid, bland words. He even used the colloquial cuz. Although Earl did not employ a particular sense of urgency with his word choice in his narrative drafts, his reflection suggests that he perceived the value of it in the future. Earl lacked the necessary focus and revision skills, but to his credit, he did try to incorporate this writing trait in his final draft.

Although the students' trend of identifying the importance of word choice in future writing situations is fascinating, I think the absence of sentence fluency speaks volumes of its abstract nature in this same question. Only one of the participants who reflected on the question regarding what writing trait he or she could use in the future responded with sentence fluency. Most of those students who chose not to respond with sentence fluency scored high on their final drafts in the sentence fluency category. Noelle 5 on the 5 -point scale; Jill scored 5 on the 5-point scale; Susie scored 4.5 on the 5-point scale; Frank 3.5 on the 5-point scale; and Earl scored 2 on 
the 5-point scale. Reflecting on my study and trying to make sense of their responses, I realized that I challenged Susie the most with her sentence fluency during this study, albeit unintentionally pushing her in this writing trait more than others.

Susie worked efficiently in class, and as a result I challenged her to improve her sentence fluency as it was not a focus in the early stages of her writing. Perhaps working individually with her on that writing trait gave her an extra sense of ownership. Regardless of the reason, Susie perceived the value of sentence fluency; this was a more challenging and a much more nebulous writing trait for all the students to grasp.

Jim made it known that sentence fluency was the most challenging writing trait we explored, per the final question of his reflection. He wrote, "Sentence fluency, that was hard to me just cause [sic] I could not think of any good repetitions, or consecutive sentences" (Reflection, Jim, 1/25/16). Here Jim undervalued his prowess because he did not think he used repetition or short, consecutive sentences well. However, what Jim may not understand is that there is more to sentence fluency than those two aspects, and his sentences, phrases, and words interacted well in his final draft. Ultimately, he did score well on sentence fluency (4.5). Yet, there may be more behind students' limited perception of sentence fluency than its abstract nature. I perceived that students were not taught sufficiently in their previous classes about how to incorporate proper sentence fluency for effect or for flow. Perhaps its lack of exposure also hinders student application.

Easy and difficult writing traits. As indicated at the onset of this section, 11 of the 12 participants chose to reflect on the last question of the reflection prompt. Although Cindy reflected on this question, she did not respond to the writing trait that came most naturally to her, nor did she select a writing trait that was the most difficult. Courtney also did not specify which 
writing came most naturally or was most difficult to her. Instead she used the vague pronoun some; and Cal did not specify a writing trait that was the most difficult.

I found this trend of reflecting on this question intriguing because this was not a compulsory reflection question; rather, in this section, they needed to respond to only two of the four questions. The responses represented all three writing traits that we examined. Tables 7 and 8 show which writing trait came most naturally and most difficult respectively. As can be seen by both tables, sentence fluency was especially challenging for most students. This trend will likely continue if sentence fluency is poorly instructed or not instructed in earlier years of writing instruction. The difficulty of word choice and conventions varied from participant to participant. Table 7

Students' Selection of Most Natural Writing Trait

\begin{tabular}{ccc}
\hline Word Choice & Sentence Fluency & Conventions \\
\hline Jim & Earl & Cal \\
Brooks & & Jill \\
Frank & & Susie \\
Noelle & & Eddie \\
\hline
\end{tabular}

Note. Jim = low-performing writer; Brooks = low-performing writer; Frank= low-performing writer; Noelle=high-performing writer; Earl $=$ low-performing writer; $\mathrm{Cal}=$ high-performing writer;

Jill $=$ high-performing writer; Susie $=$ high-performing writer; Eddie $=$ average-performing writer.

Table 8

Students' Selection of Most Difficult Writing Trait

Word Choice Sentence Fluency Conventions

\begin{tabular}{lll}
\hline Jill & Jim & Brooks \\
Earl & Frank & Cindy \\
Eddie & Susie & \\
& Noelle & \\
\hline
\end{tabular}

Note. Jill = high-performing writer; Earl = low-performing writer; Eddie = average-performing writer; $\mathrm{Jim}=$ low-performing writer; Frank $=$ low-performing writer; Susie $=$ high $=$ high-performing writer; Noelle $=$ high-performing writer; Brook $=$ low-performing writer; Cindy $=$ low-performing writer. 
One response worth noting in this section is the number of participants who suggested that sentence fluency was the most challenging writing trait. This does not come as a surprise. Susie explained that her sentences “didn't have the right flow and I tried to change them but they always turned out worse than before" (Reflection, Susie, 1/26/16). Other comments on this topic did not have as many details and were not as eloquently stated as Susie's, but they addressed similar concerns and lack of understanding. Students struggled with sentence fluency throughout the study, but their understanding came together toward the end. They were probably unable to recognize their growth throughout the process.

Although most suggested sentence fluency was the most challenging, Jill, Eddie, and Earl explained that word choice was the most challenging, but for different reasons. Jill exemplified her critical thinking when she stated, "Word choice was hardest because there are so many words to use to make a writing sound better. It's hard to choose" (Reflection, Jill, 1/27/16). This comment suggests that Jill's understanding of word possibilities expanded during this study to the point that she made deliberate choices in her word selection. The picture books seem to have taught her to wrestle with the same decisions that writers wrestle with as they select their words.

Eddie's selection of word choice was similar to Jill's, but for a different reason. He selected word choice as the most challenging writing trait because he indicated that it is hard to “think of other good words to make my writing more powerful” (Reflection, Eddie, 1/26/16). Eddie's highest score for word choice came on his final draft at 2.5. His problem was not one of critical thought and making deliberate choices, like Jill. I perceived that that he could have used more powerful words in the proper contexts had he employed the words and strategies we discussed in class. 
Earl's reason was unique and contradictory. Earl did not see the importance of including powerful words in his writing per this reflection question. He cited his lack of understanding of many words. His writing is unclear, but it seems that his lack of understanding basic words made it more challenging to understand the more advanced words we learned in this study (Reflection, Earl, 1/26/16). It appears that this unit was unable to convince him of the power of words. He was inconsistent with his reflections because he indicated that it is his word choice that will help him be a better writer in the future, an idea I elaborated on previously.

\section{Post Narrative Writing}

As part of the study, I wanted to see if students could transfer their skills to an informal, one-draft narrative shortly after the completion of the study. Two weeks after the conclusion of the study I asked students to examine a moment in their life that they would never forget. I examined the same writing traits for the participants in this one-draft copy narrative as I had in their previous writing. Before the students wrote their informal narrative, we talked briefly about the writing traits we examined with the picture books, and I encouraged them to apply those same traits. It is also important to note that I did not intervene with any of the students as they wrote this day. Some of the writing traits we examined were well represented in the post narrative while others were not. First I illustrate the word choice; next I present sentence fluency; and finally I highlight the conventions. A post narrative writing summary will also be included.

Word choice. Word choice was not well represented in the post narrative. This was surprising considering the engaging words that students learned and discussed during the study. The highest score for word choice was Susie who scored a 3 on the 5-point scale. Even though she had the highest score, there was not anything especially worthwhile about her word choice. 
This may demonstrate that word choice is a more precise writing trait that develops with multiple drafts.

Sentence fluency. One of the items that particularly stood out was the use of effective repetition. For example, Courtney employed similar components of effective sentence fluency: "She ran from her room she ran down the hall she ran over to me ..." (Post Narrative, Courtney, 2/9/16). Although Courtney needs help editing, it is clear that she emphasized a repetitious pattern that we learned while reading Scarecrow (Rylant, 2001). Similarly, Cindy employed a technique learned from the same picture book: "Never again shall I forget... The [sic] day I felt pretty Never again shall I forget the day I wore makeup for the time in my life. Never again shall I forget the day I wore a big puffy dress" (Post Narrative, Cindy, 2/8/16). Cindy's effective repetition of Never again shall I forget was an imitation of a powerful sentence from Night (Wiesel, 1958). However, it is worthwhile to note that the book did not repeat the phrase. Instead, this was something Cindy applied after a unit in which we examined picture books as mentor texts. Although she imitated a mentor text, it was not a picture book nor did we discuss this strategy. Her ability to transfer this skill into a new context is a good indication of the skill transfer in her writing, an ability that will improve her writing in future situations. These two examples when considered together and two weeks after the narrative unit concluded suggest that effective patterns of strong sentence fluency can have lasting power.

Conventions. Conventions was another writing trait that students applied well in the post narrative. Jim continued to show his prowess as he employed these conventions. For example, he incorporated a semicolon: "I had just turned 15 and got my learners permit after three attempts; that was one of the hardest tests I have ever taken" (Post Narrative, Jim, 2/8/16). This is interesting that he chose to use a semicolon here because his final narrative draft was 
riddled with colons, and only one semicolon. This suggests that Jim did understand how to properly apply semicolons in his writing, and that he retained this information. Further, this is especially interesting because, Jim, identified as a low-performing writer, correctly applied advanced conventions two weeks later. This suggests the power of picture books as mentor texts in helping him internalize writing conventions.

Cal, a high-performing writer, performed exceptionally well in his post narrative applying strong conventions. For example, he wrote: "When you first see your opponent, you have to put yourself in his shoes: how he trained, how hard he worked to get there with you on the opposite corner of the ring ..." (Post Narrative, Cal, 2/8/16). Cal's effective use of a colon to introduce his opponent adds clarity and meaning to his writing. Cal's effective use of a colon when considered with Jim's effective use of a semicolon suggests that picture books helped both low-performing writers retain their learning over time.

Post narrative writing summary. Although it is interesting that word choice was not evident in the post narrative, strong sentence fluency was employed by various participants. This was a writing trait with which many students struggled for most of the study. I found it encouraging that students used effective patterns of repetition to enhance the flow of their writing, and to add stronger meaning to their sentences. Even though the repetitious patterns are only a fraction of the possibilities students could have used while composing strong sentences, this simple pattern was not present in their early writings, and enhanced the overall prose. Perhaps this could be a springboard for greater fluency in future writing instruction. The effective conventions applied were not surprising. I perceived improved conventions to come most naturally to most students. 
The following section will address the second research question. First, I explain how I determined my growth as a teacher by reviewing the reflective log used previously. Second, I highlight the growth of students' word choice, sentence fluency, and conventions from draft to draft. Lastly, I compare four previous students' use of word choice, sentence fluency, and conventions from the 2013-2014 school year from a similar narrative.

\section{My Growth as a Teacher}

I grew as a writing instructor as a result of this study. Although I used picture books in my curriculum prior to this school year, I used them sparingly and did not use them as mentor texts. Based on the results of my students' writing, there were clear instances in which picture books as mentor texts enhanced the writing of the participants. I document how I used the reflective journal. I examine student growth and comparison with previous students.

Reflective journal. There were various moments in my study when I saw my growth as a teacher. For instance, I found new and engaging ways to incorporate picture books into my curriculum to help my students become writers. In the past I had used picture books only one or two days in the school year, and with different purposes. This study afforded me an opportunity to expand my repertoire of resources and include picture books as the integral component of student learning for narrative writing. Further, because this study was inquiry-based, I was able to explore the inquiries of my students' thinking (e. g. Reflective Journal, 11/24/15), and afford them a chance to create their understanding before I commented (Gallagher, 2015). This style of learning happened on nearly a daily basis throughout the study with few exceptions (e. g. Reflective Journal, 11/10/15;11/11/15;12/2/15; 12/14/15). This gave the students an opportunity to wrestle with the material at hand and to construct meaning before I shared my 
insights, potentially altering their understanding. This is important to their growth as they learn to become independent thinkers and to mine as a teacher.

I taught distinct mini-lessons with my students in the past about the use of conventions, but I rarely spent time discussing strong sentence fluency or strong word choice in context. This time I identified different sections of strong sentences, variation of sentences throughout the mentor text, and the locations of those sentences for students to emulate. Previously I rarely planned a mini-lesson with the purpose of examining strong sentence fluency. Similarly, I did not plan mini-lessons with the sole purpose of identifying strong words in context. I identified unique words that appeared in a text; I employed designated vocabulary words during units; and I even played with a word of the day for close to one semester. However, these methods lacked the same influence that this study afforded the students. My curriculum in past years was not harmful, but an opportunity for growth was lost. By including picture books as part of my curriculum, I gained a new, engaging way to teach specific lessons on effective sentence fluency and word choice (Reflective Journal 12/18/15; 11/24/15; 12/16/15). I also discovered an engaging and effective teaching tool by using inquiry.

A last item worth noting in my development is reflected through the growth of all of the participants, from the high-performing writers to the low-performing students. I observed more overall growth in the various writing stages of my students from the start of the study to the conclusion of it than I can recall from previous experiences. I think there are a few reasons for this: (a) I provided my students with more class time devoted to writing each day; (b) I emphasized the recursive nature of writing each day through revision; and (c) I employed picture books that resonated with them. For instance, on the first day I taught about the use of colons, I observed both Jill, a high-performing writer, and Jim, a low-performing writer, examine their 
writing and correctly identity places to incorporate colons. In this instance, Jill rearranged her sentence and omitted words to accurately use a colon. Jim examined two independent clauses that he previously separated by a period, and instead used a colon (Reflective Journal, 11/11/15). It is clear that Jill's writing development was farther along than Jim's, so she was able to play with her sentences in a more convoluted manner than Jim. Yet, it is clear that growth occurred for both of these writers.

Susie, a high-performing writer, and Cindy, an average-performing writer both showed signs of growth with their use of dialogue. For example, I noticed that Susie had a small error with the punctuation in her dialogue; I provided her with a picture books, and she fixed her error with minimal help (Reflective Journal, 1/8/16). Cindy struggled much more with the proper conventions found in dialogue. Her dialogue improved as I had a conference with her in the computer lab about dialogue while employing Slightly Invisible (Child, 2011) as a mentor text (Reflective Journal, 12/10/15).

Comparison with previous students. In the 2013-2014 school year I taught a similar narrative unit to four sophomore classes without the use of picture books. I required each student to write three drafts, and I saved my students' third draft on my password protected computer. I chose two of my highest performing students and two of my lowest performing students from that school year. I rated their word choice, sentence fluency, and conventions using the same scale with which I evaluated the current participants. There were, however, major differences with the student population. The students from the 2013-2014 had an additional year of schooling, and they were not identified as struggling writers. The two highperforming students were recognized for their outstanding scholastic achievement in northern Utah when they were seniors. They were also accepted to universities to continue their 
education, including an ivy-league school. The two low-performing students had similar struggles as the current low-performing participants: one specifically struggled with attendance and motivation while the other struggled with motivation to revise and pay attention to detail. Table 9 represents scores for my previous students' final narrative draft from the 2013-2014 school year.

Ty, a high-performing student, scored high in all writing traits. It is noteworthy that Ty's scores do not reflect an intervention of any kind beyond typical classroom instruction. He was taught effective narrative writing skills and conducted multiple revisions to refine his writing. Although his sentences flowed smoothly and were not problematic, he still lacked the effective sentence structure and strategies that were discovered in picture books. His effectiveness on both word choice and sentence fluency would have likely been higher had there been an intervention of picture books. He also displayed a strong command of the conventions of language, employing two semicolons and two colons properly.

Table 9

Final Writing Trait Scores for Previous Students, 2013-2014 School Year

\begin{tabular}{lccc}
\hline \multicolumn{1}{c}{ Student } & Word Choice & Sentence Fluency & Conventions \\
\hline Ty & 3.5 & 4.0 & 4.5 \\
Bethany & 3.5 & 4.0 & 5.0 \\
Robbie & 2.0 & 1.5 & 1.5 \\
Cecil & 2.0 & 1.5 & 1.5 \\
\hline
\end{tabular}

Note. Ty = high-performing student; Bethany = high-performing student; Robbie = low-performing student; Cecil $=$ low-performing student.

Similarly, Bethany, another high-performing student, composed a strong narrative. Her word choice was stronger, her sentence fluency more varied, and her conventions less more natural. Table 9 also illustrates the scores employed in her writing. Bethany performed similar to Ty, and could have benefitted from the current intervention of picture books. 
Robbie, a low-performing student, struggled with motivation and attitude during this unit. Students were required to complete three drafts of a narrative, but he chose to submit his second draft as his final. This is similar to what Earl, a current participate, did. Robbie displayed a lack of control in his writing: he misspelled multiple words, had run-on sentences, and did not attempt the required colon or semicolon. Table 9 highlights the scores of his final draft. There were few positives to consider. It is worthwhile to note that his highest score was word choice. However, this result is a stronger reflection of his inability to craft thoughtful sentences combined with his lack of focus with punctuation than his effective word choice. Based on the intervention of picture books with my current low-performing students, Robbie may have scored higher had he the opportunity for a similar curriculum with picture books.

I reviewed Cecil's work from 2013-2014. He was another low-performing student, but had a good attitude. He chose not to focus on making revisions in his work. Table 9 shows Cecil's scores for his final narrative. Cecil's scores are the same as Robbie's; yet, it must be explained that Cecil's scores are not a reflection of his lack of effort like Robbie's. Cecil put more effort into his writing than Robbie. For example, Cecil employed two semicolons in his writing, a requirement for this narrative. He also included much more detail in his writing than Robbie did, and Cecil's attitude was not in question. Instead, his prose was problematic. An intervention with picture books may have had a similar effect for Cecil as it did with the current population of low-performing writers with positive attitudes. Each of them experienced growth from their first draft to their final draft, and it is likely that Cecil would have experienced similar growth.

The writing trait that even the most talented students in 2013-2014 lacked was word choice. This is not a surprise as word choice was not a focus of my teaching in previous years. I 
did not yet have the vision to explore effective words in context, nor did I emphasize them in the instruction of writing. By examining The Shoetree of Chagrin (Lewis, 2001), The Right Word: Roget and His Thesaurus (Bryant, 2002) and The Promise (Davies, 2014), even students who were identified as struggling had stronger word selection than some of the strongest students in the class of 2015.

Similarly, the high-performing students from the 2013-2014 school year constructed strong sentences that interacted well within the writing. As a whole, their writing was polished and contained few grammatical errors. However, they lacked the deliberate choices to create strong sentence fluency that the current participates made. The deliberate choices of the participants in this study ultimately led, in some instances, to stronger sentence fluency throughout the narrative than that of the 2013-2014 students.

The two low-performing students from 2013-2014 struggled in many aspects. Even so, their scores for sentence fluency and conventions were lower than any of the scores from my current participants.

\section{Summary}

The majority of students recognized picture books as mentor texts through their actions. Students employed meaningful words, sentences, and conventions after examining the picture books. For example, they applied the writing traits we analyzed from the picture books in their narratives. This resulted in a large disparity in the quality of the writing from the first draft to the final draft. Examining the picture books helped me respond to my research question. The picture books positively influenced most of the participants and allowed them to apply stronger words, sentences, and conventions than they had initially. However, in some cases the picture books did not make a large difference. Further, the use of picture books allowed me to assess my 
own teaching effectiveness as a writing instructor and determine areas where I improved with the use of picture books. This was clear when I made comparisons to the writing of earlier students. 


\section{Chapter 5}

\section{Discussion}

A picture book is literature from which writers can draw ideas. For the most part, students determined the ideas of the picture books on their own. However, as the teacher, I positioned the class to analyze some of the picture books with a specific lens. For example, on days we read a book emphasizing exceptional words, I suggested the students focus on new and engaging words. Other times I asked them to notice how the sentences repeat certain phrases. This enabled the students to view the picture book for its strength, and also as a mentor text and not rely solely on me (Pytash \& Morgan, 2014). Outside of these guidelines, the students found ways to incorporate the strengths of the picture books into their own writing while becoming writers. First, I discuss the benefits of picture books. Next, I illustrate the findings of my study related to the current literature. Following this, I review past case studies using picture books in preparation for presenting the implications of this study and future research.

\section{Picture Books}

Danielson (1992) indicated that a picture book in the hands of the right teacher can be a great learning tool for any student. Many students recognized the value of picture books early in the study, and it did not take long for students to correctly apply some writing traits found in picture books (Reflective Journal, 11/11/15). This disposition worked well for students because ultimately the picture books were used as resources for students when creating their own writing (Ludlam, 1992). As we focused on three writing traits, there was always a picture book to help the students and to invite them to coauthor the text with them (Goldstone, 2001). Whether students sought a picture book of their own accord or I strategically gave them picture books 
varied by the person and the situation. Ultimately, students found guidance from examining the books.

One of the foundational results of using the picture books as mentor texts was their capacity to strengthen the writing of the participants (Saunders, 1999). Students created their own understanding of effective sentences as they saw them portrayed in the picture books. This occurred both with and without my influence. Some of their understandings took longer to develop (sentence fluency) while others were noticeable from the first moments (conventions). Ultimately, the students continued to employ picture books as mentor texts because they provided moments for students to think and act like writers (Anderson-McElveen \& Dierking, 2000). The results indicate, overall, that picture books as mentor texts can enhance secondary student writing regardless of ability level. I believe picture books resonated with students because it was something new that they had not been exposed to in an academic setting since their early days of elementary school. The organized, simple construction of picture books afforded students a chance of inquiry and play with their writing: it removed the high stakes accountability that they are now accustomed to. It allowed them to experience writing instead of being told to write. It further provided an opportunity to build their confidence with texts did not intimidate.

The following section will outline the pertinent information gleaned from this study. First I highlight the word choice. Next, I illustrate the sentence fluency. Finally, I describe the conventions. 


\section{Writing Traits}

This study examined only three of traits of quality writing. I discuss the findings of this study in connection with the current literature having to do with word choice, sentence fluency, and conventions.

Word choice. I perceived that the participants in the study lacked a robust vocabulary (Hiebert \& Cervetti, 2012) when the study began. Consequently, this hindered their initial drafts. There are various reasons why this is true, but part of the problem might be because past teachers for the participants failed to implement vocabulary enhancement strategies (Beck et al., 2002). Engaging picture books with powerful words resonated with the students throughout the study. They learned powerful words as we read the picture books together as a class, through both exposure and my introduction of others words (Elley, 1989). Students also enjoyed using new, exciting words (Spandel, 2009) in context. This was evident as some students cheerfully shouted them out in various moments. Overall, these words were successfully incorporated into the participants' writing, with some exceptions, to add meaning and enhance their quality of the prose. The moments when participants did not use the new words properly caused some distraction from the overall meaning of the writing. Occasionally I perceived these words were employed incorrectly because of lack of effort, and other times because of lack of understanding. The nature of each sentence allowed me to perceive the difference. Some students struggled learning how to use new words in context, but strong words employed correctly enhanced the prose because these powerful words demanded my attention as I rated the writing (Spandel, 2009). Even reading powerful words used out of context in the final drafts gave me pause despite the words being distracting. 
In general, the participants' writing suggested that new and engaging words were employed correctly because they were exposed to them in new and engaging formats. I also cannot discount the power of autonomy as students identified what is considered "engaging." Another key consideration for students' successful application of powerful words occurred as I modeled them in sentences (Anderson-McElveen \& Dierking, 2000). This allowed for students to see another example of the same word focused in this text applied to a separate sentence. Sometimes this took the form of common words used in uncommon contexts, and other times I needed to model correct usage of new words for students to correctly apply them in their writing.

I believe that words are powerful, but sometimes young writers do not believe the same. It was when powerful words were presented in a unique format conducive to inquiry and play that students learned for the sake of learning. They were not learning for a test score, but rather to add meaning and power to their writing.

Sentence fluency. Students' growth was most evident with sentence fluency. Many, if not all, students struggled with sentence fluency initially. To them it was an abstract concept and one that required more critical thought than many were willing to give initially. It also required more critical thought for me to score. Perhaps part of the reason it is not commonly taught is because of its difficult nature on both student and instructor.

Much of the students' growth in sentence fluency was a result of its general nonexistence in first drafts. Real growth occurred as students wrestled with and understood the nuances of strong fluency from the picture books as the study progressed. Since sentence fluency requires more critical thought to recognize and apply for developing writers than word choice and conventions, an additional intervention was necessary. I distributed a class copy of the prose for Scarecrow (Rylant, 2001). As I read it aloud to the class, they followed along. 
This was a powerful moment for the class as participants were able to (a) to hear the writing aloud (Culham, 2014; Spandel, 2009), and (b) read the words simultaneously. This suggests that the instruction of sentence fluency necessitates access to the text as it is read aloud. Rather, the instruction can be heightened as students have a strong opportunity to think critically as they read the text as the passages are read aloud instead of merely listening to the text passively.

What I perceived to be of most value to students in constructing fluent sentences was the opportunity to revise (Culham, 2014). Although there are various strategies to create sentence fluency, students generally employed strategic repetition as they emulated patterns and structures found within the picture books (O’Sullivan, 1987; Spandel, 2009). Many of the sentences they constructed with strong fluency followed these effective repetitious patterns (Bishop \& Hickman, 1992). Some of the participant attempts to construct powerful sentences flowed smoothly and effortlessly. Students either recognized the strong patterns or I made them aware of the powerful sentences as we read the books. Once students recognized good examples, most followed them effectively in their narratives. Although I felt that some attempts were contrived, perhaps I should come to expect contrived attempts as novices try their hand with new traits. Even so, they improved the fluency overall. This discovery especially shows the influence of a strong mentor text can have on writers (Culham, 2014).

After this study, I believe students want to learn how to craft beautiful sentences that interact with each other and move the reader; unfortunately, many students do not notice sentence fluency with a writer's eye without assistance. For this reason, writing teachers should focus a portion of their instruction on effective sentences, modeling them for the class to show their effect. 
Conventions. I perceived conventions to be the most easily applied writing trait for students. This can be explained because there are generally agreed-upon rules of proper conventions (Bruning et al., 2013), necessitating less imagination and ingenuity in the beginning stages of writing, and because conventions are more often taught than other traits in elementary and secondary classrooms. With the picture books acting as mentor texts, students examined proper conventions to (a) vary their writing (Culham, 2014); and (b) discover and explore potential uses (Clark, 2013). These ideas were demonstrated in multiple students' writing during the study (e.g., Jill and Eddie). Additionally, this afforded students a chance to escape convention poverty and apply their knowledge of advanced conventions in creative ways. Jill constructed one particular sentence with a colon so carefully that its effect was unmistakable, and her intended message could not be lost (Anderson-McElveen \& Dierking, 2000). Jill's demonstration of employing conventions suggests that picture books can push the strongest writers in the classroom to think deeply, even engendering critical thought and further inquiry (O'Sullivan, 1987). This stimulated conversations with me, the instructor, about writing possibilities (Pytash \& Morgan, 2014). I also observed even the most novice writers examine and negotiate the contents of the texts similarly according to their ability (Ray, 1999; Rief, 1992). Picture books can resonate with a high school audience, reaching levels others previously thought it could not (Elleman, 1996).

Many students found universally accepted ways of incorporating conventions, and did not break the rules for effect (Culham, 2014; Spandel, 2009). I did not see students manipulate the conventions to emphasize tone or other common aspects of narrative writing, but none of the picture books I examined had examples of this. Thus, students were not exposed to this possibility. Instead, they followed the patterns of accepted rules for the conventions. By 
following generally accepted patterns their writing was enhanced; however, the depth of their understanding may have plateaued, evidenced by the lack of breaking rules for effect. I believe that breaking the rules for effect requires a sound knowledge of conventions because one must understand the effect of punctuation in order to strategically incorporate it. Unfortunately, I am unable to determine from these data whether students were even aware of this possibility, or if they lacked sufficient depth to do so. Many of the students submitted work that was conventionally accurate, portraying a clear message (Bruning et al., 2013).

The overall findings for conventions suggest that with a proper mentor text and proper modeling students are capable of incorporating advanced punctuation such as colons and semicolons in their writing. The findings further suggest that all ability levels can benefit from picture books as mentor texts as the advanced students can find more creative ways to add meaning to their writing while beginners can learn basic convention rules.

\section{Past Case Studies}

There are few case studies examining picture books as mentor texts to draw from. One of the case studies presented in the review of literature (Anderson-McElveen \& Dierking, 2000) differed in many ways from the current study. For example, it had a much larger sample size $(\mathrm{N}=50)$ than my study $(\mathrm{N}=12)$ and worked with students much younger either in kindergarten or the $4^{\text {th }}$ grade. The researchers noticed that novice writers paid specific attention to words and their associations to the setting while older writers noticed the power of similes. This study emphasized the need for teacher modeling as an integral part of the writing development for students. Similarly, the present study benefited from teacher modeling for writing traits found in picture books as well. Finally, Anderson-McElveen and Dierking's (2000) study and the present study both effectively supported the writing development of students. 
Coe et al. (2011) conducted a similar study examining the effects of picture books as mentor texts as a portion of their study examining the impact of $6+1$ writing traits on $5^{\text {th }}$ grade student writing achievement. With picture books as part of the intervention, the study showed a statistically significant difference in scores. Student achievement improved from the $50^{\text {th }}$ percentile to the $54^{\text {th }}$ percentile. One of the large differences for this study was the training of the teachers. Teachers were provided with professional development opportunities to learn how to use the picture books as mentor texts whereas I had no formal training to use picture books as mentor texts. Another item worthy of note is that the Coe et al. study (2011) did not exclusively focus on picture books. Rather, they were part of a more complex intervention. The present study solely examined picture books as the intervention. Similarly, though, in both studies student writing achievement improved.

\section{Implications and Future Research}

This study produced rich results that led to strong implications. First and foremost, the findings employing picture books as mentor texts enhanced high school students' writing of all ability levels. What once was perhaps thought as an antiquated and juvenile form of instruction, picture books should be considered by writing instructors through secondary school. Further, teacher modeling was not originally part of this study, but it surfaced as a need when my students required additional guidance after discussing the traits exemplified in the picture books. Modeling clearly benefitted my students, and the implications regarding teacher modeling suggest that it should be conducted at each stage of the writing process. My growth as a teacher was also an unexpected result of the study. It was not a research question, but I could not help but notice my growth. 
Picture books as mentor texts can be effective tools for helping developing writers to improve their prose and wrestle with decisions of writers. This study provided new information by using picture books to improve struggling high school students' word choice, sentence fluency, and conventions. However, additional research is required to validate these results and to expand on the discoveries of this study. For example, it is not enough for students to merely retain these skills as they progress in their education. Can they retain and build upon these strategies and skills in future narratives in subsequent years? One of the challenges for future research of this nature is clear: good writing development takes time. A future study could use a semi-longitudinal approach from the start of $10^{\text {th }}$-grade to the completion of $12^{\text {th }}$-grade. This would afford the researcher an opportunity to examine the natural development of students' writing ability in addition to using picture books as a writing intervention.

This study showed that students were able to transfer some traits to other writings, but it needs to be examined more. Additional research is necessary to discover if students can carry their proficiency of word choice, sentence fluency, and conventions into other genres and in future narrative pieces. For example, can they use the same strategies and skills developed in the present study for critical reviews, analyses, poetry, personal writing and other genres?

More research is required to determine if students can maintain the same writing proficiency within other disciplines. The approach, style, and tone, among other writing aspects, vary for each discipline. However, the need for strong word choice, sentence fluency, and conventions remain constant. Good writing transcends genres. Mastering the writing traits in one discipline should lead to good writing in other disciplines. Keeping this in mind, it would be interesting to examine if the skills developed from the picture books in a narrative unit can positively influence student writing in science, technology, engineering, the arts, or mathematics. 
Additional research should also be conducted with the strategy of mentor texts beyond writing traits. There are many nuances of writing that can be aided by the use of mentor texts. For example, mentor texts could benefit students who wish to write an introduction or a conclusion of a specified genre. They could also turn to mentor texts to compose unfamiliar writing principles, such as clear and concise writing or analysis of data. A world of possibilities with future research exists with mentor texts.

More research is needed to determine how "regular" track and honors students respond to an intervention with picture books as mentor texts. The present study only investigated classes where the participants were previously identified by their former English Language Arts teachers as struggling. Conducting a similar study in other courses (e.g., on track or honors) may provide additional insights that were not available with the present population.

Additional research is also necessary to determine teacher growth through writing units. My growth as a writing instructor was clear; however, it was not a research question on which I focused. Inquiring more information about the nature and complexities of teacher growth in a writing unit could be a rich self-study.

This study demonstrated effective examples of teacher modeling, and future research should examine this. Although the picture books in my study illustrated effective words, sentences, and conventions, I still found the need to model to my students how I would compose such a task. Teacher modeling could be examined on the sentence level or on a holistic, global level to aid student writing. This way, students can see my thought process, how I approached it, and they, too, could approach it similarly. 
Furthermore, students were given the opportunity to reflect, but the findings showed poorly constructed reflections. Future research should examine if students can be taught to reflect at a more meaningful level, and if reflection can cause growth for future writing.

Another item worthy of future research is to examine sentence fluency and conventions with greater depth. Since the present research examined three writing traits it would be interesting to investigate only sentence fluency and conventions, but with greater depth. This could possibly strengthen proficiency in an abstract concept such as sentence fluency as instructors limit the focus and provide more picture books to emphasize this trait. This also allows for further examination with breaking the rules of conventions for effect. Since the present research did not include examples of effective broken rules of conventions (Culham, 2014; Spandel 2009), affording students a space to break the rules may provide for a greater understanding of conventions, and can also strengthen the overall sentence fluency as these broken conventions should be deliberate and intentional.

Finally, it would be good to examine the use of voice, ideas, and organization as writing traits while employing picture books as mentor texts. Many of the same picture books could be employed again, but this time examined through a new lens. New, strategic picture books would also improve the quality of such a study. While potentially examining fewer writing traits in a new study, voice could be paired with sentence fluency for further study. The traits of ideas and organization could also be paired together or independently with picture books. 


\section{References}

Anderson, J. (2005). Mechanically inclined. Portland, ME: Stenhouse.

Anderson, N. L., \& Briggs, C. (2011). Reciprocity between reading and writing: Strategic processing as common ground. The Reading Teacher, 64, 546-549. doi: 10.1598/RT.64.7.12

Anderson, R. C., \& Freebody, P. (1979). Vocabulary knowledge. Technical report no. 136. Urbana, IL: Center for the Study of Reading.

Anderson-McElveen S., \& Dierking, C. C. (2000). Children's books as models to teach writing skills. The Reading Teacher, 54, 362-64.

Beck, I. L., McKeown, M. G., \& Kucan, L. (2002). Bringing words to life: Robust vocabulary instruction. New York, NY: Guilford.

Bishop, R. S., \& Hickman, J. (1992). Beyond words: Picture books for older readers and writers. In S. Benedict \& L. Carlisle (Eds.), Four or fourteen or forty: Picture books are for everyone (pp. 1-10). Portsmouth, NH: Heinemann.

Brenner, D., Brooks, C., Gorin, J., Harris, K. R., Hooper, S., Pearson, P. D., . . \& Washington, J. (N.D.). The Reading Writing Connection. Newark, DE: International Reading Association.

Brooks, R. J. (2000). The erasure of the sentence. College Composition and Communication, 52, 96-128.

Bruning, R., Dempsey, M., Kauffman, D. F., McKim, C., \& Zumbrunn, S. (2013). Examining dimensions of self-efficacy for writing. Journal of Educational Psychology, 105, 25-38. doi: $10.1037 / \mathrm{a} 0029692$ 
Bullough, R. Jr., \& Baughman, K. (1997). “First-year teacher” eight years later: An inquiry into teacher development. New York, NY: Teachers College Press.

Burke, J. (n.d.). Writing traits rubric. Retrieved from http://www.englishcompanion.com/pdfDocs/sixtraitssummary.pdf

Carlisle, L. R. (1992a). Beyond words: Picture books for older readers and writers.

In S. Benedict \& L. Carlisle (Eds.), Ann Turner: Reaching into the past (pp.129-132). Portsmouth, NH: Heinemann.

Carlisle, L.R. (1992b). Beyond words: Picture books for older readers and writers. In S. Benedict \& L. Carlisle (Eds.), Picture books: An easy place to think (pp. 49-58). Portsmouth, NH: Heinemann.

Carnicelli, T. (2001): Words work: Activities for developing vocabulary, style, and critical thinking. Portsmouth, NH: Boynton/Cook.

Clark, U. (2013). A sense of place: Variation, linguistic hegemony and the teaching of literacy in English. English Teaching: Practice and Critique, 12, 58-75.

Coe, M., Hanita, M., Nishioka, V., \& Smiley, R., (2011). An investigation of the impact of the 6+1 Trait Writing model on grade 5 student writing achievement (NCEE 2012-4010). Washington, DC: National Center for Education Evaluation and Regional Assistance, Institute of education Sciences, U.S. Department of Education.

Costello, B., \& Kolodziej, N. J. (2006). A middle school teacher's guide for selecting picture books. Middle School Journal, 38, 27-33.

Crawford, L., Helwig, R., \& Tindal, G. (2004). Writing performance assessments: How important is extended time? Journal of Learning Disabilities, 37, 132-142. 
Culham, R. (2014). The writing thief: Using mentor texts to teach the craft of writing. Newark, DE: International Reading Association.

Culham, R., Blasingame, J., \& Coutu, R. (2010). Using mentor texts to teach writing with the traits: Middle school. New York, NY: Scholastic.

Danielson, K.E. (1992). Picture books to use with older students. Journal of Reading, 35, 652654.

Day, K. S. (1996). The challenge of style in reading picture books. Children's Literature in Education, 27, 153-66.

Dean, D. (2010, Fall Semester). “Lecture.” Brigham Young University English Teaching Practicum. Provo, UT: Brigham Young University.

Dean, D., \& Grierson, S. (2005). Re-envisioning reading and writing through combined-text picture books. Journal of Adolescent \& Adult Literacy, 48, 456-468. doi:10.1598/JAAL.48.6.2

Dorfman, L., \& Capelli, R. (2007). Mentor texts: Teaching writing through children's literature, K-6. Portland, ME: Stenhouse.

Dorfman, L., \& Capelli, R. (2009). Nonfiction mentor texts: Teaching information writing through children's literature, $K-8$. Portland, ME: Stenhouse.

Elbow, P. (2004). Writing first! Educational Leadership, 62(2), 8.

El-Hindi, A. (1997). Connecting reading and writing: College learners' metacognitive awareness. Journal of Developmental Education, 21, 10-19.

Elleman, B. (1996, March). Picture book potential. Book Links, 5(4), 5.

Elley, W. B. (1989). Vocabulary acquisition from listening to stories. Reading Research Quarterly, 24, 174-87. 
Fletcher, R. (2011). Mentor author, mentor text: Short texts, craft notes, and practical classroom use. Portsmouth, NH. Heinemann.

Friese, B. (2010, March). A collection of mentors: How the library program can support writing instruction. School Library Monthly, 26(7), 17-19.

Gallagher, K. (2011). Write like this: Teaching real-world writing through modeling \& mentor texts. Portland, ME: Stenhouse.

Gallagher, K. (2015). In the best interest of students: Staying true to what works in the ELA classroom. Portland, ME: Stenhouse.

Goldstone, B. P. (2001). Whaz up with our books? Changing picture book codes and teaching implications. The Reading Teacher, 55, 362-70.

Graham, J. (2000). Worth a thousand words: Using picture books to teach literary elements. Retrieved from ERIC database. (ED449482).

Graham, S., \& Hebert, M. (2011). Writing to read: A meta-analysis of the impact of writing and writing instruction on reading. Harvard Educational Review, 81, 710-744.

Graham, S., \& Perin, D. (2007a). Writing next: Effective strategies to improve writing of adolescents in middle and high schools - A report to Carnegie Corporation of New York. Washington, DC: Alliance for Excellent Education.

Graham, S., \& Perin, D. (2007b). A meta-analysis of writing instruction for adolescent students. Journal of Educational Psychology, 99, 445-476. doi:10.1037/00220663.99.3.445

Hadaway, N. L., \& Mundy J. (1999). Children's informational picture books visit a secondary ESL classroom. Journal of Adolescent and Adult Literacy, 42, 467-475. 
Harste, J. C. \& Short, K. G. (1988). Creating classrooms for authors: The reading-writing connection. Portsmouth, NH: Heinemann.

Heard, G. (1992). Poetry and picture books: The door to the woods. In S. Benedict, \& L. Carlisle (Eds.), Beyond words: Picture books for older readers and writers (pp. 115-122). Portsmouth, NH: Heinemann.

Hennings, D. G. (2000). Contextually relevant word study: Adolescent vocabulary development across the curriculum. Journal of Adolescent \& Adult Literacy, 44, 268-279.

Hiebert E. H., \& Cervetti, G. N. (2012). What differences in narrative and information texts mean for the learning and instruction of vocabulary. In E. J. Kame'enui \& J. F. Baumann (Eds.), Vocabulary instruction: Research to practice (pp. 322-344). New York, NY: The Guilford Press.

Honeck, A. Y. (2013). Assessing perceived writing self-efficacy beliefs in the community college environment. Master's Thesis. St. Paul, MN: Hamline University. file:///Users /Downloads/Alycia\%20Honeck\%20Capstone\%20(2).pdf

Hugo, R. (1979). The triggering town. New York, NY: W.W. Norton.

Ibrahim, N., \& Yaworski, J. (2001). How to teach 1000 vocabulary words using the internet. Journal of College Reading and Learning, 31, 133-142. doi:

$10.1080 / 10790195.2001 .10850110$

Jenks, C. K. (1992). Picture books for older children. In S. Benedict \& L. Carlisle (Eds.), Beyond words: Picture books for older readers and writers (pp. 99-106). Portsmouth, NH: Heinemann.

Kiefer, B. Z. (1995). The potential of picturebooks: From visual literacy to aesthetic understanding. Englewood Cliffs, NJ: Prentice Hall. 
Langer, J. A. (2011). Envisioning knowledge. New York, NY: Teachers College Press.

Ludlam, D. (1992). Picture books after eighth grade. In S. Benedict \& L. Carlisle (Eds.), Beyond words: Picture books for older readers and writers. (pp. 89-98). Portsmouth, NH: Heinemann.

Marchetti M., \& O’Dell, R. (2015). Writing with mentors: How to reach every writer in the room using current, engaging mentor texts. Portsmouth, NH: Heinemann.

McKeown, M. G., Beck, I. L., \& Sandora, C. (2012). Direct and rich vocabulary instruction needs to start early. In E. J. Kame'enui \& J. F. Baumann (Eds.), Vocabulary instruction research to practice (pp.17-33). New York, NY: Guilford.

Mendell, E. (2014, February 5). This is 45. Retrieved from http://www.huffingtonpost.com/emily-mendell/this-is-45the-eye-of-life_b_4648004.html

Mitchell, D., \& Pullum, T. (1998). Using children's literature to spark learning: Promoting writing with folktales. English Journal, 87, 94-97.

Mullis, I. V. S., Mellon, J. C., \& Education Commission of the States. (1980). Guidelines for describing three aspects of writing: Syntax, cohesion and mechanics Denver, CO: National Assessment of Educational Progress.

Murray, D. (1995). The craft of revision ( $2^{\text {nd }}$ ed.). Fort Worth, TX: Harcourt Brace.

Myers, S. A. (2003). Remembering the sentence. College Composition and Communication, 54, $610-28$.

National Governors Association Center for Best Practices \& Council of Chief State School Officers. (2010). Common Core State Standards for English language arts and literacy in history/social studies, science, and technical subjects. Washington, DC: Authors. doi: $10.2307 / 3594187$ 
Newkirk, T. (1992). Reasoning around picture books. In S. Benedict \& L. Carlisle (Eds.), Beyond words: Picture books for older readers and writers (pp.11-20). Portsmouth, NH: Heinemann.

O'Sullivan, C. (1987). The challenge of picture books: A teacher's guide to the use of picture books with older students. Melbourne, AU: Methuen.

Pantaleo, S. (2008). Exploring student response to contemporary picturebooks. Toronto, Canada: University of Toronto Press.

Paquette, K. R. (2007). Encouraging primary students' writing through children's literature. Early Childhood Education Journal, 35, 155-165. doi: 10.1007/s10643-0070183-6

Penno, J. F., Wilkinson, I. A. G., \& Moore, D. W. (2002). Vocabulary acquisition from teacher explanation and repeated listening to stories: Do they overcome the Matthew effect? Journal of Educational Psychology, 94, 23-33. doi: 10.1037/0022-0663.94.1.23

Pytash, K. E., \& Morgan D. N. (2014). Using mentor texts to teach writing in science and social studies. The Reading Teacher, 68, 93-102. doi: 10.1002/trtr.1276

Ranck-Buhr, W. (2013). Using picturebooks to promote academic literacy. Voices from the Middle, 20, 47-48.

Ray, K. (1999). Wondrous words: Writers and writing in the elementary classroom. Urbana, IL: National Council of Teachers of English.

Ray, K. W. (2006). Exploring inquiry as a teaching stance in the writing workshop. Language Arts, 83, 238-247. 
Rief, L. (1992). Good children's literature is for everyone, even especially for adults. In S. Benedict \& L. Carlisle (Eds.), Beyond words: Picture books for older readers and writers. (pp. 69-88). Portsmouth, NH: Heinemann.

Rose, S. K. (1983). Down from the haymow: One hundred years of sentence combining. College English, 45, 483-91.

Rupley, W. H., Logan, J. W., \& Nichols, W. D. (1999). Vocabulary instruction in a balanced reading program. The Reading Teacher, 52, 336-46.

Sagor, R. (2000). Guiding school improvement with action research. Retrieved from http://www.ascd.org/publications/books/100047/chapters/What-Is-ActionResearch\%C2\%A2.aspx

Saunders, S. L. (1999). Look—and learn. Portsmouth, NH: Heinemann.

Sloan, M. S. (1996). Encouraging young students to use interesting words in their writing. The Reading Teacher, 50, 268.

Smith, C. (2003). Vocabulary: Word choice in writing. Institute of Education Science. Washington D.C.

Smith, F. (1988). Joining the literacy club. Portsmouth, NH: Heinemann.

Spandel, V. (2001). Creating writers ( $5^{\text {th }}$ ed.). Boston, MA: Addison Wesley Longman.

Spandel, V. (2009). Creating writers through 6-trait writing assessment and instruction. Boston, MA: Pearson.

Springer, S. (2013, November). "Football, Kanye, and the Stinky Cheese man: Engaging students in analysis with high-interest text." Session presented at the Utah Council Teachers of English Conference, Salt Lake City, UT.

Tierney, R. J., \& Pearson, P. D. (1983). Toward a composing model of reading. Language 
Arts, 60, 568-80.

Uccelli, P., Dobbs, C. L., \& Scott, J. (2013). Mastering academic language: Organization and stance in the persuasive writing of high school students. Written Communication, 30, 3662. doi: $10.1177 / 0741088312469013$

Weaver, C. (1996). The great debate (again): Teaching grammar and usage. The English Journal, 85.

Wiesel, E. (1958). Night. New York, NY: Hill and Wang.

Zeek, S. (2011). Teaching the research paper through inquiry-based instruction. Inquiry, 16, 7585. 


\section{Children's Books Cited}

Bryant J., \& Sweet, M. (2014). The right word: Roget and his thesaurus. Grand Rapids, MI: Eerdmans Books for Young Readers.

Cazet, D. (2005). The perfect pumpkin. New York, NY: Simon \& Schuster.

Child, L. (2011). Slightly invisible. Somerville, MA: Candlewick.

Davies, N., \& Carlin, L. (2014). The promise. Somerville, MA: Candlewick.

Kerley, B. (2001). The Dinosaurs of Waterhouse Hawkins. New York, NY: Scholastic Press.

Lewis, J.P., \& Sheban, C. (2001). The shoetree of chagrin. Mankato, MN: Creative Editions.

Rosenthall, A.K., \& Lichtenheld, T. (2015). I wish you more. San Francisco: Chronicle Books.

Rylant, C. \& Stringer, L. (2001). Scarecrow. New York, NY: Harcourt Brace \& Company.

Shannon, D. (1998). No, David. New York, NY: Blue Sky Press.

Shulevitz, U. (2008). How I learned geography. New York, NY: Farrar, Straus, and Grioux.

Skarmeta, A., \& Ruano, A. (2000). The composition. (Ediciones Ekare, Trans.). Berkeley, CA: Publishers Group West.

Spires, A. (2014). The most magnificent thing. Toronto, Canada: Kids Can Press.

Whitman, W., \& Long, L. (2004). When I heard the learn'd astronomer. New York, NY: Simon \& Schuster. 


\section{APPENDIX A:}

\section{Writing Rubric}

WORD CHOICE: The right word, used in the right way, at the right time. The writer chooses words that create the intended effect, impression, or mood.

5 Words are precise, interesting, engaging, powerful.

Words are specific, accurate; meaning is clear.

Words and phrases are striking and memorable.

Language is natural, effective, and appropriate.

Verbs are lively, nouns precise, modifiers effective.

Choices enhance meaning and clarify meaning.

3 Words are common and obvious; they lack energy.

Words are adequate and correct in a general sense.

Words and phrases convey, but aren't memorable.

Language reaches for color; thesaurus overload.

Verbs are passive; nouns common; modifiers dull.

Choices are random: first word that came to mind.

1 Words are simple or vague; limited in scope.

Words are nonspecific, distracting, and vague.

Words and phrases are dull; detract from meaning.

Language is used incorrectly, carelessly.

Verbs, nouns, adjectives show limited vocabulary.

Jargons or clichés distract, mislead; redundancy.

SENTENCE FLUENCY: Language that flows with rhythm and grace, logic and music. Sentences are well-crafted and want to be read aloud.

5 writing flows with rhythm and cadence. Elegant.

Sentences are constructed to enhance meaning.

Sentences vary in length and structure.

Sentences use purposeful, varied beginnings.

Connecting words join an build on other words.

Writing has cadence; it moves, has a rhythm to it.

3 Writing moves along but feels more business-like.

Sentences are routine; they lack craft and music.

Sentences are usually constructed correctly.

Sentences are not all alike; there is some variety.

Connecting words absent; reader hunts for clues.

Parts invite reading aloud; choppy, awkward, stiff.

1 Writing lacks flow; it is difficult to read. 
Sentences ramble, are incomplete or awkward.

Sentences do not connect to each other at all.

Sentences begin the same way, monotonous.

Endless or no connectives (and, so, then, because).

The text does not invite reading aloud; no music.

CONVENTIONS: Includes punctuation, spelling, grammar, and usage. It does not include layout, formatting, or handwriting. The final editing phase.

5 Observes and uses standard conventions, few errors.

Spelling is mostly correct, even on difficult words.

Punctuation is accurate, even creative and effective.

Capitalization skills are evident and consistent.

Grammar and usage are correct and enhance the text.

Paragraphing is sound; reinforces organization.

Writer may manipulate conventions for style.

3 Reasonable control of conventions; distracting errors.

Spelling mostly correct; errors on difficult words.

End punctuation mostly correct; internal errors.

Capitalization generally correct; some errors.

Grammar and usage problems are not serious.

Paragraphing lacks cohesion and organization.

1 Errors distract the reader and make reading difficult.

Spelling errors are frequent and distracting.

Punctuation is often missing or incorrect.

Capitalization is random; only easiest are correct.

Grammar and usage errors are obvious and serious.

Paragraphing is missing, irregular, or frequent.

Adapted by Jim Burke. See Creating Writers (Addison Wesley Longman) by Vicki Spandel for complete exploration of the Six Traits model.

http://www.englishcompanion.com/pdfDocs/sixtraitssummary.pdf 
Appendix B:

Picture Books Employed

\begin{tabular}{|c|c|c|c|c|}
\hline Title & Author & Writing Trait & Emphasis & $\begin{array}{l}\text { Date } \\
\text { Taught }\end{array}$ \\
\hline No, David & $\begin{array}{l}\text { David Shannon } \\
\text { (1998) }\end{array}$ & Conventions & Comma & $11 / 3 / 15$ \\
\hline $\begin{array}{l}\text { How I Learned } \\
\text { Geography }\end{array}$ & $\begin{array}{l}\text { Uri Shulevitz } \\
\text { (2008) }\end{array}$ & Sentence Fluency & $\begin{array}{l}\text { Varying Sentence } \\
\text { Structure }\end{array}$ & $11 / 10 / 15$ \\
\hline $\begin{array}{l}\text { The Dinosaurs of } \\
\text { Waterhouse Hawkins }\end{array}$ & $\begin{array}{l}\text { Barbara Kerley } \\
\text { (2001) }\end{array}$ & Conventions & Colon & $11 / 12,18 / 15$ \\
\hline I Wish You More & $\begin{array}{l}\text { Amy Krouse } \\
\text { Rosenthall (2015) }\end{array}$ & Sentence Fluency & Repetitious Phrases & $11 / 19 / 15$ \\
\hline $\begin{array}{l}\text { The Most } \\
\text { Magnificent Thing }\end{array}$ & $\begin{array}{l}\text { Ashley Spires } \\
\text { (2014) }\end{array}$ & Sentence Fluency & $\begin{array}{l}\text { Short Sentences in } \\
\text { Succession }\end{array}$ & $11 / 24 / 15$ \\
\hline $\begin{array}{l}\text { The Perfect Pumpkin } \\
\text { Pie }\end{array}$ & Denys Cazet & Conventions & Conventions in Dialogue & $12 / 2,4 / 15$ \\
\hline $\begin{array}{l}\text { When I Heard The } \\
\text { Learn'd Astronomer }\end{array}$ & $\begin{array}{l}\text { Walt Whitman \& } \\
\text { Loren Long } \\
\text { (2004) }\end{array}$ & Conventions & Semicolon & $12 / 14 / 15$ \\
\hline $\begin{array}{l}\text { The Shoetree of } \\
\text { Chagrin }\end{array}$ & $\begin{array}{l}\text { J. Patrick Lewis } \\
(2001)\end{array}$ & Word Choice & N/A & $12 / 16,18 / 15$ \\
\hline Scarecrow & $\begin{array}{l}\text { Cynthia Rylant } \\
\text { (2001) }\end{array}$ & Sentence Fluency & Repetitious phrases & $12 / 18 / 15$ \\
\hline $\begin{array}{l}\text { The Right Word: } \\
\text { Roget and His } \\
\text { Thesaurus }\end{array}$ & Jen Bryant (2014) & Word Choice & $\begin{array}{l}\text { Synonyms and } \\
\text { Alternative words }\end{array}$ & $1 / 14 / 16$ \\
\hline The Promise & $\begin{array}{l}\text { Nicola Davies } \\
\text { (2014) }\end{array}$ & $\begin{array}{l}\text { Word Choice and } \\
\text { Sentence Fluency }\end{array}$ & $\begin{array}{l}\text { Common Words Used in } \\
\text { New Contexts and } \\
\text { Repetition }\end{array}$ & $1 / 20,22 / 16$ \\
\hline The Composition & $\begin{array}{l}\text { Antonio Skarmeta } \\
\text { (2003) }\end{array}$ & $\begin{array}{l}\text { Word Choice and } \\
\text { Sentence Fluency }\end{array}$ & $\begin{array}{l}\text { Common Words Used in } \\
\text { New Contexts and } \\
\text { Repetition }\end{array}$ & $1 / 20,22 / 16$ \\
\hline
\end{tabular}




\section{APPENDIX C:}

\section{Perceived Writing Self-Efficacy Beliefs Rate Scale}

Directions: On a scale from 0 (no chance) to 100 (completely certain), Please rate how sure you are that you can perform each of the writing skills described below by writing the appropriate number. Of course, there are no right or wrong answers, so do not spend too much time on any one statement. Thank you for your cooperation. Your answers will be kept strictly confidential, and you will not be identified by name.

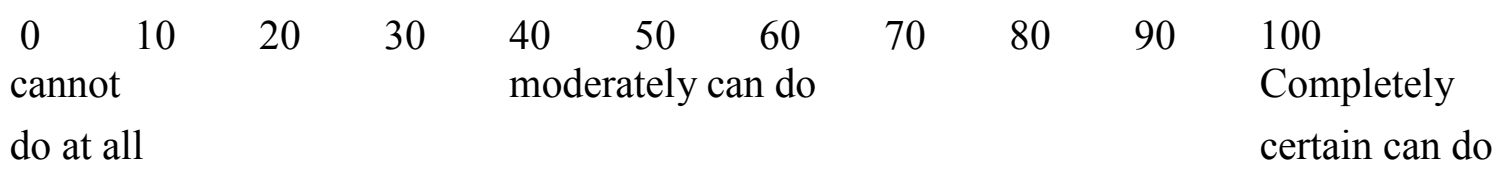

\begin{tabular}{|l|l|l|}
\hline 1. & I can write a fluent paragraph. & \\
\hline 2. & I can write a fluent essay. & \\
\hline 3. & I can correctly spell all words in an essay. & \\
\hline 4. & I can correctly punctuate an essay. & \\
\hline 5. & I can correctly use all parts of speech in an essay. & \\
\hline 6. & I can write simple sentences with good grammar. & \\
\hline 7. & I can correctly use singulars and plurals and prepositions. & \\
\hline 8. & I can correctly use conjunctions and transitions. & \\
\hline 9. & I can use a wide range of vocabulary in essays. & \\
\hline 10. & I can use synonyms instead of repeating the same words over and over again. & \\
\hline 11. & I can easily generate ideas to write about. & \\
\hline 12. & I can write a strong paragraph that has a good topic sentence or main idea. & \\
\hline 13. & $\begin{array}{l}\text { I can write paragraphs with details that support the ideas in the topic } \\
\text { sentences or main ideas. }\end{array}$ & \\
\hline 14. & I can write a proper introduction. & \\
\hline 15. & I can write a proper conclusion. & \\
\hline 16. & I can edit essays throughout the writing process. & \\
\hline 17. & $\begin{array}{l}\text { I can write a well-organized and sequenced paper with good introduction, } \\
\text { body, and conclusion. }\end{array}$ & \\
\hline 18. & I can write on an assigned topic without difficulty. \\
\hline 19. & I can get ideas across in a clear manner by staying focused without getting \\
\hline 20. & I can complete a writing task without difficulty by the due date & \\
\hline
\end{tabular}




\section{APPENDIX D}

\section{Reflection}

\section{Please respond to each question with a thoughtful, well- developed response:}

1. Explain how using picture books helped improve your word choice.

2. Explain how using picture books helped improve your sentence fluency (e.g. repetitious phrases and short, consecutive sentences).

3. Explain how using picture books helped improve your conventions (e.g. colons, semicolons, and commas).

4. Explain what writing trait explored through picture books was most helpful to your writing development.

5. What additional activities with picture books do you think may have helped improve your writing?

\section{Please respond to two of the following questions with a thoughtful, well-developed response:}

6. Which of the practices that you used might be of use to you in future reading and writing situations?

7. How will these writing characteristics help you be a better writer in the future, whether in other classes or in your own personal writing?

8. What practices of reading and writing did you do with this assignment that helped you in completing this assignment with more success?

9. Which writing characteristic (word choice, sentence fluency, and conventions) came the most naturally to you? Why? Which one was the most difficult? Why? 